\title{
STRATEGIC ENTRY DECISIONS, ACCOUNTING SIGNALS, AND RISK MANAGEMENT DISCLOSURE
}

\author{
by \\ Youli Zou \\ A thesis submitted in conformity with the requirements \\ for the degree of Doctor of Philosophy \\ Joseph L. Rotman School of Management \\ University of Toronto
}

July, 2013

(C) Copyright by Youli Zou (2013) 


\title{
STRATEGIC ENTRY DECISIONS, ACCOUNTING SIGNALS, AND RISK MANAGEMENT DISCLOSURE
}

Youli Zou

\author{
A thesis submitted in conformity with the requirements \\ for the degree of Doctor of Philosophy \\ Joseph L. Rotman School of Management \\ University of Toronto
}

\begin{abstract}
This dissertation investigates the economic consequences from hedge accounting signals and risk management disclosure. I first examine the product market consequences to these accounting signals and related disclosure in Chapter 1, then stock market reactions to disclosure requirements in Chapter 2.

Chapter 1 examines potential entrants' strategic entry decisions in response to incumbents' accounting information and related disclosure. I predict that potential entrants are more likely to enter markets in which the incumbents' accounting information suggests higher future production costs that are specific to the incumbents themselves. I further hypothesize that the relation is stronger when the accounting signals are accompanied by more disclosure. Using detailed U.S. airline industry data and hedge accounting disclosure under SFAS 133, I find that potential entrants are more likely to enter routes in which the incumbents' lower accumulated other comprehensive income from fuel hedges suggests their higher future production costs. This entry pattern is stronger when incumbents have more transparent annual report disclosure regarding their fuel hedge programs. The entry pattern is also stronger after a systematic increase in risk management disclosure requirements following the (exogenous) adoption of SFAS 161.
\end{abstract}


Chapter 2 analyzes stock returns of U.S. airlines around events leading up to the adoption of SFAS 161. SFAS 161 enhanced the disclosure requirements for derivatives and hedging activities. I find that U.S. airlines experienced statistically significant positive returns around the key events leading up to the adoption of SFAS 161. I then examine the cross-sectional variation of the returns around these events. Regression results provide initial support for the real effects theory that greater disclosure requirements could distort firms' hedging and production decisions and lead to suboptimal behavior.

In summary, this dissertation provides evidence that competitors use hedge accounting signals and related disclosure in making product market decisions. Meanwhile, additional riskmanagement disclosures may also distort firms' hedging and production behavior, leading to suboptimal decisions. This dissertation sheds light on the ongoing projects by the FASB and the IASB on hedge accounting and disclosure and informs the regulators that costs and benefits should be weighted in hedge accounting policy setting. 


\section{ACKNOWLEDGMENTS}

I would like to express my deepest appreciation to my supervisor, Ole-Kristian Hope, for his continuous support, encouragement, and mentorship throughout my time at Rotman. I am also grateful to the other members of my dissertation committee: Francesco Bova, Gus De Franco, Scott Liao, and Giri Kanagaretnam (the external reviewer) for their excellent comments and suggestions. I owe my special gratitude to Jeffrey Callen, Gordon Richardson, Franco Wong, Hai Lu, Partha Mohanram, Baohua Xin, Aida Wahid, and other members of the Rotman community

for their help and support throughout. I dedicate this dissertation to my family: my husband and best friend Yiwei, and my dearest parents. 


\section{TABLE OF CONTENTS}

ABSTRACT

ACKNOWLEDGMENTS IV

TABLE OF CONTENTS $\quad$ v

LIST OF TABLES Niii

LIST OF APPENDICES D ix

CHAPTER 1—STRATEGIC ENTRY DECISIONS, ACCOUNTING

SIGNALS, AND RISK MANAGEMENT DISCLOSURE 1

1.1 INTRODUCTION 1

1.2 LITERATURE REVIEW AND HYPOTHESES DEVELOPMENT 7

1.2.1 Literature Review: Competition and Disclosure $\quad 7$

1.2.2 Institutional Background: The U.S. Airline Industry 11

1.2.3 Risk Management Accounting and Related Disclosures 15

1.2.4 Hypotheses Development 19

1.3 SAMPLE, VARIABLE MEASUREMENTS, AND RESEARCH

$\begin{array}{ll}\text { DESIGN } & 23\end{array}$

$\begin{array}{ll}\text { 1.3.1 Sample Selection } & 23\end{array}$

$\begin{array}{ll}\text { 1.3.2 Research Design } & 24\end{array}$

1.3.3 Measure of Entry Moves (ENTRY) 25

1.3.4 Measures of Incumbents’ AOCI from Fuel Hedge (I_AOCIFH), Disclosure (I_DISC), and Firm Characteristics 26

$\begin{array}{ll}\text { 1.3.5 Measures of Control Variables } & 27\end{array}$

1.3.6 Descriptive Statistics and Correlations $\quad 27$ 
$\begin{array}{ll}\text { 1.4.1 Main Results } & 28\end{array}$

$\begin{array}{ll}\text { 1.4.2 Additional Analyses } & 31\end{array}$

$\begin{array}{ll}\text { 1.4.2.1 Individual Disclosure Items } & 31\end{array}$

1.4.2.2 Potential Endogeneity of Disclosure $\quad 32$

1.4.2.3 Product Market Consequences after Entry 34

1.4.2.4 Other Analyses $\quad 34$

$\begin{array}{ll}1.5 \text { CONCLUDING REMARKS-- CHAPTER } 1 & 37\end{array}$

CHAPTER 2: THE ECONOMIC IMPACT OF SFAS 161: EVIDENCE

FROM MARKET REACTIONS TO EVENTS SURROUNDING THE

PASSAGE OF THE STATEMENT IN THE U.S. AIRLINE INDUSTRY 39

$\begin{array}{ll}2.1 \text { INTRODUCTION } & 39\end{array}$

2.2 BACKGROUND 43

2.2.1 Hedge accounting, disclosure, and prior literature 43

2.2.2 History of events $\quad 46$

$\begin{array}{ll}2.3 \text { HYPOTHESES DEVELOPMENT } & 48\end{array}$

$\begin{array}{ll}\text { 2.3.1 Overall market reactions } & 48\end{array}$

2.3.2 Cross-sectional determinants of market reactions $\quad 49$

2.4 RESEARCH DESIGN AND DATA 51

$\begin{array}{ll}\text { 2.4.1 Research design } & 51\end{array}$

$\begin{array}{ll}\text { 2.4.1.1 Stock price reactions } & 51\end{array}$

2.4.1.2 Cross-sectional analyses $\quad 52$

2.4.2 Data and descriptive statistics $\quad 53$ 
2.5 EMPIRICAL RESULTS

2.5.1 Mean stock price reactions $\quad 55$

2.5.2 Results of cross-sectional analyses $\quad 57$

2.5.3 Additional analyses and future research 59

$\begin{array}{ll}2.6 \text { CONCLUSIONS } & 60\end{array}$

$\begin{array}{ll}\text { REFERENCES } & 61\end{array}$ 


\section{LIST OF TABLES}

$\begin{array}{lll}\text { Table 1: } & \text { Variable Definitions-Chapter } 1 & 78\end{array}$

Table 2: $\quad$ Descriptive Statistics $\quad 80$

Table 3: $\quad$ Pearson Correlations $\quad 81$

Table 4: The Impact of Incumbents’ AOCIFH (I_AOCIFH) and its Interaction 83 with Disclosure on Entry: Probit Regressions Results

Table 5: $\quad$ Regressing Disclosure Scores on Year Indicators 85

Table 6: $\quad$ The Impact of Incumbents’ AOCIFH (I_AOCIFH) on Entry: Pre- and 86 Post-SFAS 161 comparisons: Probit Regressions Results

Table 7: $\quad$ The Effects of Individual Disclosure Items on Entry: Probit Regressions 88 Results

Table 8: $\quad$ 2SLS for Disclosure, Using I_FR as the Instrument Variable 91

Table 9: $\quad$ Change in Ticket Fares before and after Entry, for Entry and Matched no 93 Entry Routes

Table 10: $\quad$ Entrant-Incumbent-Year Level Analyses: Dependent Variable=\% of 94 Entered Market Share

Table 11: $\quad$ Using Alternative Variable of Interest Measure: I_AOCIFH_ASIF 95

Table 12: $\quad$ The Impact of Incumbents’ AOCIFH (I_AOCIFH) on Entry: Partition by 97 the Sign of $I \_A O C I F H$ and by the Direction of Fuel Price Change

Table 13: The Impact of Incumbents’ AOCIFH (I_AOCIFH) and its Interaction with Disclosure on Entry: Probit Regressions Using One-airport Present Carriers as Entrants

Table 14: Variables Definition-Chapter 2

Table 15: Descriptive Statistics and Correlations (2005-2008 average)

Table 16: Average Stock Returns around Event Dates during the Deliberation of SFAS 161: U.S. Airline Industry

Table 17: $\quad$ Sefcik and Thompson (1986) Cross-sectional Analyses of Stock Price Reactions around Key Events: 1 Indicator

Table 18: $\quad$ Sefcik and Thompson (1986) Cross-sectional Analyses of Stock Price

Table 19: Average Stock Returns around Event Dates during the Deliberation of 


\section{LIST OF APPENDICES}

Appendix A: $\quad$ Construction of the Disclosure Score--Chapter 1

Appendix B: $\quad$ Description of the D.O.T. Databases and Review of the Airline $\quad 67$ Literature

Appendix C: $\quad$ Journal Entries related to Cash Flow Hedges 70

Appendix D: $\quad$ Summary of SFAS 133 Disclosure Requirements 72

Appendix E: $\quad$ Summary of Events $\quad 74$

Appendix F: $\quad$ Construction of the Disclosure Score--Chapter $2 \quad 75$

Appendix G: $\quad$ Summary of SFAS 161 disclosure requirements 76 


\section{CHAPTER 1-STRATEGIC ENTRY DECISIONS, ACCOUNTING SIGNALS, AND RISK MANAGEMENT DISCLOSURE}

\subsection{Introduction}

This paper directly investigates the product market consequences of firms' accounting signals and related disclosures. Firms are sophisticated users of information disclosed by their peer firms. Before making major strategic product-market moves, firms collect decision-relevant information. One major type of information collected is competitors' accounting information related to competitive advantages and disadvantages. In this paper, I show that incumbents' accounting signals and disclosures related to their risk management activities are relevant to potential entrants' product market decisions.

There is limited prior evidence of the product market consequences to disclosure. The reason is that the relation between competition and disclosure depends on both the nature of the competition and the nature of the information (Darrough 1993; Verrecchia 1990) - two factors which are challenging to capture empirically. The U.S. airline setting allows me to directly examine the association between potential entrant decisions and firm-specific accounting signals. Verrecchia (1990) discusses how the two types of settings - one where the competitor is a potential entrant and the other where the competitor is an existing rival—can generate opposite predictions on the relation between disclosure and competition. In the airline setting, each route is considered a separate market where potential entrants and existing incumbents are easily identified. Moreover, Darrough (1993) and Sankar (1995) note that the type of information also matters when competitors make product market decisions. Being vulnerable to jet fuel price fluctuations, airlines use fuel hedge derivatives extensively to manage and control their operation 
costs. The usage of jet fuel hedges varies significantly across the industry, and a successful hedge program serves as an effective cost control, thus providing potential competitive advantages. The accounting and disclosure regulations for fuel risk management fall under the provisions of Statement of Financial Accounting Standards No. 133 Accounting for Derivative Instruments and Hedging Activities (SFAS 133), and its later amendment Statement of Financial Accounting Standards No. 161 Disclosure about Derivative Instruments and Hedging Activities (SFAS 161). These regulations provide potentially valuable firm-specific cost-related information to financial information users, including competitors.

I first show that, after controlling for numerous other economic determinants of entry decisions, potential entrants are more likely to enter markets in which the incumbents' cash flow hedge signals indicate poorer cost control and higher future fuel expenses. Potential entrants are defined as airlines which operate at both airports of a route but are not operating the route per se, consistent with prior literature that uses airport presence as entry threat proxies. Under SFAS 133, the accumulated other comprehensive income from fuel hedges (AOCIFH) stores the unrealized gains/losses from unsettled cash flow hedge derivatives, which will be reclassified into fuel expenses (and net income) when the forecasted transactions take place in the future. I manually collect the AOCIFH information from all airlines' $10 \mathrm{~K}$ filings. The accounting construct of AOCIFH varies with the firm's specific hedging strategies, and describes how much future costs will be reduced or increased due to hedging activities. Given the common jet fuel spot prices all airlines face, a higher AOCIFH can reduce future fuel expenses by a greater amount, make the firm more competitive in pricing, and serve as a deterrent for potential entries. Similarly, a negative AOCIFH will increase future fuel expenses and decrease net income, putting the firm at 
competitive disadvantage. Thus, incumbents' firm-specific cost information can play an important role in potential entrants' strategic decisions. ${ }^{1}$

I further examine how financial disclosure related to this firm-specific accounting signal affects the relation between the probability of entry and AOCIFH. Specifically, I empirically test whether the relation between incumbents' fuel hedge signals and the probability of entry is stronger when the incumbents' disclosure about their hedge activities is more extensive. The motivation to assess AOCIFH and disclosure jointly stems from concerns of the Financial Accounting Standards Board (FASB) that investors may not fully understand the impact of cash flow hedge accounting on future firm performance due to the complexity of the standard. As a result, firms provide supplementary disclosures in their financial reports to help users interpret such signals and boost their informativeness. By carefully reading through the annual reports of my sample firms and referring to risk management disclosure regulations and extant literature, I construct a disclosure score based on the items in 10-K filings that relate to risk management activities. The scores suggest that there is significant variation in supplementary disclosure both over time and across firms. I find that the relation between cash flow hedge signals and entry by potential entrants is stronger when the hedge accounting signals are accompanied with more extensive disclosures.

Finally, in response to the complaint that hedge accounting treatments under SFAS 133 are complicated and related financial report disclosures still do not provide adequate information to users, the FASB issued SFAS 161 effective in 2008 with expanded quantitative and qualitative

\footnotetext{
${ }^{1}$ Many studies have examined entry deterrence strategies with incomplete information. For example, Milgrom and Roberts (1982) present a model where the incumbent and the entrant only know their own production costs but can infer each other's cost structure through pricing. In equilibrium, the incumbent uses limited pricing to signal his low cost and deter entry, because the entrant uses the product price to infer the incumbent's cost and expected post-entry profits. In practice, other firm-specific information can validate and complement the pricing signal, and play important roles in the entry game.
} 
disclosure requirements for hedge derivatives. This exogenous shock to the risk management disclosure regime provides a pseudo natural experiment to test the impact of disclosure on the relation between entry patterns and accounting signals. I find that after the overall information environment for risk management activities was improved following the adoption of SFAS 161, the relation between cash flow hedge signals and the entry pattern of potential entrants becomes significantly stronger compared with the pre-SFAS 161 period.

To further explore the information content of the disclosure regarding hedging activities, I examine how individual disclosure items affect the informativeness of hedging signals differently. My results suggest that three disclosure items-estimated reclassification into net income in the next year, maturity of the derivatives, and separate disclosure of AOCIFH-are considered the most helpful by potential entrants.

My results are robust to a battery of additional tests. To mitigate the potential endogeneity issue with disclosure, I employ an instrumental variable approach. In addition, I include carriers present at only one airport as potential entrants and rerun the tests. I also conduct several other robustness tests, including controlling for additional known determinants of disclosure, partitioning AOCIFH by its sign and rerunning the tests for both subsamples, accounting for fuel hedges not designated as cash flow hedges, changing the scalar for the test variable, and varying the sample size. Finally, when I collapse my sample to incumbent-entrantlevel and examine the entry pattern, the results are consistent with my primary results at routeentrant-year level.

This study contributes to the growing literature on proprietary costs of disclosure (e.g., Verrecchia 1983, 1990; Darrough and Stoughton 1990; Darrough 1993; Bamber and Cheon 1998; Guo, Lev, and Zhou 2004; Bhojraj, Blacconiere, and D’Souza 2004; Berger and Hann 2007; Li 
2010; Bens, Berger, and Monahan 2011; Bova, Dou, and Hope 2012; Ellis, Fee, and Thomas 2012). The maintained assumption in this line of literature is that disclosure of certain information compromises disclosing firms' competitive advantages because such information can be used strategically by competitors against disclosing firms. Analytical studies unambiguously specify the type of information and the type of competition in order to generate a directional prediction for the relation between disclosure and competition. By using a unique setting in which I can clearly identify the nature of the information and the nature of the competition, this paper provides for a more powerful setting to assess the product market consequences of firm-specific signals and related disclosure. My findings support both the proprietary cost of disclosure theory and the notion that product market consequences of disclosure exist. This paper also suggests that further research on the determinants of disclosure should consider both the nature of the competition and the nature of the information and choose proxies accordingly.

Additionally, my findings enrich our understanding of SFAS 133 and related regulations. Despite prescribing more uniform accounting treatments and disclosure rules for derivatives, SFAS 133 has also been criticized for creating inconsistency and confusion, especially with the cash flow hedge accounting treatment (e.g., Gigler, Kanodia, and Venugopalan 2007). Existing research primarily focuses on the financial market implications of the standard (e.g., Campbell 2011; Ahmed, Kilie, and Lobo 2006; 2011) or the impact on firms' risk management behavior (Zhang 2009). By providing evidence that potential entrants use incumbents' cash flow hedge signals to facilitate their entry decisions, my results provide another channel through which the information content of hedge accounting treatments and disclosure can be evaluated. 
This article is also one of the first to empirically investigate the effectiveness of SFAS 161. The purpose of SFAS 161 was to provide financial statement users with enhanced quantitative and qualitative disclosure for hedging activities. My paper provides evidence that hedge accounting signals proposed by SFAS 133 become more informative in assisting potential entrants' strategic decisions after the adoption of SFAS 161 in the U.S. airline industry. This result is consistent with the purpose of SFAS 161 in helping financial report users better understand firms' risk management activities and their impact on future performance.

In examining the effectiveness and informativeness of SFAS 133 and SFAS 161, this study proposes an alternative approach to evaluating the information content of accounting numbers and disclosures. Firms operating in the same product market are familiar with the business practices within the industry and are sophisticated users of peer firms' information. Thus, their evaluation of the information content of accounting measures and disclosure complements the traditional capital market value relevance approach.

Finally, my research extends the industrial organization literature that examines how firms learn from their rivals in order to optimize decisions. Accounting information, which represents firms' essential operating and financing results, is largely ignored in the industrial organization literature. Studies explaining the competition process and pattern tend to select market-level structure and characteristic variables as major candidates (Oliveria 2008; Boguslaski, Ito, and Lee 2004). This paper demonstrates the important role of competitors' firmspecific accounting information in the strategic entry process.

The next section provides a review of relevant literature and develops the hypotheses. Section 1.3 describes the research design and sample selection. Section 1.4 presents empirical 
results and Section 1.5 concludes the paper and Appendix A explains the disclosure score construction and provides descriptive statistics for the disclosure items.

\subsection{Literature Review and Hypotheses Development}

\subsubsection{Literature Review: Competition and Disclosure}

Financial disclosure provides information to facilitate internal and external users' decision making process. While shareholders use accounting information to allocate capital and evaluate managers, firms collect their competitors' information and choose their own information sharing strategies to optimize their product market decisions (e.g., Gal-Or 1985, 1986; Vives 1984, 1990; Milgrom and Roberts 1982). Thus, competitors' use of information provides another benchmark against which the information content of accounting signals and disclosures can be evaluated. While existing accounting research mainly focuses on financial market implications of accounting measures and related disclosure (see Beyer, Cohen, Lys, and Walther 2010 for a comprehensive survey), the use of such information by other external parties is relatively unexplored empirically. This paper aims to fill this gap by examining how potential entrants respond to incumbents' firm-specific accounting signals, and how additional disclosure regarding the signals impacts the response of potential entrants.

Using competing firms' product market decisions as an information content criterion requires clear identification of the nature of the information and the nature of the competition. For instance, revealing information to competitors does not necessarily reduce the disclosing firm's competitive advantages. In some cases, firms are better off sharing information so as to coordinate actions to their mutual advantages. Thus, the consequences of disclosure depend on the specific type of competition firms are engaged in and the type of information firms have. 
For this reason, analytical studies are particular specific in the type of competition and the type of information in developing their models. Gal-Or (1986) and Vives (1984) examine the information sharing strategies in an oligopoly and find that the disclosure decisions and the optimality of segment or aggregate reporting depend on the type of competition and the nature of the uncertainty in the economy. Feltham, Gigler, and Hughes (1992) consider the consequences of line-of-business versus aggregate reporting in an entry game and show that incumbents may distort their first-period production in an attempt to influence entrant beliefs because line-ofbusiness reporting provides entrants with proprietary information about the incumbent. Darrough (1993) analyzes both ex ante and ex post disclosure incentives with market-wide demand and firm-specific cost information in both Cournot and Bertrand settings. She finds that, ex ante, firms would not commit to disclosure in Bertrand/cost and Cournot/demand cases. She further demonstrates that firms' incentives diverge ex post. Specifically, in equilibrium, disclosure would seldom be observed when products are highly substitutable in the Bertrand/cost case. However, in the Cournot/demand case, virtually all values of private information would be disclosed. There are other studies examining the ex post disclosure incentives. Sankar (1995) compares firm-specific and industry-wide information sharing in a Cournot duopoly setting. Her results indicate that ex post, unfavorable news is disclosed and favorable news is withheld if the signal is more informative about an industry-wide shock. In contrast, favorable news is disclosed and unfavorable news is withheld if the signal is more informative about firm-specific shocks. Darrough and Stoughton (1990) investigate the disclosure of market-level information in an entry-game setting and posit that bad market-level news can serve as entry deterrence. These differing predictions on the relation between disclosure and competition are rooted on the premises that different types of information produce distinct product market consequences. 
Accompanying the development of theoretical studies on competition and disclosure, empirical researchers try to test such theories in different settings. Harris (1998) investigates the relation between managers' choices of which operations to report as business segments and levels of industry competition using industry concentration ratios and abnormal profit adjusting rates as the proxies. She finds that operations in less competitive industries are less likely to be reported as industry segments, suggesting that the competitive harm cited as a disincentive to segment reporting arises from a desire to protect abnormal profits and market shares in less competitive markets. Using a Census Bureau database of confidential, plant-level data, Bens et al. (2011) find similar results that a pseudo-segment is more likely to be aggregated when the proprietary costs of separate reporting are high. ${ }^{2}$

Bamber and Cheon (1998) focus on managers' decisions about how and where to disclose earnings forecasts and examine how these decisions relate to proprietary costs proxied by growth opportunity and industry concentration ratios. They find that forecasts made by firms experiencing high growth opportunities or in concentrated product-markets are likely to be more reactive and reluctant disclosures issued to limited audiences. Li (2010) looks at how management forecasts quantity and quality are affected by product market competition and finds that competition from potential entrants (captured by industry plant and equipment size) increases disclosure quantity while competition from existing rivals (captured by industry concentration ratio) decreases disclosure quantity, and that the association is less pronounced for industry leaders.

\footnotetext{
${ }^{2}$ Less competitive (high concentration ratios) does not necessary mean low proprietary cost. Instead, in Harris (1998), a less competitive environment measured by a slower abnormal profit adjusting rate and a higher industry concentration ratio means more to lose for the firm, thus higher proprietary costs. In many other settings (e.g., Verrecchia and Weber 2006; Li 2010), by more competitive (a lower concentration ratio), the authors mean higher proprietary costs. This phenomenon further highlights the necessity of identifying the nature of competition.
} 
Being aware that the traditional competition measures such as concentrations ratios and industry profitability and size measures are crude and may not capture the competition nature they intend to, ${ }^{3}$ more recent studies start to examine the disclosure behavior in particular industries or settings and complement with competition proxies specific to these settings. Guo et al. (2004) investigate the disclosure of product related information by Biotech firms in their IPOs and their competition measures include the availability of a patent, stage of the product, and the availability of venture capital. They find that these three proprietary cost proxies stand out as consistent determinants of the extent of disclosure by IPOs. Bhojraj et al. (2004) focus on the electric utility industry's disclosure of strategies to protect the firm's existing customers base and plans to exploit emerging opportunities under deregulation and find that product market-related incentives (greater threat of competitor entry captured by higher expected future market demand) deter disclosure. Dedman and Lennox (2009) investigate the disclosure of sales and cost of sales. In addition to using industry concentration ratios and abnormal profits as competition proxies, they also employ a measure constructed from surveying managers about their perceived competition. Ellis et al. (2012) choose the setting of disclosure about firms' customers and use the rate of nondisclosure of a firm's rivals as one of their competition proxies. They find that an individual firm's decision to conceal information about its major customers is strongly associated with the rate at which its rivals conceal information regarding their customers.

To summarize, this line of growing literature suggests that in order to have a clear and directional prediction on the association between competition and disclosure, one has to specify both the nature of the competition and the nature of the information. The U.S. airline industry setting provides an ideal setting to identify and distinguish the nature of information and the nature of competition.

\footnotetext{
${ }^{3}$ See Karuna (2010) and Ali et al. (2009) for detailed discussion.
} 


\subsubsection{Institutional Background: The U.S. Airline Industry}

The U.S. Airline Deregulation Act in 1978 gradually removed government control over fares, routes, and market entries, and allowed free competition in the U.S. passenger air travel market. ${ }^{4}$ Meanwhile, the industry is still under the supervision of the Department of Transportation (D.O.T hereafter) and is required to provide substantial filings which are publicly available (e.g., ticket prices, on-time performance, passenger volume, financial statements, etc.). ${ }^{5}$ With active competition and a rich data environment, a long line of literature has used the airline industry to examine various competition-related research questions (Borenstein 1989; Berry 1990; Borenstein and Rose 1994; Hayes and Ross 1998; Boguskaski et al. 2004; Goolsbee and Syverson 2008; Gerardi and Shapiro 2009; Aguirregabiria and Ho 2012, among many others).

I explore the U.S. airline setting to examine the informational role of accounting signals and disclosure in potential entrants' product market decisions. The airline industry setting offers several advantages over cross-industry studies. First, each route is considered a unique product market with the transportation service between the two airports provided by carriers being homogenous or highly substitutable products. ${ }^{6}$ Defining markets and examining competition at the route level is a common procedure in the economics literature on competition using the airline industry setting. For example, Borenstein and Rose (1994) study the dispersion in prices

\footnotetext{
${ }^{4}$ Extensive research has been conducted to determine whether the competition in the airline industry is closer to the Bertrand or Cournot model. Brander and Zhang (1990) conclude that the competition in the airline industry is closer to the Cournot type, but their conclusion stems from analysis of only non-stop flights on selected duopolistic markets originating from the congested O'Hara airport. More recent studies find that the competition is closer to the Bertrand type. Neven, Roller, and Zhang (1998) provide an industry-wide analysis of the European market and find that the pattern is consistent with Bertrand competition. Busse (2002) examines the price war in the U.S airline industry and discovers that over the time period the paper considers (1985-1992) price cuts by one airline were always matched by competitors. The findings suggest that fierce price competition is characteristic in the deregulated U.S airline industry. Besides, rather narrow observed profit margins in the industry are not consistent with Cournot-type competition.

${ }^{5}$ Please see the U.S. Department of Transportation websites (http://www.dot.gov and http://www.rita.dot.gov) for data available for the airline industry.

${ }^{6}$ Meanwhile, the supply, demand, and product prices for each product market are available through public resources. For example, the D.O.T provides passenger volumes for each carrier-route, and the Origin and Destination Survey (DB1B) database surveys 10\% of all tickets quarterly, including ticket prices
} 
airlines charge to different customers in the same product market, where the same product market is defined as the same route. Using the U.S. airline setting, Goolsbee and Syverson (2008) examine how incumbents respond to the threat of entry by competitors and define the incumbents and the threat of entry at the route-quarter level. Gerardi and Shapiro (2009) analyze the effects of competition on price dispersion in the airline industry using a panel data in which an observation is a flight conducted by a specific airline between two airports in a specific time period. Furthermore, Aguirregabiria and Ho (2012, 163) write the following: "Definition of a market and a product. From the point of view of airlines' entry and exit decisions, a market is a non-directional city-pair. For the model of demand and price competition, a route is a directional round-trip between an origin city and a destination city. These definitions are the same as in Berry (1992) and Berry et al. (2006), among others, and similar to the ones used by Borenstein (1989) or Ciliberto and Tamer (2009) with the only difference that they consider airport-pairs instead of city-pairs." Please see Appendix B for a complete discussion of the databases and review of airline studies using the similar setting.

A well-defined product market is essential in addressing what the relation is between competition and disclosure. The research design in this paper, where markets are defined as routes, complements the traditional way of defining markets using SIC codes and measuring competition with concentration ratios by two- or three-digit SIC codes. SIC code-based competition proxies could also produce misleading results because they only include public firms in the calculations. Ali, Klasa, and Yeung (2009) replicate prior studies and show that some of the results reverse when both public and private firms are included in the competition proxy calculation. Using each route as a market avoids such problems because the market share data for all carriers are publicly available. 
In addition, incumbents and potential entrants are directly observable for each route in the airline industry. In particular, I am able to identify carriers who posit the most entry threats to incumbents. Following prior economics research using airport presence as proxies for entry threat (Hurdle et al. 1989; Sinclair 1995; Goolsbee and Syverson 2008), potential entrants are defined as those carriers who operate at both of the airports but are not operating the route per se. For example, an airline has flights to and from Boston, as well as flights to and from Cleveland, but has not yet operated the Boston-Cleveland route per se. In this case, the airline posits the most significant threat to the incumbent carriers of the route because it is already paying for slots at both airports and the marginal cost of entering is relatively low. Goolsbee and Syverson (2008) estimate that operating at both endpoints of a route translates into a 70 times higher probability of entering for the route than for other routes. Consistent with this finding, most of the entries in my sample period are launched by carriers operating at both airports.

The U.S. airline industry is characterized by fierce price competition. ${ }^{7}$ Demand is pricesensitive and carriers have limited pricing power over consumers. Meanwhile, fuel and labor costs are the two biggest cost drivers of the industry, exceeding $50 \%$ of total operating expenses. ${ }^{8}$ Importantly, compared with labor (and other) costs, fuel prices are highly volatile and uncertain, explaining $78.9 \%$ of the variation in total operating costs of my sample. The jet fuel spot price in commodity markets is an external factor that airlines have little control over, and fuel-price increases cannot be easily passed through to customers because of competitive pressures. Airlines have tried repeatedly to raise fares in response to high fuel costs, but with

\footnotetext{
${ }^{7}$ Forming airline alliances is another form of the competition dynamics in the industry. By joining an alliance, airlines can (1) extend their network through code sharing; (2) reduce costs through sharing maintenance/operational facilities. I exclude code sharing observations by eliminating tickets with ticketing carriers different from operating carriers. The facilities/maintenance sharing usually happens between one legacy and one really small airline that sole operate under the legacy airline or international airlines. These observations are immaterial in my sample.

${ }^{8}$ According to U.S. Air Transport Association reports, for 2010 Q3, fuel and labor costs represent $25.4 \%$ and $24.7 \%$ of operating expenses, respectively. For more summary data on U.S. air transportation, please see http://www.airlines.org/Economics/DataAnalysis/Pages_Admin/DataAnalysis.aspx.
} 
little success. For example, Continental Airlines rescinded a fare hike after trying a number of times to boost overall fares. The airline said the airfare increases were due to high fuel costs, but intense airline competition left the firm unable to pass along fuel costs to customers. ${ }^{9}$

In order to manage fuel price risk and achieve price competitiveness, airlines intensively engage fuel hedges using jet-fuel related derivatives. Typical derivative instruments include forward contracts, futures contracts, options, collars, swaps, etc. (Clubley 1999; Morrell and Swan 2006). Fuel hedge contracts serve as a cost control mechanism for airlines. Chang and Shao (2011) compare operating cost control strategies for airlines and rank fuel hedging strategies as the second most significant and important among the 21 strategies extracted from questionnaires answered by airline industry experts.

Despite the fact that all carriers face the same spot fuel price and that they all hedge their fuel, the extent of hedging, the derivatives used, and the hedging outcomes vary significantly. ${ }^{10}$ Given the thin profit margin in the airline industry, the ability to manage market risk and reduce fuel expenses is essential for future performance and is highly valued in the industry. ${ }^{11}$ Carter, Rogers, and Simkins (2006a, 2006b) show that fuel hedge is positively related to firm value in the U.S. airline industry (see also Allayannis and Weston 2001; Mackay and Moeller 2007; Bartram, Brown, and Conrad 2011). ${ }^{12}$ Under the provisions of SFAS 133, airlines designate these derivatives as cash flow hedges if they pass certain criteria. This accounting standard intends to provide financial statement users with more transparent information on firms' use of

\footnotetext{
${ }^{9}$ See "Continental Raises Domestic Fares, Cites Fuel costs" (Reuters, February 27, 2004) and "Continental Airlines Resends Latest Fare Hike" (Reuters, June 7, 2004).

${ }^{10}$ Commenting on fuel hedge strategies in the industry, the Chief Financial Officer of United Airlines, Kathryn Mikells, said in 2010 that "As an industry we are highly fragmented. Everybody has taken a different position." See http://www.reuters.com/article/2010/02/25/us-travel-leisure-summit-fuel-hedging-idUSTRE61O59Z20100225

${ }^{11}$ Vice President of Southwest Airline Scott Topping highlighted that "fuel hedging will continue to play a strategic role in the industry and be a potential source of competitive advantage" (Carter et al. 2006a).

${ }^{12}$ Campello, Lin, Ma, and Zou (2011) identify several specific mechanisms through which hedging can affect real and financial corporate outcomes. Another motivation implied in the literature for corporate hedging is to signal management competence (DeMarzo and Duffie 1995; Morrell and Swan 2006).
} 
derivative instruments. I discuss the accounting treatment and disclosure requirements for cash flow hedge under SFAS 133 in more detail in the following section.

\subsubsection{Risk Management Accounting and Related Disclosures}

The last decades have witnessed impressive growth in the use of financial derivatives and instruments in risk management. Before the adoption of SFAS 133 in 2000, the accounting treatment for derivative instruments was incomplete and inconsistent. ${ }^{13}$ As a result, the FASB has issued a series of accounting and disclosure requirements for derivatives, intending to supply more publicly available information and improve the information content of derivatives. ${ }^{14}$ This suggests that the FASB believes that such information is beneficial to financial statement users. Following these regulations on enhanced disclosure, studies have emerged examining the usefulness and value relevance of such disclosures (Venkatachalam 1996; Wong 1999; Seow and Tam 2002; Jorion 2002). The general theme from this line of research is that expanded disclosures provide incremental information to the market and are value-relevant.

To address the concern that historical-cost accounting and prior disclosure requirements may not fully reflect a firm's underlying risk profile, SFAS 133 requires that an entity must recognize all derivatives in the balance sheet at fair values, and record changes in fair values of the derivatives in corresponding accounts, depending on which kind of hedge the derivatives are designated as. Three categories of hedges are allowed: hedges for foreign currency exposure, fair-value hedges for recognized assets, and cash flow hedges for recognized assets or forecasted

\footnotetext{
${ }^{13}$ Under the FASB Accounting Standards Codification effective for interim and annual periods ending after September 15, 2009, SFAS 133 corresponds to ASC 815 and SFAS 161 corresponds to ASC 815-10-50.

${ }^{14}$ Before the disclosure requirements on derivatives were officially issued, firms selectively reported their derivative transactions, including gains and losses. SFAS 105, effective from 1990, required firms to report the face, contract, or notional principal amount of financial instruments with off-balance-sheet risk. SFAS 107 (1991) expanded such disclosure to include the fair value amount of all financial instruments in the notes to financial statements. In 1994, the FASB issued SFAS 119, mandating firms to provide disaggregated notional value disclosures.
} 
transactions. Following the instructions and industry norm, all designated fuel hedges in my airline sample are designated as cash flow hedges. For derivatives designated as cash flow hedges, the effective portion of the derivatives' gains and losses is initially reported as a component of other comprehensive income and subsequently reclassified into earnings when the forecasted transactions affect earnings. Therefore, unrealized cash flow hedge gains/losses in AOCI at any given balance sheet date represents the cumulative gain/loss position of the firm's cash flow hedge activities. A positive AOCI from fuel hedge (AOCIFH) occurs when the fair value of hedging derivatives increases (e.g., when the jet fuel prices go up and the firm hedges against it). The positive AOCIFH will be reclassified into income to offset the fuel expenses when the position closes in the future. Thus, the value of AOCIFH informs about a firm's cost control ability, current hedge outcomes, and the impact on future performance. ${ }^{15} 16$

SFAS 133 has generated intense debate on the economic consequences of its accounting treatment and disclosure requirements. Proponents of the standard maintain that the fair value recognition makes the use of derivatives more transparent and benefits the financial markets (e.g., Melumad, Weyns, and Ziv 1999; Zhang 2009; Ahmed et al. 2011). However, SFAS 133 has been criticized for being overly complex. Many firms intensively object to extensive derivative disclosures on the grounds of implementation costs and their need to protect proprietary information. ${ }^{17}$ In a survey of over 300 financial executives by the Treasury Management Association (TMA) in 1997 regarding the draft proposals of SFAS 133, Thomas Logan,

\footnotetext{
${ }^{15}$ To fully account for the impact of fuel hedges, in additional analyses, I further include the ineffective portion of fuel hedges and the occasional undesignated part and the inferences are unaffected.

${ }^{16}$ Appendix C provides an illustration of the journal entries associated with an option derivative that is designated as a cash flow hedge under SFAS 133.

${ }^{17}$ As General Motors phrases it: "If GM disclosed the volume of its commodity derivatives contracts and their anticipated cash flows, a competitor could calculate the purchase price of GM's components" (Miller and Culp 1996). In addition, Ford Motor Co.'s comment letter to the SEC on SFAS 133 states that "Disclosures about the extent of hedging activities could harm our competitive position because of the proprietary nature of the information. Providing details of transactions could disclose information that would make Ford vulnerable to competitors operating in the marketplace" (Marshall and Weetman 2007).
} 
Chairman of TMA, noted that "Half of the respondents to the TMA survey stated that at least some of the disclosures required by the proposed FASB and SEC requirements would be proprietary information that could provide competitors with an unfair business advantage." Carter, Rogers, and Simkins (2006c) state that by 2005 Southwest, for competitive reasons, became more secretive about disclosing what they were employing as hedging commodities and whether the company was using options or swaps to hedge. Seow and Tam (2002) show that, in the case of derivative-related disclosures by U.S. banks, the disclosures contain new information to the market. Their findings suggest that if the information is new to investors it is likely also new to competitors and could lead to proprietary costs, either by lowering barriers to entry or by loss of market share to new or existing competitors.

An interesting observation is the often noncompliance by disclosing entities. Bhamornsiri and Schroeder (2004) examine the disclosure of information on the use of derivative financial instruments by Dow 30 companies under the provisions of SFAS 133. Their results indicate that compliance with the provisions by the sample companies is mixed. Firms complied with the qualitative guidelines while inconsistencies were found in meeting the quantitative requirements. My disclosure scores also indicate inconsistent and incomplete disclosure regarding hedgingrelated derivative use across firms and years. For example, SFAS 133 requires entities to disclose the amount of AOCI from cash flow hedges expected to be reclassified into net income in the next year, yet only $44 \%$ of my sample firm-years disclose such information. This estimated reclassification is considered highly proprietary and closely related to the fuel expenses/net income in the next year. I follow the prescription of SFAS 133, FRR No. 48, and prior literature on risk management disclosure to construct my disclosure scores. ${ }^{18}$ Specifically, I identify

\footnotetext{
${ }^{18}$ FRR 48 mandates that firms provide in their 10-K reports quantitative market risk information relating to each material category of market risk to which they are exposed to. Within each risk category, FRR 48 allows companies
} 
thirteen items that are either mandated or encouraged by these regulations and are considered informative in assessing the risk exposure and risk management portfolio. Then for each item, a value of one is granted if such disclosure is provided by the firm, and zero otherwise. The overall disclosure score for each firm-year observation is the average for all available items. More descriptive details are included in Appendix A. Appendix D provides a brief summary of the disclosure requirements under SFAS 133.

In response to the claim that the complexity of SFAS 133 accounting treatments and the lack of adequate disclosure regarding hedging activities impede financial statement users' assessment of firms' risk positions and performance, the FASB issued SFAS 161 in March 2008. SFAS 161 does not change the basic scope of SFAS 133, but it does require additional qualitative and quantitative disclosures about an entity's derivative and hedging activities. These enhanced disclosures are intended to help users better understand how derivative instruments and hedging activities affect an entity's financial position, financial performance, and cash flows. ${ }^{19}$ SFAS 161 is effective for fiscal years beginning on November 15, 2008 and after. By requiring firms to disclose managements' intent and explain their behavior and possible consequences, SFAS 161 reflects the FASB's effort and attempt to bridge the gap in financial statements between what happened and what may occur in the future. Shifting the disclosure requirements for all firms, especially including forward-looking discussions, should affect the overall

to present quantitative market risk information using one or more of the following three formats: tabular presentation, sensitivity analyses, or value-at-risk disclosures.

${ }^{19}$ Please see Appendix G for a brief summary of the disclosure requirements under SFAS 161. Specifically, some of the significant disclosures required include the following five categories: (1) an entity's objectives for holding or using derivatives and its strategies for achieving those objectives discussed in the context of the derivative's primary underlying risk exposure; (2) the level of an entity's derivative activity (e.g., total notional amount of contracts); (3) the location and fair value amounts of derivatives instruments, hedged items, and related gains and losses in the balance sheet and income statements, presented in a tabular format; (4) the existence and nature of credit-risk-related contingent features and the circumstances in which those features could be triggered in derivatives instruments that are in a net liability position at the end of the reporting period; and (5) cross-referencing among the notes to the extent that the required disclosures are presented in more than a single note. 
informativeness of hedge accounting signals. This study is one of the first to provide evidence on financial statements users' response to such incremental disclosures.

\subsubsection{Hypotheses Development}

The financial instruments used in fuel hedges in the airline industry, if designated as hedges, are classified as cash flow hedges under SFAS 133. The unrealized gains/losses from the change in fair value of the cash flow hedge instrument are recorded in AOCI and later transferred to net income when the hedge position is closed. The AOCIFH is a forward-looking measure providing information on the firm's future fuel expenses and fuel price exposure.

To illustrate, an airline expects to consume jet fuel in the near future. Worrying that the fuel price will go up in the future, the firm purchases a jet fuel call option designated as a cash flow hedge currently. When the fuel price goes up and the fair value of the option increases, a gain is recorded in AOCI at each fiscal date before the fuel consumption happens. Later when the fuel is purchased at the spot price and consumed, the hedge position is closed at the same time, and gains recorded in AOCI from this option are transferred to the income statement by offsetting fuel expenses. Thus, compared with another airline that purchases fuel at spot prices and has no storage of gains from AOCI to be released, the fuel expenses for the firm in my example is lower, which puts it at a competitive advantage. In the airline industry, the amounts of AOCI are economically important. For example, Alaska Air Group reported a hedging loss of $\$ 52.4$ million net of tax for the third quarter in 2011, while its net earnings for the period were $\$ 77.5$ million. ${ }^{20}$ In addition, the impact from fuel hedging to firm's net income exhibits certain persistence. I examine the auto-correlation of the amount transferred into fuel expenses from 
AOCI each year and find that for my sample firms the median auto-correlation of this flow variable is 0.23 and statistically significant.

From the above example, one can observe that the current period AOCIFH contains important information regarding the firm's cost structure in future periods (e.g., Chang and Shao 2011). A higher AOCIFH signals better cost control by the incumbent in the future, which works as a natural entry deterrence (Salop 1979; Milgrom and Roberts 1982). The intuition in Salop's (1979) model and later literature is that, when the incumbent is of the low-cost type, he will signal his type by charging a lower price to competitors in order to deter entrances and maintain his market power. This signal is costly for a high-cost type to mimic, and as a result, production costs affect incumbents' ability to cut prices in the competition process. In contrast, a lower AOCIFH signals higher fuel costs in the future. ${ }^{21}$ The fuel hedge programs adopted by airlines vary significantly over time and across firms (Clubley 1999; Morrell and Swan 2006). Thus, given the fluctuations on fuel prices and the complexity of hedging derivatives, it is difficult to predict other firms' future fuel costs without knowledge of their hedging effects on fuel expenses. The AOCIFH reduces the uncertainly of assessing the firm's future performance by providing information on the amount of fuel expenses which could be reduced in the future. Using a cross-industry sample, Campbell (2011) shows that the level of AOCI from hedge derivatives has incremental prediction power of a firm's future performance and the market does not fully understand it. ${ }^{22}$ Jones and Smith (2011) document that other comprehensive income

\footnotetext{
${ }^{21}$ This paper uses the raw value of AOCIFH (scaled by total assets) as the firm-specific signals, not the absolute values of AOCIFH, because the impact of AOCIFH on future net incomes is directional.

${ }^{22}$ Campbell (2013) predicts a negative relation between AOCI and firm performance because the author uses observations from all industries where the hedged items can be inputs and outputs, and because the author assumes a mean-reverting trend for all these commodities. My sample is based on one industry where the hedged item is the input and the general price trend is upward. A replication of Campbell (2013) on my airline industry sample reveals a positive relation between AOCIFH and future performance.
} 
gains and losses have predictive value for both future income and future cash flow, and are value relevant.

The incremental information that AOCIFH has over general profitability measures (e.g., ROA) is crucial to answering the research questions in this paper. Standard profitability measures are highly aggregated and summarize a firm's overall performance. For example, a high ROA could due to high overall market demand, low overall market supply, failure of competitors, and/or the firm's own successful marketing/pricing/cost control etc. In contrast, AOCIFH is an accounting signal about firm-specific input costs. Differentiating the nature of the information being disclosed is essential to infer the relation between disclosure and competition. ${ }^{23}$ Prior studies primarily focus on conventional profitability measures and view them as signals that attract competition, which is not necessarily the case. In my empirical analyses, I control for both the incumbents' and the entrants' profitability and non-financial performance measures.

Based on the above arguments, my first hypothesis is:

H1: Potential entrants are more likely to enter routes for which the incumbents have lower AOCIFH.

Under SFAS 133, the unrealized cash flow hedge gains/losses in AOCI at any given balance sheet date represent the cumulative change of fair value of the firm's active, unsettled cash flow hedge derivatives. However, both the SEC and the FASB have taken positions

\footnotetext{
${ }^{23}$ Many studies have examined entry deterrence strategies with incomplete information. For example, Milgrom and Roberts (1982) present a model where the incumbent and the entrant only know their own production costs but can infer each other's cost structure through pricing. In equilibrium, the incumbent uses limited pricing to signal his low cost and deter entry, because the entrant uses the product price to infer the incumbent's cost and expected post-entry profits. In practice, other firm-specific information can validate and complement the pricing signal, and play important roles in the entry game.
} 
suggesting that investors may not fully understand and impound the implications of AOCI for the entity's financial position, financial performance, and cash flows. The AOCIFH will be released to offset fuel expenses over time (one or several fiscal periods), depending on the maturity and the forecasted transaction date of hedge items. In addition, AOCIFH from the current period does not necessarily equal the amount that will be offsetting fuel expenses in the next period. ${ }^{24}$ More extensive information on the derivatives (e.g., types, maturities, strike prices, etc.) aids outsiders in understanding the changes in fair value up to now, facilitates the estimation of the potential changes in fair value beyond the current period, and enhances the informativeness and precision of AOCIFH in informing about future firm performance.

Thus, SFAS 133 also requires firms to discuss their hedging objectives and their use of derivatives to meet these objectives. In addition, quantitative and qualitative disclosures beyond the mandated scope are encouraged by the FASB to help users better understand cash flow hedge accounting. Typical disclosures include the derivative details, credit risk from the derivatives, sensitivity analyses, percentage of expected fuel consumption hedged for the future periods (ranging from the next quarter to the next couple of years), expected amount of AOCI to be reclassified into net income in the next 12 months, future hedge strategies, and so on. The disclosures of hedge instruments beyond the value of AOCIFH provide valuable information for financial statement users to interpret the AOCI numbers and to assess the firm's risk position and future firm performance. Thus, I expect that a more transparent and extensive disclosure of such information will enhance the informativeness of AOCIFH, which leads to the first part of my second hypothesis:

\footnotetext{
${ }^{24}$ The change in fair value after current period fiscal year end and before the maturity of the instrument is not reflected in current period AOCI.
} 
H2a: The relation between incumbents' AOCIFH and entrants' entry decisions is stronger when the incumbents' disclosure on fuel hedge activity is more transparent.

SFAS 161 expanded both the qualitative and quantitative disclosure requirements for derivative instruments governed by SFAS 133 . The purpose of SFAS 161 was to help financial statement users better understand the implications for the firm's future performance of hedge derivatives, related accounting treatments, and disclosures governed by SFAS 133. This exogenous shift of disclosure requirements could have a significant impact on the informativeness of hedge accounting signals. With extended disclosure and tabulated details on balance sheet/income statement impacts from hedging derivatives that were not mandated before SFAS 161, financial statement users should find hedge accounting information more informative for the firm's future performance. Specifically, potential entrants should find the incumbent's AOCIFH more informative. This leads to the second part of my second hypothesis:

H2b: The relation between incumbents' AOCIFH and entrants' entry decision is stronger after the implementation of SFAS 161.

\subsection{Sample, Variable Measurements, and Research Design}

\subsubsection{Sample Selection}

I focus on U.S. domestic routes with both endpoints in the 48 continental states and my sample period spans 2001-2010. The route level information is collected from The Airline Origin and Destination Survey Databank 1B (DB1B), a random survey of 10\% of all airline passenger tickets for each calendar quarter starting from $1993 .{ }^{25}$ Consistent with prior literature, a market is

\footnotetext{
${ }^{25}$ This database and its preceding form DB1A are the primary source of information on actual prices of tickets sold and are widely used in the economics literature. See Borenstein (1989), Berry (1990, 1992), Borenstein and Rose
} 
defined as a non-directional pair of an origin and a destination airport. I focus on the 2,000 busiest routes each year, and eliminate directional travels with more than two coupons and those with ticketing carriers different from operating carriers. ${ }^{26}$ For each entrant-route-year, there could be more than one incumbent. Given that the entry decision is at the entrant-route-year level, I collapse the entrant-route-year-incumbent level data to entrant-route-year level. For incumbent-related variables, I use the weighted average value of all incumbents for the entrantroute-year as incumbent characteristic proxies. The final sample consists of 2,829 entrant-routeyear level observations after merging with the control variable databases, with 994 unique routes and 142 unique pairs of entrant-incumbent.

\subsubsection{Research Design}

Several empirical studies have modeled entry determinants in the airline industry (e.g., Morrison and Winston 1990; Sinclair 1995; Oliveira 2008). Following this line of literature and controlling for numerous economic factors, I use the following probit regression models to test whether potential entrants' decisions are affected by incumbents' firm-specific cash flow hedge signals, and how the disclosure related to the signal impacts the relation (route subscripts are omitted):

(1994), Boguslaski, Ito, and Lee (2004), Goolsbee and Syverson (2008), Gerardi and Shapiro (2009), Aguirregabiria and Ho (2011), among many others. The database consists of three tables: Coupon, Market, and Ticket. My sample is constructed from the Market table. A coupon is a piece of paper that indicates a passenger's itinerary, and identifies a segment of travel. For example, a round-way flight from Boston to Las Vegas then back to Boston that stops in Chicago in both ways would have four coupons, Boston-to-Chicago, and Chicago-to-Las Vegas. The Coupon table provides coupon-specific information. The Market table contains directional market characteristics for each domestic itinerary, while the Ticket table contain itinerary level characteristics. For the above example, there will be four observations in the Coupon table, two in the Market table (one for each way), and one in the Ticket table. The DB1B database contains a very large amount of data. For example, 2010:Q1 contains approximately 7.9 million coupons, 4.9 million markets, and 2.8 million tickets.

${ }^{26}$ These routes have more than $70 \%$ of all domestic passengers. Each time a passenger changes flights, a new coupon is collected. Eliminating flights with too many coupons gives a clearer sample of incumbents. Travels with ticketing carriers different from operating carriers represent code sharing among airlines. Removing them gives me a cleaner sample of incumbents and potential entrants, who are actually competing instead of forming alliances. 


$$
\begin{aligned}
\operatorname{ENTRY}_{t+1}=a_{0} & +a_{1} * I_{-} \text {AOCIFH } H_{t}+\sum_{i} b_{i} * \text { INCUMBENT CONTROLS } \\
& +\sum_{j} b_{j} * \text { ENTRANT CONTROLS }{ }_{j, t}+\sum_{k} b_{k} * \text { OTHER CONTROLS } S_{k, t}+e
\end{aligned}
$$

$$
\begin{aligned}
\text { ENTRY }_{t+1}=a_{0} & +a_{1} * I_{-} \text {AOCIFH } H_{t}+a_{2} * I_{-} D I S C_{t}+a_{3} * I_{-} \text {AOCIFH }_{t} * I_{-} D I S C_{t} \\
& +\sum_{i} b_{i} * \text { INCUMBENT CONTROLS } S_{i, t}+\sum_{j} b_{j} * \text { ENTRANT CONTROLS }_{j, t} \\
& +\sum_{k} b_{k} * \text { OTHER CONTROLS } \\
k, t & +e
\end{aligned}
$$

Please see Table 1 for detailed variable definitions.

\subsubsection{Measure of Entry Moves (ENTRY)}

I define potential entrants as the airlines that have flights to/from both of the endpoints but are not operating the route per se (Goolsbee and Syverson 2008). Then I track whether and when these potential entrants start providing services for the route. If the entrant starts flying the route, and continues the operation for at least three out of the four following quarters, then I consider that it has entered the market. After entering the route, the entrant becomes one of the incumbents and I remove it from my potential entrant sample for the periods after the entrance. However, the route can still stay in the sample because it may have other potential entrants. If the potential entrant continues not serving the route, then it stays in my entrant sample. The variable ENTRY is an annual indicator variable equal to one if the entrant enters the route in the year following the release of the financial report, and zero otherwise. In this way, I make sure that the entrants have time to observe and analyze information from the financial reports. 


\subsubsection{Measures of Incumbents' AOCI from Fuel Hedge (I_AOCIFH), Disclosure (I_DISC), and Firm Characteristics ${ }^{27}$}

When the firm has cash flow hedges other than fuel hedges, the Accumulated Other Comprehensive Income - Derivatives Unrealized Gain/Loss from COMPUSTAT is the sum for all AOCI from cash flow hedges. In addition, there exist entry errors for this variable. In order to minimize such errors, I manually collect the AOCIFH information from all airlines' 10K filings. As most routes have multiple incumbents, following Goolsbee and Syverson (2008), both AOCIFH and other carrier-specific control variables are averaged across carriers for each entrant-route-year weighted by each incumbent's passenger volume share for the route. I_AOCIFH is the weighted average of all incumbents' accumulated other comprehensive income for fuel hedge. $A O C I F H$ is scaled by total asset before weighting. Incumbents' and entrants' firm characteristics are obtained and calculated using COMPUSTAT data.

I also collect fuel hedge disclosure data from the $10-\mathrm{K}$ filings. Following the prescriptions of SFAS 133, SFAS 161, FRR No. 48, and prior risk management disclosure literature (Linsmeier and Pearson 1997; Perignon and Smith 2010), I identify 13 items as valuable information that assists financial statement users in assessing the firm's risk exposure and performance. I assign a score of one if the item is disclosed and zero if applicable but not disclosed. The overall disclosure score is the average across the scores for the 13 items. I_DISC is the weighted average of fuel hedge disclosure scores for all the incumbents of the route. Please refer to Appendix A for disclosure requirements and the disclosure score construction and Table 1 for variables definitions.

\footnotetext{
${ }^{27}$ I use prefix " $I_{-}$" for incumbent variables and " $E_{-}$” for entrant variables.
} 


\subsubsection{Measures of Control Variables}

Entry decisions clearly depend on the demand for and the supply of air transportation for the local area. Prior studies consider a large set of economic variables as determinants of entry decisions, such as current air transportation supplies of the route from airlines, the distance between the two endpoints, the population and income levels of the endpoint cities, existing competition arising from incumbents, and so on (Oliveira 2008; Boguslaski et al. 2004). Following this line of literature, I identify the Metropolitan Statistical Area for the origin and destination airports, and obtain their demographic information from the Bureau of Economic Analysis, U.S. Department of Commerce. Such information includes the level of population, population changes, per capita income, total income, and other factors that may determine the total demand for air travel.

To measure the supply of air transportation, I obtain the total number of passengers for each route-carrier-month from the T100 schedule, another D.O.T. database. I include the Herfindahl index for each route-year using the market share data of all incumbents. Riley Jr., Pearson, and Trompeter (2003) suggest that for the airline industry, non-financial performance measures are value relevant as well. Thus, I include common non-financial performance measures in the industry as control variables. For example, the loading factor is often used by airline industry financial analysts and is calculated as the number of passengers divided by total seats available for that carrier-route.

\subsubsection{Descriptive Statistics and Correlations}

Appendix A provides descriptive statistics for my self-constructed disclosure scores. It is interesting to note that not all firms fully disclose all items, even for the required ones under 
SFAS 133. For example, SFAS 133 requires entities to disclose the amount of AOCIFH expected to be reclassified into net income in the next year, yet only $44 \%$ of my sample firm-years disclose such information (consistent with such information being perceived as proprietary by firms). Table 2 provides descriptive statistics for the regression variables. Approximately $7.4 \%$ of the final sample observations have $E N T R Y=1$. This number is consistent with Berry's (1992) finding that $6.46 \%$ of the 3,590 potential entrants in his sample which served both cities decided to enter. The raw values of AOCIFH range from -1.278 billion to 1.574 billion. On average, incumbents' AOCIFH amounts $0.33 \%$ of their total assets. Table 3 shows that, consistent with H1, ENTRY has a negative correlation with IAOCIFH. It also shows that ENTRY has strong correlations with market structure variables as prior studies suggest.

\subsection{Empirical Results}

\subsubsection{Main Results}

Table 4 reports probit regression results for $\mathrm{H} 1$ and $\mathrm{H} 2 \mathrm{a}$. The analyses are conducted at the entrant-route-year level with two-way clustering of standard errors by route and year, and the inclusion of year fixed effects. I first test whether the incumbents' lower AOCIFH leads to a higher probability of entrance by potential entrants and expect the coefficient of $I \_A O C I F H$ to be negative. In column (1), I first include only $I \_A O C I F H$ and route structure control variables. The positive and significant coefficient on $M E A N P O P$ is consistent with findings in prior studies and the intuition that routes for which the endpoint cities have higher population are more attractive to entrants. The significantly positive sign on route Herfindahl index $H H I$ is consistent with prior findings that, controlling for the size of the market, more concentrated routes appear more 
attractive to potential entrants. The coefficient of $I_{-} A O C I F H$ is significant and negative as predicted with a z-statistic of -3.93 .

Next I include more incumbent characteristics as control variables in column (2) and I_AOCIFH again loads significantly negative. In the following analyses, I use the full model where both incumbent and entrant characteristics are included together with market structure controls. In column (3), I_AOCIFH has a coefficient of -9.04 with a z-statistic of -3.74 , suggesting that entrants are more likely to enter routes for which incumbents have lower I_AOCIFH for the year. This finding is consistent with H1 that a lower $I \_A O C I F H$ indicates higher future fuel expenses for the incumbents, and that potential entrants are more likely to enter markets in which the incumbents have a lower degree of competitive advantage due to their higher firm-specific production costs. The positive and significant sign on entrants' overall profitability $E_{-} R O A$ suggests that more financially sound airlines are more aggressive in route expanding. Since for all three models the coefficient estimates for I_AOCIFH are highly significant and quantitatively similar, and that the explanatory power increases significantly as I move from column (1) to column (3), I present results that include both incumbent and entrant controls in the following tables.

In column (4) of Table 4, I test whether more transparent and extensive financial statement disclosure regarding fuel hedges helps potential entrants better understand the implications of $I \_A O C I F H$. I include $I \_D I S C D$, the incumbents' disclosure score variable, and the interaction term of $I \_D I S C D$ and $I \_A O C I F H$ in the regression and predict the sign of the interaction term to be negative. ${ }^{28}$ The result is consistent with my hypothesis. The main effect of I_AOCIFH becomes slightly weaker but is still significant at the 5\% level. More importantly, the

\footnotetext{
${ }^{28} I_{-} D I S C D$ is an indicator variable for whether the value of $I_{-} D I S C$ is above or below the sample median. Indicator variables instead of raw values are used for the ease of interpreting the results. The inferences are unaffected when decile ranking or percentile ranking is used instead.
} 
interaction effect is negative and significant at the $1 \%$ level, as expected (coefficient $=-10.376$ with a z-statistic=-2.72). In sum, these results suggest that incumbents' AOCIFH is more informative when incumbents' disclosure regarding fuel hedge is more extensive.

As to the economic significance, in column (3), a one standard deviation increase of I_AOCIFH, holding other variables at the mean values, reduces the probability of entry by $1.4 \%$. This result is economically significant given the base rate that $7.6 \%$ of the potential entrants actually entered. This amount is also comparable to the marginal effects of other economic determinants of entry, such as the distance of the routes and the size of the market.

Interpreting interaction terms in non-linear models is challenging. The interactive effect does not equal the marginal effect of the interaction term and can be of the opposite sign since the interactive effect also varies with the value of control variables. In order to assess the interactive effect, I follow the methodology in Norton, Wang, and Ai (2004). After the correction, the mean effect has a z-statistic of -2.05 and is significant at the $5 \%$ level.

The results in Table 5 indicate that aggregated disclosure scores in years 2008, 2009, and 2010 are significantly higher than that in 2001, while most of the other years' disclosures are not significantly different from that in 2001. SFAS 161 applies to fiscal years beginning on and after Nov. 15, 2008 and encourages early adoption. The results in Table 5 and the original 10-K filings of the airlines suggest an early adoption of the new disclosure regulation. The exogenous shift in disclosure regime introduced by SFAS 161 in March 2008 provides a pseudo natural experiment to further test the effects of disclosure on the information content of cash flow hedge accounting signals. As the deliberation and announcement of SFAS 161 are unlikely to be caused by the competition in the airline industry, the exogenous shock further mitigates potential endogeneity problems of disclosure. 
In order to test how the new disclosure regime governed by SFAS 161 affects the information content of I_AOCIFH to potential entrants, I partition the sample into two subperiods. The pre-SFAS 161 subsample consists of observations with disclosures before the year 2008, and the post-SFAS 161 subsample with disclosures from $2008 .^{29}$ Table 6 reports the regression results for both sub-periods. In the pre-SFAS 161 years (Column 1), the coefficient of I_AOCIFH is -11.770 with a z-statistic of -2.24 , significant at the $5 \%$ level. In the post-SFAS 161 period test (Column 2), the coefficient estimate is -15.302 (significant at the $1 \%$ level), which is consistent with an increased effect post SFAS 161. I formally test whether the coefficient of I_AOCIFH is statistically significantly higher in the post-SFAS 161 period by using a fully interactive model. This test shows a significant difference with (two-sided) p-value $=0.028$, suggesting that SFAS 161 improves the overall information environment for derivatives and hedge activities by mandating more quantitative and qualitative disclosures.

\subsubsection{Additional Analyses}

\subsubsection{Individual Disclosure Items}

Among the several disclosure items used to construct my disclosure score, the disclosure of estimated reclassification of AOCIFH to earnings in the next 12 months is likely of particular interest to financial statement users. It is forward looking and is directly related to the exact amounts eventually reclassified into reported earnings in the future. Despite the mandated disclosure of such information, interestingly only $44 \%$ of my sample firms disclose this information. This observation is consistent with Bhamornsiri and Schroeder's (2004) findings that compliance with the SFAS 133 is mixed. In Table 7, I test how individual disclosure items

\footnotetext{
${ }^{29}$ Partitioning the sample by 2009 - the year SFAS 161 becoming mandatory for most of my sample firms - leaves the inferences unaffected. However, the post-SFAS 161 will have fewer observations and the comparability between the two samples will be reduced. Thus, I choose to partition by the year 2008, which is also suggested by Table 5 .
} 
affect the informativeness of I_AOCIFH. In Column 1, I only include the estimated reclassification disclosure and its interaction with $I \_A O C I F H .{ }^{30}$ In column 2 , I also include the aggregated score for all other items and its interaction term with $I \_A O C I F H$. All the interaction variables have the prefix "INT_." Column 3 includes the individual disclosure scores and their interaction terms with $I \_A O C I F H .^{31}$

The results in Table 7 suggest that certain disclosure items are viewed as especially informative by competitors. The interaction between I_RECLASS and I_AOCIFH (INT_RECLASS) loads significantly negative across all the three specifications, suggesting that the disclosure of estimated reclassification from AOCI into net income in the next 12 months provides incremental information to the potential entrants regarding the incumbents' fuel hedge and costs. In addition, two other disclosures - whether the AOCI for fuel hedge is separated from AOCI for other cash flow hedges if there are other cash flow hedges (INT_TYPE), and the maturity of the fuel hedge instruments (INT_CURRENT)—appear informative to potential entrants.

\subsubsection{Potential Endogeneity of Disclosure}

It is important to address issues related to potential endogeneity of risk management disclosure. Although the regressions include numerous control variables motivated by prior research, in untabulated tests I include the number of segments and the number of sell-side analysts following the firm as additional controls and no inferences are impacted. Moreover, I focus on the interaction term between disclosure and the accounting signal instead of the

\footnotetext{
${ }^{30}$ The I_RECLASS and other disclosure scores in Table 7 are ranked in deciles, with rank $=1$ as the lowest score and 10 as the highest. The results are similar when I use indicator variables instead of deciles ranking.

${ }^{31}$ In order to reduce the model complexity, column 3 includes nine individual scores and the aggregate of the other four. The other four items are those with the least variation with means of 1, 0.98, 0.96, and 0.89 (items 9, 2, 6, and 1 in Appendix A). The inferences are not affected when I expand the model and include all the items.
} 
disclosure per se, because the relation between disclosure and entry decisions is conditional on the nature of the information. As both Rajan and Zingales (1998) and Lang, Lin, and Maffett (2012) emphasize, focusing on interaction terms makes it more difficult to envision a consistent theory in which causality is reversed yet the subsample results hold.

Additionally, the test of $\mathrm{H} 2 \mathrm{~b}$ further mitigates the concern of potential endogeneity problem. The exogenous shock of SFAS 161 improves overall disclosure quality by mandating enhanced disclosure requirements. The passage of this regulation is unlikely to be solely driven by the competition from one industry. The results from Table 6 suggest that $I \_A O C I F H$ becomes more informative after the disclosure regime shift introduced by SFAS 161.

Notwithstanding the above comments, I further employ an instrumental variable approach to control for potential endogeneity issues of disclosure. In the first stage, I use the percentage of international revenue to total revenue as the instrument $\left(I_{-} F R\right) .{ }^{32}$ As an airline provides services to (from) domestic airports from (to) international airports, part of the revenue is realized in foreign currencies and the firm is subject to foreign exchange risk. The use and disclosure of exchange risk hedging instruments are affected by the scale of international services. Research shows that disclosure patterns are correlated across different risk categories. Also, the accounting regulations governing hedging instruments have common requirements for all risk types. Thus, the scale of international services is an important determinant of risk management disclosure. Finally, the instrument is uncorrelated with the residuals in the second stage regression. I obtain the data from D.O.T. T100 tables which provide both domestic and international volume information for all carriers.

\footnotetext{
${ }^{32}$ The revenue measure Revenue-Seat-Miles (RSM) is an industry specific non-financial performance measurement widely used by financial analysts. It is calculated as the sum of the product of number of passengers and the distance of the flight for all flights by the carrier.
} 
Table 8 reports the 2SLS test results. The first stage model has a pseudo $R^{2}$ of $26.67 \%$ and $I$ _FR loads significantly with a z-statistic of 6.06 with a predicted sign (and does not load if included in the main regression). I further conduct weak instrument analyses and the F-statistic for whether the instrument equals zero is 25.83 which exceeds the critical value for weak instrument of 8.96 using the tests suggested by Stock, Wright, and Yogo (2002) and Larcker and Rusticus (2010). Column 2 in Table 8 uses the predicted value of disclosure score and the results are similar to those in Table 4. In sum, these results, along with the analyses described above, suggest that the reported findings are robust to controlling for potential endogeneity of disclosure.

\subsubsection{Product Market Consequences after Entry}

In the next test, I show that market entry is costly to the incumbents. To show this, I compute the incumbents' ticket price features (coach-class only) before and after entry for routes with at least one potential entrant entering (i.e., entered routes). Then I compare the before-after differences for entered routes with routes matched on years. This difference-in-differences approach measures the relative impact of entrance on incumbents, controlling for economic factors. Table 9 reports how the mean, median, and standard deviation of ticket fares change. They all reduce by a greater and significant amount after the entrance for the entered routes than for the matched routes, suggesting entrances intensify the competition and reduce incumbents' revenues.

\subsubsection{Other Analyses}

Following prior literature, the probit regressions in this paper are conducted on the entrant-route-year level sample because route-level entry decisions are directly observable. This 
approach is consistent with the notion that firm-level competition is reflected in route-level decisions. In order words, route level decisions should be consistent with firm-level competitive advantages and disadvantages. To verify this, I conduct firm-level analyses based on the same sample. Specifically, I collapse the entry decisions to firm level and examine how such decisions respond to firm-level information. This alternative sample consists of 665 observations. Each year, for each entrant-incumbent pair, I calculate the percentage of routes entered by the entrant in the following year among all the routes for this entrant-incumbent pair. Three percentage variables are calculated based on a) the number of route, b) the revenue-seat-miles of routes, and c) the revenue-seat-miles served by the incumbent. Table 10 presents the results from regressing these percentage variables on incumbents' and entrants' AOCIFH and control variables. I find that consistent with my route-level results potential entrants are more likely to launch entries towards incumbents with lower AOCIFH. We also observe a positive and significant sign for $E \_A O C I F H$, suggesting that airlines benefiting more from fuel hedging are more likely to launch entries. However, given the low adjusted R-squares of the regressions, that the dependent variables are aggregated from multiple routes they compete on, and that the model does not include market-level economic determinants of entry), we should interpret the results with caution.

In addition to the derivatives designated as cash flow hedges, some airlines also have fuel hedges that are not designated as cash flow hedges and the change in the fair values is recognized in net income in the current period. This part of income, especially the unrealized part, can potentially provide information regarding future fuel expenses. I add the total value of net income from non-designated fuel hedges and the unrealized part of net income from nondesignated fuel hedges back to the I_AOCIFH respectively, and use the new measures as my 
accounting signals. Table 11 shows the results using the alternative measure of AOCIFH by adding net income from non-designated fuel hedges to $I \_A O C I F H\left(I \_A O C I F H \_A S I F\right)$. Again, no conclusions are altered. Changing the scalar for AOCIFH from total assets to sales leaves my inferences unaffected.

I partition my sample into route-years with positive/non-positive $I \_A O C I F H$ subsamples and rerun the tests. A positive value of $I \_A O C I F H$ indicates that fuel hedge activities reduce fuel expenses, and a negative value suggests that fuel hedge programs increase future expenses compared to not hedging. ${ }^{33}$ Although both are informative regarding incumbents' future fuel expenses, they may have different implications. Table 12 provides the results from such partitions. My results in Columns 1 and 2 show that $I \_A O C I F H$ is significant in both subsamples, suggesting that my results are not driven only by a certain type of $I \_A O C I F H$. In Columns 3 and 4 I partition my sample into two subsamples based on the direction of oil price change during that year and the inferences are not impacted. This suggests that my results are not driven by years when the oil prices spiked.

Airport presences are used to proxy for the degree of entry threats and following prior literature my sample of potential entrants include only those present at both airports. I expand the sample by also including carriers present at one of the airports as potential entrants and rerun the entrant-route-year level tests. The new sample contains 4,021 observations from 1,332 unique routes. The percentage of entry is lower when potential entrants are defined less restrictively here, with the actual number of entry only increases slightly. Table 13 shows the results using the expanded sample. We can observe that the inferences are unchanged: I_AOCIFH has a z-statistic

\footnotetext{
${ }^{33}$ This could happen when jet fuel spot prices drop and the firm hedges on that. In this case, the hedging firm does not fully enjoy the benefit of dropping fuel prices due to existing hedging programs.
} 
of -3.25 compared to -3.74 in Table 4 Column 3 for H1, and a z-statistic of -2.96 compared to 2.72 in Table 4 Column 4 for H1b.

\subsection{Concluding Remarks}

This study investigates how potential entrants' strategic product market decisions are affected by incumbents' risk management information in the U.S. airline setting. My findings suggest that potential entrants make use of incumbents' firm-specific accounting signals resulting from risk management activities. Further, more extensive disclosure of such risk management activities enhances the informativeness of related signals, indicating the importance of such disclosure.

Showing that accounting information and disclosure are "competition-relevant" is a necessary condition for proprietary costs being an important determinant of disclosure. A review of analytical studies on the relation between disclosure and competition suggests that the relation depends on both the nature of the competition and the nature of the information. This paper contributes to the literature by identifying a unique setting in which both the nature of the information and the nature of the competition are clearly identified. In this airline industry setting, I examine potential entrants' strategic response to incumbents' firm-specific information. I find that entrants are more likely to enter markets for which the incumbents have firm-specific unfavorable performance. Furthermore, the relation is stronger when the accounting signals conveying such information are accompanied with more transparent supplementary disclosures. My findings support the hypothesis that costly consequences of disclosure exist, thus providing greater confidence to the proprietary cost of disclosure theory. The article also suggests that 
further research on determinants of disclosure should consider the nature of competition and the nature of information and choose proxies accordingly.

Additionally, this paper suggests that cash flow hedge accounting and disclosure under SFAS 133 are informative and important to competitors. It extends the debate on SFAS 133 by providing another channel to evaluate the information content and economic consequences of accounting standards. Peer firms and competitors are sophisticated players in the market and usually have solid understanding of the business practices within the industry. Their use of such information in making product market decisions suggests that SFAS 133 and cash flow hedge accounting provide important information that facilitates decision making.

In response to the complaint that hedge accounting treatments under SFAS 133 are too complicated and related financial statement disclosures are not adequate, the FASB issued SFAS 161, intending to improve the disclosure quality of hedge instruments and facilitate users' digesting hedge accounting information. This study is one of the first to empirically investigate the effectiveness of SFAS 161. My results suggest that SFAS 161 effectively shifts the disclosure regime and increases the overall usefulness of accumulated other comprehensive from cash flow hedges significantly from the pre-SFAS 161 period. These findings echo the claim that more transparent disclosures are necessary for accounting information to be effectively and efficiently used. 
CHAPTER 2: THE ECONOMIC IMPACT OF SFAS 161: EVIDENCE FROM MARKET

REACTIONS TO EVENTS SURROUNDING THE PASSAGE OF THE STATEMENT IN

THE U.S. AIRLINE INDUSTRY

\subsection{Introduction}

This paper investigates the economic consequences of Statement No. 161 Disclosures about Derivative Instruments and Hedging Activities, an Amendment of FASB Statement No. 133 (SFAS 161) by examining market reactions to events during the deliberation process. The primary objectives of this accounting regulation are to enhance the degree of transparency and to promote users' understanding of how and why an entity uses derivative instruments, how derivatives are accounted for, and to what degree they affect an entity's financial positions. To achieve these objectives, SFAS 161 requires additional qualitative and quantitative disclosures about an entity's risk exposures, about how derivative instruments and related hedged items are accounted for, and about how derivative instruments affect an entity's financial position, results of operations, and cash flows. The new disclosure requirements under SFAS apply to derivative instruments and hedged items defined under Statement No. 133 Accounting for Derivative Instruments and Hedging Activities (SFAS 133) and its related interpretations. ${ }^{34}$

Since the adoption of SFAS 133 in 2001, various constituents have expressed criticism and concern that Statement 133 does not prescribe transparent disclosures that allow users of financial statements to assess the overall risk of derivatives from both a qualitative and a quantitative perspective. As a result, the Financial Accounting Standards Board (FASB) decided

\footnotetext{
${ }^{34}$ Under the FASB Accounting Standards Codification, SFAS 133 corresponds to ASC 815 and SFAS 161 corresponds to ASC 815-10-50.
} 
to add a project to its technical agenda on March 9, 2008 to reconsider the disclosure requirements under SFAS 133. Issues discussed include the scope of disclosure (all financial instruments or only those hedging-related), presentation of financial statement implications, credit risk exposures, tabulation requirements, etc. The board received 63 comment letters from both users and preparers of financial statements after releasing the Exposure Draft, holding different views toward the new disclosure requirements. After considering such opinions, on March 19, 2008, the FASB issued SFAS 161, effective for fiscal years and interim periods beginning after November 15, 2008, with early application encouraged.

In this paper, I focus on two issues related to the controversy over the adoption of SFAS 161. First, I examine the market reactions to events leading up to the adoption of SFAS 161. SFAS 161 did not prescribe any new accounting measurement and recognition treatments; however, it required more disclosure on hedging-related activities. As a result, the standard did not directly change the cash flow of the firm, nor did it change reported accounting numbers. In other words, the introduction of SFAS 161 provides a clear setting to examine the economic implications of enhanced disclosure without the confounding effects from changes in accounting treatments.

There are reasons to expect either positive or negative, or no market reactions, to events leading up to the adoption of SFAS 161 based on different alternative mechanisms how it affects firms. On one hand, and consistent with FASB's initial intent, investors appreciate more information regarding the extremely complicated use of hedging derivatives, which suggests the market should react positively (the transparency argument). On the other hand, my review of the comment letters to the Exposure Draft suggests major concerns related to increased preparation costs, the idea that new disclosures could potentially mislead users, and proprietary (or 
competitive) costs. More importantly, one particular line of literature suggests that hedge accounting and disclosure may change and in some cases distort firms' behavior and result in suboptimal decisions (e.g., Sapra 2002; Gigler et al. 2007; Zhang 2009) (the real effect argument). Thus, it is an empirical question whether and to what extent the market reacts to events related to the deliberation process of SFAS 161. The market reaction tests suggest that the overall effect is positive: mean returns around the event dates are positive and significant, and the positive and significant returns are around four board meetings after the release of the Exposure Draft, and the last two events clarifying important details shortly before the effective date.

Second, I examine whether market reactions vary systematically in the cross-section with firm characteristics. The mean market reactions likely reflect the net effects from the (perceived) benefits and (perceived) costs from the regulation, and cross-sectional analyses allow me to separate the potentially countervailing effects of improved disclosure versus value-destroying behavior. I focus on two firm characteristics that generate different predictions under the transparency theory and the real effect theory: (1) the pre-adoption risk management disclosure level (based on a disclosure score from hand-collected risk-management disclosures), and (2) the pre-adoption hedging scope. Despite the overall positive market returns that are consistent with the transparency story, the cross-sectional analyses provide evidence that is also consistent with the real effect theory. Specifically, firms with lower pre-adoption risk management disclosure level and higher hedging scope experience more negative (or less positive) returns around the event dates.

In this paper, I focus on the U.S. airline industry for several reasons. First, because firms from different industries manage different underlying risks, the overall impact from enhanced 
disclosure can be hard to interpret. In addition, most of the firms in the U.S. airline industry are publicly traded so the inferences from examining the market reaction for these public firms are representative for the whole industry. Finally, the cross-sectional analyses require firm characteristics that are hand-collected from the 10-K filings. Given the high cost of handcollecting, I restrict my sample to the U.S. airline industry for which fuel hedging is very common and extremely important. Thus, a caveat is that the results and inferences from this paper are not necessarily generalizable to other industries. ${ }^{35}$

This is one of the first papers to examine the economic implications of SFAS 161. Prior studies on hedge accounting mainly focused on SFAS 133. The new hedge accounting treatments under SFAS 133 provided the users with information previously not easily available and the market reacted to such new information, albeit not completely (Campbell 2013; Ahmed et al 2011; Makar et al. 2013). The primary reason for the incomplete reaction is the complex nature of hedging instruments and limited disclosure about the use of such instruments that impede full understanding and assessment of hedging activities. By studying market reactions to key SFAS 161 events, this study speaks directly to the discussion on the importance of more disclosure regarding hedging activities. The FASB and the International Accounting Standards Board have been on addressing various issues related to SFAS 133 and this paper can provide policy implications to standard setters.

In addition, this paper sheds light on the theory and empirical work on real effects of accounting and disclosure. Although theoretical studies on real effects of accounting are growing, empirically testing such theories is more challenging. This paper provides some initial evidence

\footnotetext{
${ }^{35}$ Table 19 presents the results using the whole CRSP sample. The results are similar but weaker. Please see the discussion in Section 2.5.3.
} 
supporting the idea that investors anticipate that more hedge disclosure may distort firm behavior and result in suboptimal decisions.

Section 2.2 provides a discussion of the evolvement of SFAS 133 and SFAS 161, and reviews key research on these standards. Hypotheses are developed in Section 2.3. I discuss my research design and data source in Section 2.4, and present empirical results in Section 2.5. Section 2.6 concludes the paper.

\subsection{Background}

\subsubsection{Hedge accounting, disclosure, and prior literature}

SFAS 133 was issued in 1998 and effective for fiscal years beginning after June 15, 2000. It established standards of financial reporting and accounting for derivative instruments and hedging activities and its disclosure requirements superseded FASB Statements No. 105 and No. 119. While certain disclosures from SFAS 105 and SFAS 119 were incorporated into SFAS 133, many of them were not carried forward in order to smooth and ease the implementation of SFAS 133. Since its issuance, the disclosure requirements in SFAS 133 have been criticized for not providing adequate information about derivative instruments and hedging activities. As a result, in March 2005, the FASB agreed to add a project to its agenda to reconsider the disclosure requirements of SFAS 133.

The Board intended to provide an enhanced understanding of: 1) How and why an entity uses derivative instruments; 2) How derivative instruments and related hedged items are 
accounted for under SFAS 133 and its related interpretations; and 3) How derivative instruments affect an entity's financial position, results of operations, and cash flows.

Many of the respondents considered the proposed disclosure requirements to go beyond what is necessary to meet the three objectives of the project. The staff identified seven significant concerns raised by respondents that were later discussed or addressed in board meetings. Please see Section 2.2.2, Appendix E and Appendix G for details.

The purpose of enhanced disclosure is to improve the informational environment of derivative use in hedging activities. As a result, the market should respond positively to events that increase the likelihood of greater disclosure requirements. There has been a large literature on how more transparent disclosure increases firm value (see Healy and Palepu 2001; Beyer, Cohen, Lys, and Walther 2010 for more details). Specific to hedge accounting and disclosure, Melumad, Weyns, and Ziv (1999) show that under a certain definition of fair-value hedge accounting, the manager's hedging decision preserves the optimal economic hedge while under no-hedge accounting, the manager may deviate from the firm's optimal economic hedging decision. Kanodia, Mukherji, Sapra, and Venugopalan (2000) identify social benefits to hedge accounting disclosure through more informative future market prices. Zhang (2009) empirically tests whether SFAS 133 influenced corporate risk management behavior and finds that after the adoption, risk exposure and cash flow volatility decreased for firms that were previously ineffective hedgers. Ahmed, Kilic, and Lobo (2011) compare the risk relevance of accounting measures of bank derivative exposure to bond markets prior to and post SFAS 133 and find that SFAS 133 has increased the risk relevance of accounting measures of derivatives exposures to bond investors and benefited banks in terms of reducing their cost of capital. Panaretou, Shackleton, and Taylor (2013) investigate the information asymmetry measured by analysts' 
ability to forecast earnings under the IFRS accounting for derivatives setting and find that the positive effect from increased transparency of derivative disclosure dominates the negative effects due to increased earnings volatility and/or deviation of hedging policy for U.K. firms. Makar, Wang, and Alam (2013) focus on the mixed attributes of SFAS 133 cash flow hedge modeled by Gigler, Kanodia, and Venugopalan (2007) and show empirically that cash flow hedge adjustments reported in other comprehensive income are mispriced in the predicted way. Their results suggest that SFAS 133 mixed attribute model does not provide the information necessary for investors to understand the net economic effects of cash flow hedges and call for more disclosure to facilitate the information process.

However, there has been a growing line of research on the potential costs of increased hedge disclosure. DeMarzo and Duffie (1995) view profits as a signal about management talent and show that hedge position disclosure may lead to suboptimal hedging on the part of the manager. Sapra (2002) investigates the consequences of hedge disclosures on a firm's risk management strategy and shows that greater transparency about a firm's derivative activities is not necessarily a panacea for imprudent risk management strategies. Hughes, Kao, and Williams (2002) develop a model that takes into account proprietary cost of hedging disclosure and they show that on balance, no disclosure is preferred. Chen, Tan, and Wang (2012) conduct two experiments with experienced accountings to investigate how fair value accounting affects managers' real economic decisions. They find that participants are more likely to make suboptimal decisions when both the economic and fair value accounting impact information is presented than only economic impact information is presented or when both the economic and historical cost accounting impact information is presented. 
To summarize, the transparency argument and the real effects theory represent the benefit side and the cost side of enhanced disclosure. As lines of arguments are not mutually exclusive, the net effect is an empirical question. In order to shed more light on the implications of enhanced hedge disclosure, I examine market reactions to events leading up to the adoption of SFAS 161. The overall (direct and indirect) impact should be reflected in the stock prices and market reaction to such events should inform us about the net benefits/costs. In addition, because the benefit from more transparency story and the hedging behavior distortion story generate different predictions in terms of how the market reactions vary with certain determinants, the cross-sectional analyses can potentially distinguish between the two forces. Another advantage of this setting is that unlike SFAS 133, SFAS 161 does not directly change reported accounting numbers. My study thus complements prior studies on the economic consequences of SFAS 133.

\subsubsection{History of events}

Even though enhanced disclosure of derivative instruments in hedging activities is not likely to directly affect the reported accounting numbers, the history of events and the evolvement of the regulation suggest that participants in the process believed that increased disclosure will induce economic consequences. The initiation of the project is the result of increasing critiques that disclosure under SFAS 133was not adequate. As a result, on March 9, 2005, the FASB added the project to their agenda to consider requiring more disclosure for hedging activities and use of derivatives. Four board meetings were held to discuss the scope, objectives, tabular disclosure contents, and effective date in July 2005, July 2006, September 2006, and October 2006, respectively. The Exposure Draft was released on December 8, 2006 and responses from interested parties wishing to comment on the Exposure Draft had to be received by March 2, 2007. In the Exposure Draft, the board set up the three objectives of the 
new regulation and determined that the new regulation applies to all derivative instruments and related hedged items accounted for under SFAS 133 and its related interpretations. The Exposure Draft also asked for the disclosure of notional amounts and fair values of derivative instruments in tables by primary underlying risk, accounting designation, and purpose, as well as disclosure of gains and losses on hedged items that are in a designated and qualifying hedging relationship under SFAS 133. In addition, it provided an illustration of the application of the proposed statement, and set the statement to be effective for fiscal years and interim periods ending after December 15, 2007.

The board received 63 comment letters in the short time period, and the major concerns raised were that 1) the disclosure of notional amount would be misleading and unnecessary, and imposes operational difficulties; 2) tabular disclosure of notional amount and fair value by underlying risk, accounting designation, and purpose is unrealistic and operationally impossible; 3) annual and interim disclosure is unnecessary; and 4) the effective date is too soon. The FASB subsequently held four more board meetings to discuss such issues and released the official statement on March 19, 2008.

Appendix E provides the detail of the events leading up to the adoption of SFAS 161. To summarize, the 13 events I investigate include the announcement of adding the project to the agenda, four board meetings following that, the announcement of the Exposure Draft, another four board meetings redeliberating the issues raised by respondents, the announcement of the official regulation, and two clarifications after the announcement and before the official effective date. The media coverage is mostly concentrated on the release of the Exposure Draft, the announcement of official regulation, and the two subsequent clarifications rather than on board 
meetings. ${ }^{36}$ Nevertheless, because all the board meeting schedules are available prior to the meetings and meeting decisions are usually immediately publicly available from the FASB website, I include the meetings in my event list. ${ }^{37}$

\subsection{Hypotheses Development}

\subsubsection{Overall market reactions}

I use the stock price reactions to events leading up to SFAS 161 to examine the importance of enhanced disclosure about derivatives and hedging activities. I restrict my sample to U.S. airlines. Airlines are heavy users of hedging programs and as such are expected to be significantly affected by enhanced disclosure requirements. Focusing on one industry consisting mainly of public companies further allows me to hand-collect data for my cross-sectional analyses.

The potential positive impact of enhanced disclosure is obvious. That is, the use of financial derivatives in hedging activities is becoming more prevalent. ${ }^{38}$ The nature of such transactions is complex; however, the disclosure is highly aggregated and lacks transparency. Thus more transparent disclosure of derivatives and hedge activities reduces information asymmetry between the firm and equity holders and enhances firm value. In addition, improved information environment facilitates the monitoring of management and indirectly disciplines

\footnotetext{
${ }^{36}$ The thirteen events are identified by searching the FASB website, announcements made in the Wall Street Journal, Dow Jones News Wire, PR Newswire, and other web sources. I also read through the FASB board meetings handouts, decisions summary, and minutes to identify the nature of events.

${ }^{37}$ FASB website allows subscription to board meetings and sends out action alerts for upcoming events. Thus, it is reasonable to assume that firms follow FASB schedule for events they are interested in. NOTE CHANGES

${ }^{38}$ Bartram, Brown, and Fehle (2009) examine foreign exchange, interest rate, and commodity price derivatives held by 7,319 non-financial companies in 50 countries, including the Unites States, for the years 2000 and 2001. They find that for the entire sample, $60.3 \%$ use some type of derivatives, and this number is $64.9 \%$ for U.S.
} 
firms' hedging and production decisions (Melumad et al. 1999; Zhang 2009; Ahmed et al. 2011; Panaretou et al. 2013).

However, there is also reason to expect that firms incur certain costs from enhanced disclosure through several channels. Most importantly, more disclosure could distort firms' hedging and production behavior and result in suboptimal decisions. My first hypothesis is as follows (stated in the null).

H1: The overall stock market returns around the events leading to the adoption of SFAS 161 are zero.

\subsubsection{Cross-sectional determinants of market reactions}

I further explore the underlying mechanisms through which enhanced disclosure affects market reactions. I focus on two (hand-collected) firm characteristics that could affect the market reaction to enhanced disclosure. The first characteristic is the risk management disclosure level prior to the adoption of SFAS 161. Under the transparency theory, firms experiencing a greater improvement of their information environment should display more positive market reactions. In other words, if a firm had poor risk management disclosure prior to the adoption, the shareholders appreciate the enhanced disclosure more compared with a firm that had similar disclosure prior to and after the adoption of the standard. Thus we should observe a negative relation between the pre-adoption disclosure level and market reaction to events.

In contrast, under the real effect theory, firms that have to provide more disclosure after the adoption are subject to more severe distortion, and bear higher costs from suboptimal 
decisions compared with firms that were closer to the post-adoption disclosure requirements. In this circumstance, I expect a positive relation between the pre-adoption risk management disclosure level and market reactions to related events. The first part of Hypothesis 2 is stated as follows (in the null).

H2a: The stock market returns around the events leading up to the adoption of SFAS 161 is not related to the pre-adoption risk management disclosure level.

The second determinant I consider is the scope of hedging. Airlines usually disclose the percentage of next year's expected consumption of fuel being hedged. ${ }^{39}$ Under the transparency story, if a firm is a heavy user of hedge instruments, its investors should appreciate enhanced disclosure of such derivatives more than investors of a firm that hedges very little of its expected consumption. Thus I expect a positive relation between the percentage of hedged future transactions and market reactions around the key events.

The real effect theory, however, generates a different prediction on the relation between the scope of hedging and market reactions. When enhanced disclosure distorts hedging behaviors, firms that have a broader scope are more vulnerable because hedging is a more vital part of their operations, thus are subject to more potential loss from suboptimal decisions. The second part of Hypothesis 2 is as follows (in the null):

H2b: The overall stock market returns around the events leading up to the adoption of SFAS 161 is not related to the pre-adoption hedging scope.

\footnotetext{
${ }^{39}$ Specifically, airlines disclose the portion of expected fuel consumption that is being hedged. For example, in its 2007 10-K filing, Southwest Airlines disclosed that it had hedging programs in place to protect against over $70 \%$ of its 2008 total anticipated jet fuel requirements, over $55 \%$ of its 2009 requirements, nearly $30 \%$ of 2010 requirements, over $15 \%$ of 2011 requirements, and over $15 \%$ for 2012.
} 


\subsection{Research Design and Data}

\subsubsection{Research design}

I estimate the average stock price reactions of my sample firms (as a portfolio) around the key events leading up to SFAS 161. Because my sample firms are subject to the same events and are in the same industry, a portfolio approach is advantageous to firm-specific time serious approach as the portfolio approach account for the residual correlation across firms (Sefcik and Thompson 1986). I use the following model:

$$
r_{t}=\alpha+\beta r_{M, \mathrm{t}}+\sum_{s=1}^{S} \gamma_{s} d_{s, t}+\varepsilon_{t}
$$

where $r_{t}$ is the daily value-weighted portfolio return of my sample firms, $r_{M, t}$ is the daily return on the CRSP value-weighted market index, and $d_{s, t}$ is an indicator variable that takes the value of one on the three days centered on an event $s(=1, \ldots, \mathrm{S})$, and zero otherwise. The coefficient $\gamma_{s}$ is the estimated stock return reaction of the portfolio to the event.

\subsubsection{Stock price reactions}

The indicators from Equation (1) are identified as follows. First, in order to estimate the overall effect of the market reaction, one indicator is assigned the value of one for all the dates around the 13 key events, and zero otherwise. The estimated coefficient thus measures the average return in response to the statement proposing and requiring additional disclosure. Second, among the 13 events, there are four board meetings before the release of the Exposure Draft and another four after receiving the comment letters. These meetings are similar in nature so I denote the four meetings before the Exposure Draft with one single indicator variable, and all the four 
meetings after the Exposure draft with another indicator variable. In this way, seven indicators are constructed for the 3-day windows around the events: D1 for Event 1 (adding the project to the FASB agenda), D2 for Events 2 through 5 (four board meetings), D3 for Event 6 (release of the Exposure Draft), D4 for Events 7-10 (four board meetings after the Exposure Draft), D5 for Event 11 (Announcement of SFAS 161), D6 for Event 12 (credit derivative disclosure requirements), and $D 7$ for Event 13 ( clarification of the effective date). Please see Appendix E for further description of the events.

\subsubsection{Cross-sectional analyses}

To further investigate the specific channels through which enhanced disclosure affects investors, I examine cross-sectional determinants of event period reactions. A common two-step approach involves the regression of event period residual returns on proxies for the different determinants of the cross-sectional variation. In the first stage, market-model parameters are estimated in the periods outside the event period using firm-specific time series regressions. In the second stage, event period residual returns generated from the first stage are regressed on the vector of cross-sectional determinants. However, because the time-series regressions in the first stage are estimated over the same time period using the same event dates for all sample firms from the same industry, the residuals in the second-stage cross-sectional regression model will be cross-correlated. To obtain correct inferences, I use the portfolio time-series regression approach suggested by Sefcik and Thompson (1986) to account for cross-correlation and heteroskedasticity. To illustrate how it works, for each of the cross-sectional determinants, I construct a weighting scheme vector to form a portfolio consisting of the sample firms. Then I regress the portfolio return on market return and event indicator variables, and the coefficients of the event indicators measure the mean returns around event dates, and the standard errors are 
unbiased. To form these portfolios define a $t \times j$ matrix of returns for $t$ periods and $j$ firms, $R$. Define a second $j \times k$ matrix $F$, where $\mathrm{k}$ is the number of cross-sectional determinants plus the intercept. The first column of $F$ is a column of ones to capture the intercept and the remaining columns are firm-specific characteristics. A $k \times t$ matrix of portfolio returns is formed from $F$ and the matrix of firm returns $R$ as $\left(F^{\prime} F\right)^{-1} F^{\prime} R^{\prime}$.

The firm characteristics I consider as cross-sectional determinants include the preadoption risk management disclosure level (DISC) and the percentage of hedged future consumption of fuel (SCOPE). Besides these two variables of interest, I also select control variables suggested by prior research that could explain the variation in stock market responses around the key event dates. Prior studies suggest that a firm's financial strength can affect its ability to hedge (Froot, Scharfstein, and Stein 1993; Haushalter 2000; Geczy, Minton, and Schrand 1997). In the airline industry, low cost carriers usually gain financial advantages by operating a few types of aircrafts. Thus, the control variables include the pre-adoption level of accumulated other comprehensive income fuel hedge to capture the financial statement impact to firms from fuel hedging $(A O C I F H)$, whether the firm is a low cost carrier (LOWCOST), and the firm's performance (ROA). Following prior studies (Beatty, Chamberlain, and Magliolo 1996; Dou, Wong, and Xin 2013), all firm characteristics are the average values for 2005-2008 the preadoption event period.

\subsubsection{Data and descriptive statistics}

As mentioned I focus on U.S. public traded airlines. Daily firm and market returns are extracted from CRSP. Following the prescriptions of SFAS 133, FRR No. 48, and prior risk management disclosure literature (Linsmeier and Pearson 1997; Perignon and Smith 2010), I 
identify thirteen items as valuable information that helps assess the firm's risk exposure and performance. I assign a score of one if the item is disclosed and zero otherwise (see Appendix F for the disclosure score construction details). The disclosure score (DISC) is the average value of indicators for the 13 items. I also hand-collect the percentage of future consumption of fuel being hedged (SCOPE). The accumulated other comprehensive income from fuel hedge is manually collected from $10-\mathrm{K}$ filings, then deflated by total assets, and denoted as AOCIFH. Low-cost carriers (LOWCOST) include Airtran Holdings, Allegiant, Jetblue Airways, Southwest Airlines, and Frontier Airlines. All continuous variables are winsorized at 1\% and 99\%.

The thirteen events are identified by searching the FASB website, announcements made in the Wall Street Journal, Dow Jones News Wire, PR Newswire, and other web sources. Appendix E summarizes these key events.

Table 15 provides the descriptive statistics of cross-sectional determinants. Because the key events span 2005-2008, for each firm, I calculate the average characteristics over the four years as the cross-sectional determinants. In addition to the four determinants in the crosssectional analyses, I also provide descriptive characteristics for the un-deflated accumulated other comprehensive inform from fuel hedge $\left(A O C I_{-} R A W\right)$. The dollar amount of $A O C I{ }_{-} R A W$ has an average of -37.117 million, with the $5^{\text {th }}$ percentile of -631.000 million and $95^{\text {th }}$ percentile 437.500 million, suggesting that the economic impact from fuel hedging is significant, especially given the thin profit margin for the airline industry. On average, my sample firms hedge $25.1 \%$ of their expected fuel consumption in the next year. Panel B presents the correlations. 


\subsection{Empirical Results}

\subsubsection{Mean stock price reactions}

Table 16 presents the estimation of Equation (1) over the period from January 1, 2005 to December 31, 2008. Using the portfolio approach outlined above, the estimation does not suffer the cross-correlation problem. I only report the coefficients and t-statistics for the event indicator variables. ${ }^{40}$ When all events are captured by one single indicator variable, the coefficient measures the average market daily return for such events. This is reported as the mean market reaction to all the events in Table 16 . The portfolio average return around the event dates is $1.3 \%$, and statistically significant (at the 5\% level using a two-tailed test), suggesting that on average, the market appreciates the proposed enhanced risk management disclosures. In other words, the market perceived that the FASB achieved its initial objective of improving the information environment of derivative use in risk management.

Table 16 also reports the results from the alternative model in which seven indicator variables (D1-D7) are used to capture the 13 events. We observe that three out of the seven indicator variables are significant: $D 4, D 6$, and $D 7 . D 4$ denotes the four board meetings held after receiving the comment letters to redeliberate issues raised by respondents (May, July, September, and December 2007, respectively). Closer examination of the decisions made at those four board meetings reveals that the FASB relaxed the disclosure requirements after taking into account the issues raised by respondents (mainly financial report preparers). For example, the disclosure requirement of notional amount in tables from the Exposure Draft was removed in the discussion of the four board meetings. Also, the Exposure Draft initially asked for qualitative

\footnotetext{
${ }^{40}$ Estimated intercepts are economically zero, and the estimated market beta is close to one, suggesting that the regression captures the data-generating process reasonably well.
} 
discussion of derivative use and quantitative disclosure of fair values, gains and losses by primary underlying risk, accounting designation, and purpose. After considering the opinions from the comment letters in these four meetings, the board decided that such disaggregation requirements were too great a burden and replaced them with less stringent requirements. ${ }^{41}$ The negative and significant coefficient of $D 4$ is consistent with investors reacting negatively to the decisions from the board meetings of relaxing disclosure requirements, consistent with the

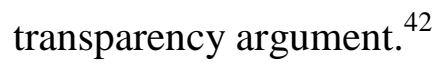

D6 represents the date the FASB decided to require credit derivative disclosures and additional disclosure about the current status of the guarantee/collateral. Investors are concerned about firms' credit risk from their hedging activities and the positive and significant sign on D6 suggests that requiring additional disclosure is considered helpful by the market. ${ }^{43} D 7$ is when the FASB issued clarification that SFAS 161 applies to both the fiscal year and interim periods beginning after November 15, 2008, which means that for firms with December 31 fiscal yearend, SFAS 161 is effective for the 10-Q for the first quarter of 2009. Before the clarification, the users and preparers were confused about from which reporting period they should comply with SFAS 161 and there was a misunderstanding that SFAS 161 was effective for the fiscal year beginning after November 15, 2008. Clarifying that the regulation applies to both fiscal year and interim periods means that SFAS 161 is effective sooner than people originally thought it would

\footnotetext{
${ }^{41}$ Specifically, the disclosure requirements for fair value and gains/losses related to derivatives were relaxed so that the amounts should only be presented separately for derivatives designated and not designated as hedging instruments, instead of further by primary underlying risk, accounting designation, and purpose.

${ }^{42}$ Wong (1999) shows that risk exposure is associated with disaggregated disclosures about notional amount and fair value of foreign exchange derivatives, suggesting that users of financial statements use this information to perform a complete exposure assessment.

${ }^{43}$ For the airline industry, profit margins are extremely low, and defaults by counterparties could trigger financial distress easily.
} 
be for most firms. The positive and significant sign for $D 7$ indicates that the market welcomed the more immediate compliance.

In contrast, we do not observe significant coefficients for $D 1-D 3$ and $D 5$, suggesting that these events are not associated with significant changes in investors' expectations of the impact of the regulations. The insignificant response around the release of SFAS 161 in March 2008 could be attributed to the four board meetings in 2007 that provide pre-emptive information regarding the disclosure requirements. ${ }^{44}$

In summary, the market reaction tests indicate a net positive market reaction to enhanced disclosure requirements. In the next section, I examine whether the market reactions vary systematically with cross-sectional determinants.

\subsubsection{Results of cross-sectional analyses}

Table 17 reports the estimations of the portfolio time-series regressions over the same period when all events are denoted by one indicator variable. In column (1), only the two variables of interest are used in the cross-sectional analysis. The positive and significant coefficient on DISC suggests that firms with higher pre-adoption risk management disclosure experienced higher market returns. In other words, firms that had poorer pre-adoption disclosure and thus will have to enhance their disclosure to a greater extent due to SFAS 161 are affected negatively, consistent with the real effect argument (H2a). In addition, airlines having more of their expected fuel consumption hedged (SCOPE) experience less positive (more negative) stock

\footnotetext{
${ }^{44}$ The significance of market returns depends on how much of the information is unexpected, and the magnitude of the wealth impact from the event. Thus it is not surprising to find that some events don't have significant market responses. For example, among the 21 events leading up to SFAS 115 identified in Beatty et al. (1996), three events have significant market reactions around them. Similarly, depending on the specification only 3-4 out of the 17 events leading up to SOX from Zhang (2007) and 1-3 events out of the 9 leading up to SFAS 123R in Dou et al. (2013) have significant returns around them. What they do find is that (1) the mean returns for all events are significant, and (2) the returns around the most significant and unexpected events are significant.
} 
returns around the event dates, consistent with the real effect theory that enhanced disclosure firms using hedging more heavily could suffer from consequences of enhanced disclosure (H2b).

In Columns (2)-(4) of Table 17, I include additional control variables (one control variable one at a time due to their high correlations) to capture the possibility that the market reactions to enhanced risk management disclosure may vary with a firm's ability to hedge. The coefficient of DISC remains positive and significant for two of the three specifications, and SCOPE is negative and significant in all the three specifications. We also observe that the three control variables (ROA, AOCIFH, and LOWCOST) all have negative coefficients, suggesting that shareholders of more profitable airlines, airlines with better hedging outcomes, and low-cost carriers respond negatively to enhanced disclosure requirements.

Table 18 reports cross-sectional test results where the 13 events are captured by the 7 indicator variables. Again, Panel A is the basic specification with the two variables of interest, and Panels B-D include control variables. Similar to results from Table 17, I find some evidence supporting the real effects theory. For event indicators $D 3, D 6$, and $D 7$, firms with higher preadoption risk management disclosure (DISC) experienced higher market returns around such events, and firms covering a greater portion of their expected fuel consumptions with hedging programs (SCOPE) experience more negative (less positive) returns from enhanced disclosure around such events.

To summarize, the cross-sectional analyses provide some support for the real effects theory that enhanced disclosure could induce distorted hedging and production decisions, which consequently destroy firm value. These negative effects partially offset the positive effects from more transparent information environment. 


\subsubsection{Additional analyses and future research}

The correlation table suggests that DISC and SCOPE have a relatively high correlation. When I include them one at a time and rerun the tests, the inferences are unchanged, suggesting that the results are not driven by multicollinearity. In addition, instead of adding control variables one at a time, I run the complete model with all the three control variables, and the inferences for the test variables are not affected.

My primary analyses are based on the U.S. airline industry for 2005-2008, which consists of 41 firm-year observations with available accounting and return information. Although the portfolio approach uses time-series regressions for the 1,007 trading dates during 2005-2008 and small sample size is not a major concern in this case, I perform tests using model (1) with the whole CRSP sample to see if the results from the U.S. airline industry is generalizable to the whole sample. The results are reported in Table 19. As we can see, the average return for all the events is not significantly different from zero. However, when I break the events into seven indicators as in Table 16, D4 is negative and significant, and D6 is positively significant (for the U.S. airline industry sample, D4 is negatively significant, and D6 and D7 are positively significant). The weaker results for the whole CRSP universe sample is likely due to the fact that compared to the airline industry where using derivatives for hedging is very common and important, the average CRSP firms do not employ derivatives as intensively, thus they are not affected by SFAS 161 as much as are airlines.

The cross-sectional analyses provide some initial evidence on the economic consequences of enhanced disclosure: investors expect value-destroying decisions due to more disclosure requirements. To further explore this theory, by examining the hedging and 
production decisions, as well as risk exposure before and after the adoption SFAS 161, future research can seek more evidence on how enhanced disclosure could change real actions.

\subsection{Conclusions}

In this paper, I examine the stock market reactions to the key events leading up to the adoption of SFAS 161 to provide empirical evidence on the economic impact of enhanced risk management disclosure. Focusing on the U.S. airline industry where fuel price risk management is common and essential, I document strong positive stock returns around key event dates, suggesting that the benefits from more transparent disclosure dominates other potential costs. My

cross-sectional analyses provide some initial evidence supporting the real effects theory of enhanced risk management disclosure. Firms that had to increase their disclosure levels and that had a greater portion of their expected fuel consumptions hedged experienced less positive market reactions around the key events leading up to SFAS 161. These results suggest that despite the desirable benefits from a better information environment, standard setters should also weight the costs from distorted hedging and production decisions from enhanced disclosure requirements. 


\section{REFERENCES}

Aguirregabiria, V. and C-Y. Ho. 2012. A dynamic oligopoly game of the U.S. airline industry: Estimation and policy experiments. Journal of Econometrics 168 (1): 156-173.

Ahmed, A., E. Kilic, and G. Lobo. 2006. Does recognition versus disclosure matter? Evidence from value-relevance of banks' recognized and disclosed derivative financial instruments. The Accounting Review 81: 567-588.

Ahmed, A., E. Kilic, and G. Lobo. 2011. Effects of SFAS 133 on risk relevance of accounting measures of banks' derivative exposure. The Accounting Review 86: 769-804.

Ali, A., S. Klasa, and E. Yeung. 2009. The limitations of industry concentration measures constructed with Compustat data: Implications for finance research. Review of Financial Studies 22 (10): 3839-3871.

Allayannis, G and J.P. Weston. 2001. The use of foreign currency derivatives and firm market value. Review of Financial Studies 14 (1): 243-276.

Bailey, E. E. and J. C. Panzar. 1981. The contestability of airline markets during the transition to deregulation. Law and Contemporary Problems 44 (1): 125-145.

Bamber, L. S., and Y. S. Cheon. 1998. Discretionary Management Earnings Forecast Disclosures: Antecedents and Outcomes Associated with Forecast Venue and Forecast Specificity Choices. Journal of Accounting Research 36 (2): 167-190.

Bartram, S. M., G. W. Brown, and F. R. Fehle. 2009. International evidence on financial derivatives usage. Financial Management 38 (1): 185-206.

Bartram, S. M., G. W. Brown, and J. Conrad. 2011. The effects of derivatives on firm risk and value. Journal of Financial and Quantitative Analysis 46 (4): 967-999.

Bens, D., P. Berger, and S. Monahan. 2011. Discretionary disclosure in financial reporting: an examination comparing internal firm data to externally reported segment data. The Accounting Review 86: 417-449.

Berger, P. G., and R. N. Hann. 2007. Segment Profitability and the Proprietary and Agency Costs of Disclosure. The Accounting Review 82 (4): 869-906.

Berry, S. 1990. Airport presence as product differentiation. American Economic Review 80:394399.

Berry, S. 1992. Estimation of a model of entry in the airline industry. Econometrica 60: 889-917.

Berry, S., M. Carnall, and P. Spiller. 2006. Airline hubs: costs, markups and the implications of customer heterogeneity. Advances in Airline Economics. Vol. 1: Competition Policy and Antitrust 183-214.

Beatty, A. S. Chamberlain, and J. Magliolo. 1996. An empirical analysis of the economic implications of fair value accounting for investment securities. Journal of Accounting and Economics 22: 43-77.

Beyer, A., D. A. Cohen, T. Z. Lys, and B. R. Walther. 2010. The financial reporting environment: Review of recent literature. Journal of Accounting and Economics 50 (2-3): 296-343.

Bhamornsiri, S. and R. Schroeder. 2004. The disclosure of information on derivatives under SFAS No. 133: Evidence from the Dow 30. Managerial Auditing Journal 19 (5): 669680.

Bhojraj, S., W. G. Blacconiero, and J. D. D'Souza. 2004. Voluntary disclosure in a multiaudience setting: An empirical investigation. The Accounting Review 79 (4): 921-947.

Boguslaski, C.,H. Ito, and D. Lee. 2004. Entry patterns in the Southwest Airlines Route System. Review of Industrial Organization 25: 317-350. 
Borenstein, S. 1989. Hubs and high fares: Dominance and market power in the U.S. airline industry. Rand Journal of Economics 20 (30): 344-365.

Borenstein, S., and N. Rose. 1994. Competition and price dispersion in the U.S. airline industry. Journal of Political Economy 102 (4): 653-683.

Bova, F., Y. Dou, and O-K. Hope. 2013. Employee Ownership and Firm Disclosure. Working paper, University of Toronto and New York University.

Brander, J. A. and A. Zhang. 1990. Market Conduct in the Airline Industry: an Empirical Investigation. Rand Journal of Economic 21: 567-583.

Busse, M. 2002. Firm Financial Condition and Airline Price Wars. Rand Journal of Economics 33: 298-318.

Campbell, J.L. 2013. The fair value of cash flow hedges, future profitability and stock returns. Working paper, University of Georgia.

Campello, M., C. Lin, Y. Ma, and H. Zou. 2011. The real and financial implications of corporate hedging. Journal of Finance 66 (5): 1615-1647.

Carter, D., D. Rogers, and B. Simkins. 2006a. Hedging and value in the U.S. Airline Industry. Journal of Applied Corporate Finance 18 (4): 21-33.

Carter, D., D. Rogers, and B. Simkins. 2006b. Does hedging affect firm value? Evidence from the US airline industry. Financial Management Spring: 53-86.

Carter, D., D. Rogers, and B. Simkins. 2006c. Fuel hedging in the Airline Industry: The case of Southwest Airlines. Working Paper Series. Oklahoma State University.

Chang, Y-H, and P-C Shao. 2011. Operating cost control strategies for airlines. African Journal of Business Management 5 (26): 10396-10409.

Chen, W., H-T. Tan, and E. Y. Wang. 2012. Fair value accounting and managers' hedging decisions. Journal of Accounting Research 51 (1): 67-103.

Ciliberto, F. and E. Tamer. 2009. Market structure and multiple equilibria in airline markets. Econometrica 77: 1791-1828.

Clubley, Sally. 1999. An Early Take Off. Risk May.

Darrough, M. and N. Stoughton. 1990, Financial disclosure policy in an entry game, Journal of Accounting and Economics 12: 219-43.

Darrough, M. 1993. Disclosure policy and competition: Cournot vs. Bertrand. The Accounting Review 68 (3): 534-561.

Dedman, E. and C. Lennox. 2009. Perceived competition, profitability and the withholding of information about sales and the cost of sales. Journal of Accounting and Economics 48 (2-3): 210-230.

DeMarzo, P, and D. Duffie. 1995. Corporate incentives for hedging and hedge accounting. Review of Financial Studies 8 (3): 743-771.

Dou, Y., M. H. F. Wong, and B. Xin. 2013. Evidence on the real effects of accounting: The case of employee stock option expensing. Working paper. New York University and University of Toronto.

Ellis, J. A., C. E. Fee, and S. E. Thomas. 2012. Proprietary costs and the disclosure of information about customers. Journal of Accounting Research. 50 (3): 685-727.

FASB, 1990. Statement of Financial Accounting Standards No. 105, Disclosure of Information about Financial Instruments with Off-Balance-Sheet Risk and Financial Instruments with Concentrations of Credit Risk

FASB, 1991. Statement of Financial Accounting Standards No. 107, Disclosures about Fair Value of Financial Instruments 
FASB, 1994. Statement of Financial Accounting Standards No. 119, Disclosure about Derivative Financial Instruments and Fair Value of Financial Instruments

FASB 1999. Statement of financial accounting standards No. 133, Accounting for derivative instruments and hedging activities.

FASB 2008. Statement of financial accounting standards No. 161, Disclosures about derivative instruments and hedging activities.

Feltham, G., F. Gigler, and J. Hughes. 1992. The effects of line-of-business reporting on competition in oligopoly settings. Contemporary Accounting Research 9 (1): 1-23.

Froot, K., D. S. Scharfstein, and J. C. Stein. 1993. Risk management coordinating corporate investment and financing policies. Journal of Finance 48: 1629-1658.

Gal-Or, E. 1985. Information sharing in Oligopoly. Econometrica 3 (2): 329-343.

Gal-Or, E. 1986. Information transmission-Cournot and Bertrand Equilibria. Review of Economic Studies LIII: 85-92.

Geczy, C., B. A. Minton, and C. Schrand. 1997. Why firms use currency derivatives. Journal of Finance 52: 1323-1354.

Gerardi, K and A. H. Shapiro. 2009. Does competition reduce price dispersion? New evidence from the airline industry. Journal of Political Economy 117 (1): 1-37.

Gigler, F., C. Kanodia, and R. Venugopalan. 2007. Assessing the information content of markto-market accounting with mixed attributes: The case of cash flow hedges. Journal of Accounting Research 45 (2): 257-276.

Goolsbee, A. and C. Syverson. 2008. How do incumbents respond to the threat of entry? Evidence from the major airlines. The Quarterly Journal of Economics 123 (4): 16111633.

Guo, R., B. Lev, and N. Zhou. 2004. Competitive Costs of Disclosure by Biotech IPOs. Journal of Accounting Research 42 (2): 319-355.

Harris, M. S. 1998. The association between competition and managers' business segment reporting decisions. Journal of Accounting Research 36: 111-128.

Haushalter, G. D. 2000. Financing policy, basis risk, and corporate hedging: Evidence from oil and gas producers. Journal of Finance 55: 107-152.

Hayes, K. and L. Ross. 1998. Is airline price dispersion the result of careful planning or competitive forces? Review of Industrial Organization 13: 523-542.

Healy, P. M., and K. G. Palepu. 2001. Information asymmetry, corporate disclosure, and the capital market: A review of the empirical disclosure literature. Journal of Accounting and Economics 31 (1-3): 405-440.

Hughes, J., J. Kao, and M. Williams. 2002. Public disclosure of forward contracts and revelation of proprietary information. Review of Accounting Studies 7: 459-478.

Hurdle, G. J., R. L. Johnson, A. S. Joskow, G. J. Werden, and M. A. Williams. 1989. Concentration, potential entry, and performance in the airline industry. Journal of Industrial Economics 38 (2): 119-139.

Jones, D. A., and K. J. Smith. 2011. Comparing the value relevance, predictive value, and persistence of other comprehensive income and special items. The Accounting Review 86 (6): 2047-2073.

Jorion, P. 2002. How informative are Value-at-Risk disclosures? The Accounting Review 77 (4): 911-931.

Kanodia, C., A. Mukherji, H. Sapra, and R. Venugopalan. 2000. Hedge disclosures, future prices, and production distortions. Journal of Accounting Research 38 (Supplement): 53-82. 
Kawaller, I.G. 2004. What analysts need to know about accounting for derivatives? Financial Analysts Journal 60 (2): 24-30.

Karuna, C. 2010. Discussion of "The impact of product market competition on the quantity and quality of voluntary disclosures". Review of Accounting Studies 15: 712-723.

Lang, M., K. Lins, and M. Maffett. 2012. Transparency, liquidity, and valuation: International evidence on when transparency matters most. Journal of Accounting Research 50 (3): $729-774$.

Larcker, D.F. and T.O. Rusticus. 2010. On the use of instrumental variables in accounting research. Journal of Accounting and Economics 49 (3): 186-205.

$\mathrm{Li}, \mathrm{X}$. 2010. The impacts of product market competition on the quantity and quality of voluntary disclosures. Review of Accounting Studies 15: 663-711.

Linsmeier, T. J., and N. D. Pearson 1997. Quantitative disclosure of market risk in the SEC release. Accounting Horizon 11 (1): 107-135.

Mackay, P and S. B. Moeller. 2007. The value of corporate risk management. Journal of Finance 62 (3): 1379-1419.

Makar, S., L. Wang, and P. Alam. The mixed attribute model in SFAS 133 cash flow hedge accounting: Implications for the market pricing. Review of Accounting Studies 18 (1): 6694.

Marshall, A. and P. Weetman. 2007. Modelling transparency in disclosure: The case of foreign exchange risk management. Journal of Business, Finance \& Accounting 34 (5-6): $705-$ 739.

Melumad, N. D., G. Weyns, and A. Ziv. 1999. Comparing Alternative Hedge Accounting Standards: Shareholders' Perspective. Review of Accounting Studies 4 (3-4): 265-292.

Milgrom, P., and J. Roberts. 1982. Limited pricing and entry under incomplete information: An equilibrium analysis. Econometrica 50 (2): 443-459.

Miller, M. H. and C. L. Culp. 1996. The SEC's Costly Disclosure Rules. Wall Street Journal June.

Morrell, P. and W. Swan. 2006. Airline Jet Fuel Hedging: Theory and practice. Transport Reviews 26 (6): 713-730.

Morrison, S. A. and C. Winston. 1987. Empirical implications and tests of the contestability hypothesis. Journal of Law and Economics 30: 53-66.

Morrison, S. A. and C. Winston. 1995. The Evolution of the Airline Industry. Brookings. Washington, D.C.

Neven, D. J., L.-H. Roller, and Z. Zhang. 1998. Union Power and Product Market Competition: Evidence from the Airline Industry. Centre for Economic Policy Research Discussion Paper No. 1912.

Norton, E. C., H. Wang, and C. Ai. 2004. Computing interaction effects and standard errors in logit and probit models. The Stata Journal 4 (2): 154-167.

Oliveira, A. 2008. An empirical model of low-cost carrier entry. Transportation Research Part A 42: 673-695.

Panaretou, A., M. B. Shackleton, and P. A. Taylor. 2013. Corporate risk management and hedge accounting. Contemporary Accounting Research 30 (1): 116-139.

Perignon, C. and D. R. Smith. 2010. The level and quality of Value-at-Risk disclosure by commercial banks. Journal of Banking \& Finance 34 (2): 362-377.

Rajan, R. G., and L. Zingales. 1998. Financial dependence and growth. American Economic Review 88 (3): 559-586. 
Riley Jr., R.A., T. A. Pearson, and G. Trompeter. 2003. The value relevance of non-financial performance variables and accounting information: the case of the airline industry. Journal of Accounting and Public Policy 22 (3): 231-254.

Salop, S.C. 1979. Strategic entry deterrence. American Economic Review 69 (2): 335-338.

Sankar, M. R. 1995. Disclosure of Predecision Information in a Duopoly. Contemporary Accounting Research 11: 829-859.

Seow, G.S, and K. Tam. 2002. The Usefulness of Derivative-Related Accounting Disclosures. Review of Quantitative Finance and Accounting 18 (3): 273-291.

Sinclair, R. A. 1995. An empirical model of entry and exit in airline markets. Review of Industrial Organization 10 (5): 541-557.

Sapra, H. 2002. Do mandatory hedge disclosures discourage or encourage excessive speculation? Journal of Accounting Research 40 (3): 933-963.

Sefcik, S. E., and R. Thompson. 1986. An approach to statistical inference in cross-sectional models with security abnormal returns as dependent variable. Journal of Accounting and Research 24 (2): 316-334.

Stock, J.H., J.H. Wright, and M. Yogo. 2002. A survey of weak instruments and weak identification in generalized method of moments. Journal of Business \& Economics Statistics 20: 518-529.

Venkatachalam, M. 1996. Value relevance of banks' derivative disclosures. Journal of Accounting and Economics 22 (1-3): 327-355.

Verrecchia, R. 1983. Discretionary Disclosure. Journal of Accounting and Economics 5: 365-380.

Verrecchia, R. 1990. Endogenous proprietary costs through firm interdependence. Journal of Accounting and Economics 12: 245-250.

Verrecchia, R. E. and J. Weber. 2006. Redacted disclosure. Journal of Accounting Research 44: 791-814.

Vives, X. 1984. Duopoly information equilibrium; Cournot and Bertrand. Journal of Economic Theory 34: 71-94.

Vives, X. 1990. Trade association disclosure rules, incentives to share information, and welfare. RAND Journal of Economics 21 (3): 409-430.

Wong, M. H. F. 1999. The association between SFAS 119 derivatives disclosures and the foreign exchange risk exposure of manufacturing firms. Journal of Accounting Research 38 (2): 387-417.

Zhang, H. 2009. Effect of derivative accounting rules on corporate risk management behavior. Journal of Accounting and Economics 47: 244-264.

Zhang, I. X. 2007. Economic consequences of the Sarbanes-Oxley Act of 2002. Journal of Accounting and Economics 44: 74-115. 


\section{Appendix A: Construction of the Disclosure Score}

\begin{tabular}{|c|l|c|}
\hline No. & Disclosure & Average Score \\
\hline 1 & $\begin{array}{l}\text { Is there sensitivity disclosure regarding fuel hedge? (FIN No. 48R } \\
\text { requires at least one of the following disclosure: sensitivity disclosure, } \\
\text { tabulate disclosure, or VaR disclosure) }\end{array}$ & 0.89 \\
\hline 2 & Is the type of instruments disclosed? & 0.98 \\
\hline 3 & Is the strike/floor/ceiling price of the instruments disclosed? & 0.59 \\
\hline 4 & Is credit risk exposure from the instruments disclosed? & 0.65 \\
\hline 5 & $\begin{array}{l}\text { Is the maturity/term/current vs. noncurrent nature of the instruments } \\
\text { disclosed? }\end{array}$ & 0.73 \\
\hline 6 & $\begin{array}{l}\text { Is the percentage of fuel usage in the next 12 months being hedged } \\
\text { disclosed }\end{array}$ & 0.96 \\
\hline 7 & $\begin{array}{l}\text { If there is instruments not designated as CFH, is the realized vs. non- } \\
\text { realized gain or loss disclosed? }\end{array}$ & 0.73 \\
\hline 8 & $\begin{array}{l}\text { If there are instruments not designated as CFH, is the fair value of } \\
\text { CFH and non-CFH disclosed? }\end{array}$ & 1 \\
\hline 9 & $\begin{array}{l}\text { Whether hedging derivatives and instruments are designated as cash } \\
\text { flow hedge (CFH) is disclosed? }\end{array}$ & 0.8 \\
\hline 10 & $\begin{array}{l}\text { If designated as CFH, is the estimated amount to be reclassified from } \\
\text { AOCI to income in the next 12 months disclosed? }\end{array}$ & 0.44 \\
\hline 11 & If designated as CFH, is the ineffective portion disclosed? & 0.8 \\
\hline 12 & $\begin{array}{l}\text { If designated as CFH, is current period OCI from the change in fair } \\
\text { value of instruments disclosed? }\end{array}$ & $\begin{array}{l}\text { If designated as CFH, and there is CFH other than fuel hedge, is the } \\
\text { AOCI for fuel hedge reported separately? }\end{array}$ \\
\hline
\end{tabular}

Note: For each disclosure item, if such information is disclosed by the firm in the 10 -K filings, then a value of 1 is granted, and zero otherwise. Items 6, 9, 10, and 11 are required disclosures by SFAS 133. 


\section{Appendix B: Description of the D.O.T. Databases and Review of the Airline Literature}

The databases used in this paper are publically available from the U. S. Department of Transportation website (http://www.dot.gov and http://www.rita.dot.gov). The route level information is collected from The Airline Origin and Destination Survey Databank 1B (DB1B), a random survey of $10 \%$ of all airline passenger tickets for each calendar quarter starting from 1993. The database consists of three tables: Coupon, Market, and Ticker. A coupon is a piece of paper that indicates a passenger's itinerary, and identifies a segment of travel. Each time a passenger changes flights, a new coupon is collected. For example, a round-way flight from Boston to Las Vegas then back to Boston that stops in Chicago in both ways would have four coupons, Boston-to-Chicago, Chicago-to-Las Vegas, Las Vegas-to-Chicago, and Chicago-toBoston. The Coupon table provides coupon-specific information. The Market table contains directional market characteristics for each domestic itinerary, while the Ticket table contain itinerary level characteristics. For the above example, there will be four observations in the Coupon table, two in the Market table (one for each way), and one in the Ticket table. The DB1B database contains a very large amount of data. For example, 2010:Q1 contains approximately 7.9 million coupons, 4.9 million markets, and 2.8 million tickets. The DB1B database contains itinerary information such as origin and destination airports locations, ticket prices, fair class, operating carriers, ticketing carriers, non-stop distances between the airports, actual miles flown, etc.

I construct my sample from the Market table that contains directional market information. However, I do not distinguish between the origin airports and the destination airports. That is, an observation of flight from Boston to Chicago and another observation of 
flight from Chicago to Boston from the Market table are treated as belonging to the same route Boston-Chicago. The DB1B also provides information regarding the fare class of each ticket. Each ticket is labeled as either coach-class, business-class, or first-class, and I eliminate all firstclass and business-class itineraries. I then eliminate airport pairs with non-stop distances greater than 3,000 miles or shorter than 100 miles to make the sample more representative of the most common travel pattern. I further eliminate directional flights with more than two coupons to make sure that incumbents are clearly identified. Travels with ticketing carriers different from operating carriers represent code sharing among airlines. Removing them gives me a cleaner sample of incumbents and potential entrants, who are actually competing instead of forming alliances. After eliminating these unreliable observations, I calculate the number of passengers transported by each carrier for each quarter and delete any carriers with quarterly observation fewer than 100 (given that the dataset is $10 \%$ random survey of all tickets, 100 DB1B observations translates into an actual 1,000 passengers each quarter, or 8 passengers daily). These carriers are unlikely to be valid competitors. After aggregating the data to quarter-routecarrier level, I identify incumbents and potential entrants for each calendar quarter, and if a potential entrant starts to operate the route for at least three out of the four quarters of a year, the potential entrant is considered to have entered the market. However, the DB1B does not provide the number of seats available information for each route-carrier. I obtain such information from the T100 tables.

The Economics and Industrial Organization literature has a long history of using the airline industry to investigate the competition dynamics and test various theories. As a matter of fact, studies by academic economists were a significant force in the movement towards deregulation of the domestic airline industry in the early 1970s. Since the deregulation, 
economists have continued intensive study of the industry, in part because of the unusual availability of reliable firm- and transaction-level data. The other reason that the airline industry is of particular interests to researchers is that the tactics, strategies, and results of competition in this dynamic, complex, and innovative service industry have provided a rare opportunity to learn about the market process.

Many of the earlier studies centered on the contestability theory which suggests that the disciplining effect of potential competition (if the costs of entry and exit are low) will result in competitive markets so that the number of actual competitors should have no effect on prices. With the airports and carriers information from DB1B and its proceeding form DB1A, researchers demonstrate that an airline can enter a new market quickly and with low cost, especially if the entrant already serves one or both of the endpoints of the route (Bailey and Panzar 1981), and that most of the new market entries were from new competitors already serving at least one of the points (Berry 1992).

However, potential competition appears to be no perfect substitute for actual competition, and there emerged a fair amount of studies exploring the effects form both potential competition and exiting competitors on price levels and dispersion using the DB1B data (Morrison and Winston 1987; Borenstein 1989; Borenstein and Rose 1994; Goolsbee and Syverson 2008; Gerardi and Shapiro 2009). In addition, determinants of entry decisions and exit decisions are examined with the DB1B data in Sinclair (1995), Boguslaski et al. (2004), and Oliveria (2008) where entry and exit are considered proxies for profitability. In this paper I extend the entry decision models by allowing firm-specific signals as determinants in addition to traditional market characteristics. 


\section{Appendix C: Journal Entries related to Cash Flow Hedges}

This appendix provides an example of the journal entries associated with an investment in an option derivative that is designated as a cash flow hedge under SFAS 133.

\section{Date=October 2012}

The firm buys jet fuel option hedge for $\$ 1,000$ cash to cover a future fuel purchase and expected consumption currently worth $\$ 6,000$.

$$
\begin{array}{lr}
\text { Dr Investment in Option } & \$ 1,000 \\
\text { Cr Cash } & \$ 1,000
\end{array}
$$

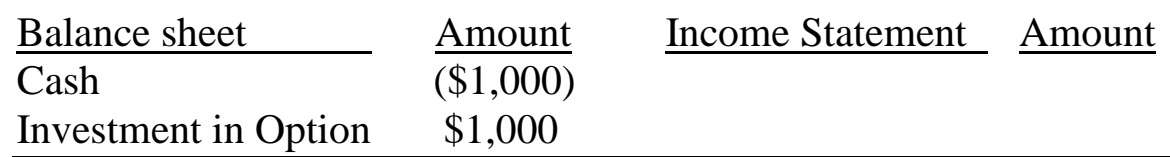

\section{Date=December 2012}

The underlying price of the option (jet fuel) goes up and hedge increases in value by $\$ 1,500$. The accounting period is completed and statements are presented.

\begin{tabular}{|c|c|c|}
\hline Balance sheet & Amount & Income Statement \\
\hline Cash & $(\$ 1,000)$ & \\
\hline Investment Option & $\$ 2,500$ & \\
\hline
\end{tabular}

$$
\begin{aligned}
& \text { Dr Investment in Option } \$ 1,500 \\
& \mathrm{Cr} \quad \mathrm{OCI}-\mathrm{CFH} \text { derivative gain } \quad \$ 1,500 \\
& \text { Dr OCI- }-\mathrm{CFH} \text { derivative gain } \$ 1,500 \\
& \mathrm{Cr} \quad \text { AOCI- } \mathrm{CFH} \text { derivative gain } \$ \$ 1,500
\end{aligned}
$$

\section{Date $=$ March 2013}

The underlying price of the option (jet fuel) goes up and the hedge increases in value by $\$ 500$. The firm sells the hedge for $\$ 3,000$ and purchases jet fuel at the current value of $\$ 8,000$ $(\$ 6,000+\$ 1,500+\$ 500)$.

$$
\begin{aligned}
& \text { Dr Investment in Option } \$ 500 \\
& \text { Cr OCI-CFH derivative gain } \$ 500
\end{aligned}
$$

Dr OCI $-\mathrm{CFH}$ derivative gain $\quad \$ 500$ 


$$
\begin{array}{lc}
\text { Cr AOCI-CFH derivative gain } & \$ 500 \\
\text { Dr Cash } & \$ 3,000 \\
\text { Cr Investment in Option } & \$ 3,000 \\
\text { Dr Inventory } & \$ 8,000 \\
\text { Cr Cash } & \$ 8,000
\end{array}
$$

\begin{tabular}{|c|c|c|}
\hline Balance sheet & Amount & Income Statement \\
\hline Cash & $(\$ 6,000)$ & \\
\hline Investment on Option & -- & \\
\hline Inventory & $\$ 8,000$ & \\
\hline AOCI-CFH derivatives & $(\$ 2,000)$ & \\
\hline
\end{tabular}

\begin{tabular}{|c|c|c|c|}
\hline Balance sheet & Amount & Income Statement & Amount \\
\hline Cash & $\overline{(\$ 5,000)}$ & & \\
\hline Investment in Option & -- & & \\
\hline Inventory & -- & Fuel Expenses & $\$ 8,000$ \\
\hline \multirow[t]{2}{*}{$\mathrm{AOCI}-\mathrm{CFH}$ derivatives } & \multirow[t]{2}{*}{--} & Fuel Expenses & $(\$ 2,000)$ \\
\hline & & Net Fuel Expenses & $\$ 6,000$ \\
\hline
\end{tabular}

\section{Date=March 2013}

The firm consumes the jet fuel in providing services, and releases gain from AOCI, resulting in fuel expenses of $\$ 5,000$.

$$
\begin{array}{clc}
\text { Dr } & \text { Fuel Expenses } & \$ 8,000 \\
\text { Cr } & \text { Inventory } & \$ 8,000 \\
& & \\
\text { Dr } & \text { AOCI_CFH derivative gains } & \$ 2,000 \\
\text { Cr } & \text { Fuel Expenses } & \$ 2,000
\end{array}
$$




\section{Appendix D: Summary of SFAS 133 Disclosure Requirements}

The following must be disclosed by all reporting entities that use derivative instruments (Paragraph 44)

- Objectives for using each derivative, whether for hedging or for speculation

- The context needed to understand objectives.

- Qualitative disclosures are encouraged.

The following must be disclosed if derivatives are used in hedging relationships (Paragraph 45)

- Risk management policies must be specified, identifying exposures to be hedged and hedging strategies for managing the associated risks.

- Identification of the type of hedging relationship (i.e., fair value, cash flow, net investment in foreign operation), if applicable.

- The hedged item must be explicitly identified.

- Ineffective hedge results must be disclosed.

- Any component of the derivatives' results that is excluded from the hedge effectiveness assessment must be disclosed.

Specific requirements for cash flow hedges (Paragraph 45b)

- A description of the conditions that will result in the reclassification of accumulated other comprehensive income into earnings, and a schedule of the estimated reclassification expected in the coming 12 months must be disclosed.

- The maximum length of time over which hedging is anticipated (except for variable interest rate exposures) must be disclosed. 
- Entities must disclose the amount reclassified into earnings as a result of discontinued cash flow hedges because the forecasted transaction is no longer probable.

- Specific requirements for hedges of net investments in foreign operations (Paragraph 45c)

- Entities must disclose the amount of the derivatives' results that is included in the cumulative translation adjustment during the reporting period. 
Appendix E: Summary of Events

\begin{tabular}{|c|c|c|c|}
\hline No. & Date & Event/News Title & Summary \\
\hline 1 & $09 / 03 / 2005$ & $\begin{array}{l}\text { FASB Mulls Expanded Disclosure Rules For Derivatives } \\
\text { (Dow Jones Newswire) }\end{array}$ & Add the project to the agenda \\
\hline 2 & 06/07/2005 & FASB Board Meeting & $\begin{array}{l}\text { Decided scope limited to SFAS } 133 \text { and } \\
\text { hedged items }\end{array}$ \\
\hline 3 & $19 / 07 / 2006$ & FASB Board Meeting & $\begin{array}{l}\text { Discussed the } 3 \text { objectives, counterparty credit } \\
\text { risk, disclosure of notional, fair value, and } \\
\text { gains losses by major underlying, accounting } \\
\text { designation }\end{array}$ \\
\hline 4 & 06/09/2006 & FASB Board Meeting & $\begin{array}{l}\text { Discussed gross or net presentation; whether } \\
\text { should cover derivatives existing throughout } \\
\text { the period but not at the end of the period }\end{array}$ \\
\hline 5 & $18 / 10 / 2006$ & FASB Board Meeting & $\begin{array}{l}\text { Set effective date, decided tabular disclosure } \\
\text { format }\end{array}$ \\
\hline 6 & $08 / 12 / 2006$ & Exposure Draft Issued & $\begin{array}{l}\text { Comment letters should be received by March } \\
2,2007 \text {. Effective for fiscal year and interim } \\
\text { periods beginning after December } 15,2007\end{array}$ \\
\hline 7 & $02 / 05 / 2007$ & FASB Board Meeting & $\begin{array}{l}\text { Summarized and discussed the issues raised in } \\
\text { comment letters }\end{array}$ \\
\hline 8 & $25 / 07 / 2007$ & FASB Board Meeting & $\begin{array}{l}\text { Discussed the scope and decide to retain the } \\
\text { same scope }\end{array}$ \\
\hline 9 & $26 / 09 / 2007$ & FASB Board Meeting & Agreed on the revised tabular format. \\
\hline 10 & $05 / 12 / 2007$ & FASB Board Meeting & $\begin{array}{l}\text { Completed the redeliberations/relax notional } \\
\text { amount disclosure }\end{array}$ \\
\hline 11 & $19 / 03 / 2008$ & Announcement of SFAS 161 & $\begin{array}{l}\text { Effective for fiscal year and interim periods } \\
\text { beginning after November } 15,2008\end{array}$ \\
\hline 12 & $30 / 04 / 2008$ & Amendments to disclosure requirements & Amended credit derivative disclosures \\
\hline 13 & $12 / 09 / 2008$ & FASB Board Meeting and Announcement & $\begin{array}{l}\text { Clarified the effective date applies to both } \\
\text { fiscal year and interim periods }\end{array}$ \\
\hline
\end{tabular}




\section{Appendix F: Construction of the Disclosure Score}

\begin{tabular}{|c|c|}
\hline No. & Disclosure \\
\hline 1 & $\begin{array}{l}\text { Is there sensitivity disclosure regarding fuel hedge? (FIN No. } 48 \mathrm{R} \text { requires at least } \\
\text { one of the following disclosure: sensitivity disclosure, tabulate disclosure, or VaR } \\
\text { disclosure) }\end{array}$ \\
\hline 2 & Is the type of instruments disclosed? \\
\hline 3 & Is the strike/floor/ceiling price of the instruments disclosed? \\
\hline 4 & Is credit risk exposure from the instruments disclosed? \\
\hline 5 & Is the maturity/term/current vs. noncurrent nature of the instruments disclosed? \\
\hline 6 & Is the percentage of fuel usage in the next 12 months being hedged disclosed \\
\hline 7 & $\begin{array}{l}\text { If there is instruments not designated as } \mathrm{CFH} \text {, is the realized vs. non-realized gain or } \\
\text { loss disclosed? }\end{array}$ \\
\hline 8 & $\begin{array}{l}\text { If there are instruments not designated as } \mathrm{CFH} \text {, is the fair value of } \mathrm{CFH} \text { and non-CFH } \\
\text { disclosed? }\end{array}$ \\
\hline 9 & $\begin{array}{l}\text { Whether hedging derivatives and instruments are designated as cash flow hedge } \\
(\mathrm{CFH}) \text { is disclosed? }\end{array}$ \\
\hline 10 & $\begin{array}{l}\text { If designated as } \mathrm{CFH} \text {, is the estimated amount to be reclassified from AOCI to income } \\
\text { in the next } 12 \text { months disclosed? }\end{array}$ \\
\hline 11 & If designated as $\mathrm{CFH}$, is the ineffective portion disclosed? \\
\hline 12 & $\begin{array}{l}\text { If designated as } \mathrm{CFH} \text {, is current period OCI from the change in fair value of } \\
\text { instruments disclosed? }\end{array}$ \\
\hline 13 & $\begin{array}{l}\text { If designated as } \mathrm{CFH} \text {, and there is } \mathrm{CFH} \text { other than fuel hedge, is the AOCI for fuel } \\
\text { hedge reported separately? }\end{array}$ \\
\hline
\end{tabular}

Note: For each disclosure item, if such information is disclosed by the firm in the 10-K filings, then a value of 1 is granted, and zero otherwise. Items $6,9,10$, and 11 are required disclosures by SFAS 133. 


\section{Appendix G: Summary of SFAS 161 disclosure requirements}

The additional disclosures required by FAS 161 are summarized below:

- Entities must provide information outlining the reasons for holding or issuing derivative instruments. Disclosures should be in the context of overall risk exposures.

- For derivatives used as hedges, the organization should provide a description of those designated as a) fair value hedges, b) cash flow hedges, and c) foreign currency hedges. In addition, for derivatives held solely as investments, the entity needs to provide the purpose for holding such an investment.

- Qualitative information about the entity's objectives and strategies for using derivative instruments should be made in the context of the entity's overall risk exposures relating to interest risk, foreign currency exchange rate risk, commodity price risk, credit risk, and equity price risk. If made, those disclosures should include a discussion of those exposures even though the entity does not manage some or all the risks through the use of these derivatives.

- For each reporting period in which a statement of financial position is presented, the following should be disclosed in tabular form by type of derivative contract:

- The location and fair value amounts of derivative instruments reported in the statement of financial position

- The location and amount of gains and losses reported in the statement of operations. Gains and losses should be presented separately for:

- Derivative instruments designated as fair value hedges

- The effective portion of gains and losses on cash flow hedges and net investment hedges recognized in OCI 
- The effective portion of gains and losses on cash flow hedges and net investment hedges reclassified out of OCI and into earnings

- The portion of gains and losses for cash flow hedges and net investment hedges representing a) the amount of the hedges' ineffectiveness and b) the amount excluded from the assessment of hedge effectiveness

- Derivatives not designated as hedges

- For each reporting period for which a statement of financial position is presented, the following should be disclosed:

- The existence and nature of credit-risk-related contingent features and circumstances that could be triggered in instruments that are in a net liability position

- The aggregate fair value of such derivatives

- The aggregate value of assets that are already reported as collateral at the end of the reporting period

- The aggregate fair value of additional assets that would be reported as collateral

- The aggregate fair value of assets needed to settle the instrument immediately if credit-risk-related contingent features were triggered 
TABLE 1: Variable Definitions-Chapter 1

\begin{tabular}{|c|c|}
\hline VARIABLE & DEFINITION \\
\hline \multicolumn{2}{|l|}{ Key test variables: } \\
\hline I_AOCIFH & $\begin{array}{l}\text { Weighted average of the route-year's all incumbents' AOCI for fuel } \\
\text { hedge. AOCI is scaled by total asset before weighting. }\end{array}$ \\
\hline I_DISC & $\begin{array}{l}\text { Weighted average of the route-years' all incumbents' disclosure } \\
\text { scores. }\end{array}$ \\
\hline$I \_D I S C D$ & $=1$ when above median. \\
\hline I_AOCIFH $\times I \_D I S C D$ & The product of $I \_A O C I F H$ and $I \_D I S C D$ \\
\hline \multicolumn{2}{|c|}{ Incumbents' and entrants' characteristics } \\
\hline$I \_L F$ & $\begin{array}{l}\text { Weighted average of all incumbents' loading factor. Loading factor is } \\
\text { a common performance measure of airlines = passengers carried/total } \\
\text { seats available }\end{array}$ \\
\hline I_LEV & $\begin{array}{l}\text { Weighted average of all incumbents' leverage. Leverage is calculated } \\
\text { as long term debt/total asset }\end{array}$ \\
\hline I_SIZE & Weighted average of all incumbents' size. size $=\log ($ total asset $)$ \\
\hline$I \_R O A$ & $\begin{array}{l}\text { Weighted average of all incumbents' ROA. ROA=net income/total } \\
\text { asset }\end{array}$ \\
\hline I_LOSS & $\begin{array}{l}\text { Weighted average of all incumbents' loss indicator. Loss=1 if net } \\
\text { income }<0\end{array}$ \\
\hline I_FUELEXP & $\begin{array}{l}\text { Log of ( } 1+\text { Weighted average of all incumbents' fuel expense as \% of } \\
\text { their total operating expenses). }\end{array}$ \\
\hline I_LOSS & Weighted average of all incumbents' loss indicator. \\
\hline I_CFO & $\begin{array}{l}\text { Weighted average of all incumbents' cash flow from operation. cash } \\
\text { flow from operation is scaled by total asset }\end{array}$ \\
\hline$I \_F R$ & $\begin{array}{l}\text { Weighted average of all incumbents' percentage of international RSM } \\
\text { to its total RSM. }\end{array}$ \\
\hline E_AOCIFH & Entrant's AOCI scaled by total asset \\
\hline$E \_L E V$ & Entrant's leverage \\
\hline E_SIZE & Entrant's size \\
\hline$E \_R O A$ & Entrant's ROA \\
\hline E_LOSS & Entrant's loss indicator variable \\
\hline E_FUELEXP & Log of $(1+$ Entrant's fuel expense as $\%$ of total operating expenses $)$ \\
\hline$E_{-} L O S S$ & Entrant's loss indicator \\
\hline$E_{-} C F O$ & Entrant's cash from operation \\
\hline
\end{tabular}




\section{Route characteristics}

ORIGININCOME

DESTINCOME

$H U B$

$H H I$

MKTSIZE

DISTANCE

DISTANCE2

DENSITY

DENSITY2

MEANPOP
The route's origin's income measured as log(income/1000);

The route's destination's income

Indicator variable $=1$ if at least one of the airports is the hub of some airlines

the HHI of the route calculated using the passengers carried by each carrier

the market size of the route, calculated as the total passengers of the route*the distance of the route

The non-stop distance of the route; in thousand miles

The square of distance

The number of passengers of the route; in thousands

The square of DENSITY

the natural log of the mean population for both endpoint MSA 
TABLE 2: Descriptive Statistics

\begin{tabular}{|c|c|c|c|c|c|c|c|c|c|c|}
\hline Variable & $\mathrm{N}$ & mean & $\mathrm{sd}$ & p5 & p50 & p95 & $\min$ & $\max$ & $\mathrm{p} 25$ & $\mathrm{p} 75$ \\
\hline ENTRY & 2,829 & 0.07 & 0.26 & 0.00 & 0.00 & 1.00 & 0.00 & 1.00 & 0.00 & 0.00 \\
\hline I_AOCIFH(\%) & 2,829 & 0.33 & 0.02 & -2.83 & 0.00 & 4.64 & -6.61 & 7.48 & -0.26 & 0.13 \\
\hline$I \_S I Z E$ & 2,829 & 8.29 & 3.02 & 0.01 & 9.46 & 10.40 & -0.15 & 10.71 & 8.49 & 9.89 \\
\hline$I \_R O A$ & 2,829 & -0.06 & 0.67 & -0.24 & -0.01 & 0.05 & -19.72 & 0.89 & -0.07 & 0.02 \\
\hline I_FUELEXP & 2,829 & 2.66 & 0.94 & 0.01 & 2.95 & 3.47 & 0.00 & 3.97 & 2.55 & 3.13 \\
\hline I_CFO & 2,825 & 0.05 & 0.09 & -0.07 & 0.04 & 0.26 & -0.44 & 0.34 & 0.00 & 0.09 \\
\hline$I \_L F$ & 2,829 & 0.70 & 0.11 & 0.51 & 0.70 & 0.86 & 0.03 & 1.00 & 0.64 & 0.76 \\
\hline$I \_L O S S$ & 2,829 & 0.53 & 0.49 & 0.00 & 0.89 & 1.00 & 0.00 & 1.00 & 0.00 & 1.00 \\
\hline$I \_L E V$ & 2,829 & 0.29 & 0.17 & 0.00 & 0.34 & 0.53 & 0.00 & 0.60 & 0.15 & 0.42 \\
\hline$E \_A O C I$ & 2,829 & 0.00 & 0.01 & -0.01 & 0.00 & 0.02 & -0.07 & 0.23 & 0.00 & 0.00 \\
\hline$E \_S I Z E$ & 2,829 & 9.02 & 1.11 & 7.06 & 9.26 & 10.39 & -0.15 & 10.71 & 8.41 & 9.89 \\
\hline$E \_R O A$ & 2,829 & -0.06 & 0.66 & -0.21 & -0.01 & 0.05 & -19.72 & 0.89 & -0.06 & 0.02 \\
\hline$E \_F U E L E X P$ & 2,829 & 2.97 & 0.33 & 2.37 & 3.00 & 3.49 & 2.18 & 3.97 & 2.73 & 3.21 \\
\hline$E_{-} C F O$ & 2,829 & 0.06 & 0.07 & -0.06 & 0.05 & 0.15 & -0.44 & 0.35 & 0.01 & 0.09 \\
\hline$E_{-} L O S S$ & 2,825 & 0.64 & 0.48 & 0.00 & 1.00 & 1.00 & 0.00 & 1.00 & 0.00 & 1.00 \\
\hline$E \_L E V$ & 2,829 & 0.36 & 0.12 & 0.08 & 0.38 & 0.54 & 0.00 & 0.60 & 0.30 & 0.45 \\
\hline ORIGININCOME & 2,829 & 39.49 & 7.17 & 29.57 & 38.69 & 54.91 & 21.32 & 62.63 & 34.49 & 43.25 \\
\hline DESTINCOME & 2,829 & 39.48 & 7.42 & 29.46 & 38.85 & 54.91 & 19.72 & 62.63 & 34.03 & 43.01 \\
\hline$H U B$ & 2,829 & 0.52 & 0.50 & 0.00 & 1.00 & 1.00 & 0.00 & 1.00 & 0.00 & 1.00 \\
\hline $\mathrm{HHI}$ & 2,829 & 0.22 & 0.36 & 0.00 & 0.00 & 0.99 & 0.00 & 1.00 & 0.00 & 0.42 \\
\hline DISTANCE & 2,829 & 7.54 & 5.80 & 2.16 & 5.81 & 22.95 & 1.00 & 29.94 & 3.49 & 9.25 \\
\hline DISTANCE2 & 2,829 & 90.47 & 150.63 & 4.67 & 33.76 & 526.70 & 1.00 & 896.40 & 12.18 & 85.56 \\
\hline DENSITY & 2,829 & 23.48 & 26.09 & 2.62 & 13.32 & 75.61 & 1.77 & 190.18 & 5.95 & 31.99 \\
\hline DENSITY2 & 2,825 & 1231.71 & 3118.69 & 6.85 & 177.32 & 5716.42 & 3.12 & 36169.95 & 35.38 & 1023.30 \\
\hline$M E A N P O P$ & 2,829 & 8.07 & 0.72 & 6.98 & 8.07 & 9.26 & 5.00 & 9.67 & 7.60 & 8.57 \\
\hline MKTSIZE & 2,829 & 14.49 & 1.32 & 12.27 & 14.65 & 16.34 & 6.75 & 18.10 & 13.71 & 15.40 \\
\hline
\end{tabular}

Notes: ORIGININCOME and DESTINCOME are in thousand dollars, DISTANCE is in hundred miles, and DENSITY is in thousands. Variable definitions are provided in Table 1. 
TABLE 3: Pearson

Correlations

$$
\begin{array}{lllllllllllllll}
E N T R Y & (1) & (2) & (3) & (4) & (5) & (6) & (7) & (8) & (9) & (10) & \text { (11) } & \text { (12) } & \text { (13) } & \text { (14) } \\
\hline
\end{array}
$$

\begin{tabular}{|c|c|c|c|c|c|c|c|c|c|c|c|c|c|c|c|}
\hline & & & & & & & & & & & & & & & \\
\hline I_AOCI FH(1) & -0.01 & & & & & & & & & & & & & & \\
\hline I_SIZE (2) & 0.02 & $0.05^{*}$ & & & & & & & & & & & & & \\
\hline$I \_R O A(3)$ & 0.01 & $-0.05^{*}$ & $0.07 *$ & & & & & & & & & & & & \\
\hline I_FUELEXP (4) & 0.02 & 0.01 & $0.88^{*}$ & -0.01 & & & & & & & & & & & \\
\hline$I C F O(5)$ & 0.01 & $0.54^{*}$ & $0.14^{*}$ & $0.24^{*}$ & $0.26^{*}$ & & & & & & & & & & \\
\hline $\operatorname{ILF}(6)$ & $0.08 *$ & -0.01 & -0.00 & $\overline{-}^{-}$ & 0.01 & -0.03 & & & & & & & & & \\
\hline $\operatorname{ILOSS}(7)$ & 0.00 & $-0.17 *$ & $0.39 *$ & $\begin{array}{c}- \\
0.15^{*}\end{array}$ & $0.24 *$ & $\begin{array}{c}- \\
0.45^{*}\end{array}$ & 0.02 & & & & & & & & \\
\hline $\operatorname{ILEV}(8)$ & $0.06^{*}$ & $-0.15^{*}$ & $0.53^{*}$ & $0.08^{*}$ & $0.51^{*}$ & $0 . \overline{0} *$ & 0.02 & $0.38 *$ & & & & & & & \\
\hline EAOCIFH (9) & 0.03 & $0.08^{*}$ & 0.02 & $0.05^{*}$ & $\overline{-}^{-} 05^{*}$ & $0.08^{*}$ & -0.01 & $\begin{array}{c}- \\
0.04 *\end{array}$ & -0.02 & & & & & & \\
\hline ESIZE (10) & -0.01 & $-0.09 *$ & -0.07 & 0.02 & -0.03 & -0.02 & $\overline{0 .} 4^{-}$ & -0.00 & -0.02 & $\begin{array}{c}- \\
0.17 *\end{array}$ & & & & & \\
\hline EROA (11) & 0.02 & -0.02 & 0.01 & -0.01 & 0.02 & 0.01 & 0.01 & 0.01 & -0.02 & $\begin{array}{c}- \\
0.53 *\end{array}$ & $0.26^{*}$ & & & & \\
\hline EFUELEXP (12) & 0.00 & $-0.06^{*}$ & -0.03 & $0.07 *$ & 0.142 & 0.03 & 0.03 & $\begin{array}{c}- \\
0.19^{*}\end{array}$ & $\begin{array}{c}- \\
0.07 *\end{array}$ & $0 . \overline{15^{*}}$ & $\begin{array}{c}- \\
0.09^{*}\end{array}$ & $0.06^{*}$ & & & \\
\hline$E C F O(13)$ & 0.02 & $0.11^{*}$ & $0.04 *$ & 0.00 & 0.03 & $0.18^{*}$ & $0.06^{*}$ & $0 . \overline{19 *}$ & $0.05^{*}$ & $0.16^{*}$ & $\overline{0 .}-\overline{34} *$ & $0.31 *$ & $0.29 *$ & & \\
\hline $\operatorname{ELOSS}(14)$ & 0.00 & $-0.06 *$ & $0.04 *$ & -0.00 & $0.05^{-}$ & $-\overline{-}$ & $\overline{-}^{-}$ & $0.29 *$ & -0.01 & $\overline{-}-11^{*}$ & $0.24 *$ & $-\overline{-}$ & $-0.23 *$ & $\overline{-}-\overline{5} 1^{*}$ & \\
\hline$E L E V(15)$ & -0.01 & -0.01 & -0.01 & -0.03 & $\begin{array}{c}- \\
0.04 *\end{array}$ & $\begin{array}{c}- \\
0.07 *\end{array}$ & $\begin{array}{c}- \\
0.04 *\end{array}$ & $0.08 *$ & -0.02 & $\begin{array}{c}- \\
0.11 *\end{array}$ & $0.15^{*}$ & $0.15^{*}$ & $\stackrel{-}{0.2013 *}$ & $\begin{array}{c}- \\
0.19 *\end{array}$ & $\begin{array}{c}0.06 \\
*\end{array}$ \\
\hline
\end{tabular}


TABLE 3: continued

\begin{tabular}{|c|c|c|c|c|c|c|c|c|c|c|}
\hline & ENTRY & (1) & $(2)$ & $(3)$ & (4) & $(5)$ & $(6)$ & $(7)$ & $(8)$ & $(9)$ \\
\hline ORIGININCOME (1) & $0.04 *$ & & & & & & & & & \\
\hline DESTINCOME (2) & 0.02 & $0.16^{*}$ & & & & & & & & \\
\hline$H U B(3)$ & $0.06^{*}$ & $0.08 *$ & -0.02 & & & & & & & \\
\hline $\mathrm{HHI}(4)$ & $-0.03 *$ & $0.05^{*}$ & $0.08 *$ & $0.07 *$ & & & & & & \\
\hline DISTANCE (5) & $0.12 *$ & $0.06^{*}$ & $0.11^{*}$ & -0.03 & $0.13 *$ & & & & & \\
\hline DISTANCE2 (6) & $0.08 *$ & 0.03 & $0.10 *$ & $-0.06 *$ & $0.10^{*}$ & $0.95^{*}$ & & & & \\
\hline DENSITY (7) & 0.01 & $0.08 *$ & $0.09 *$ & $-0.18 *$ & $-0.14^{*}$ & $-0.14 *$ & $-0.11 *$ & & & \\
\hline DENSITY2 (8) & -0.00 & $0.05^{*}$ & $0.07 *$ & $-0.14 *$ & $-0.09 *$ & $-0.13 *$ & $-0.09 *$ & $0.89 *$ & & \\
\hline$M E A N P O P(9)$ & $0.06^{*}$ & $0.29 *$ & $0.18 *$ & $0.30 *$ & $0.08 *$ & 0.01 & -0.01 & $0.18 *$ & $0.10 *$ & \\
\hline MKSIZE (10) & $0.11 *$ & $0.14^{*}$ & $0.15^{*}$ & $-0.14^{*}$ & -0.02 & $0.41^{*}$ & $0.35^{*}$ & $0.61 *$ & $0.39 *$ & $0.20 *$ \\
\hline
\end{tabular}

*: Significant at the $5 \%$ or lower level. Variable definitions are provided in Table 1. 
TABLE 4: The Impact of Incumbents' AOCIFH (I_AOCIFH) and its Interaction with Disclosure on Entry: Probit Regressions Results

\begin{tabular}{|c|c|c|c|c|}
\hline & (1) & (2) & (3) & (4) \\
\hline & ENTRY & ENTRY & ENTRY & ENTRY \\
\hline \multirow[t]{2}{*}{ I_AOCIFH (-) } & $-7.747 * * *$ & $-8.874 * * *$ & $-9.040 * * *$ & $-8.294 * *$ \\
\hline & $(-3.93)$ & $(-4.35)$ & $(-3.74)$ & $(-2.15)$ \\
\hline \multirow[t]{2}{*}{ I_AOCIFH $\times I \_D I S C D(-)$} & & & & $-10.376^{* * *}$ \\
\hline & & & & $(-2.72)$ \\
\hline \multirow[t]{2}{*}{$I \_D I S C D$} & & & & 0.194 \\
\hline & & & & $(0.74)$ \\
\hline \multirow[t]{2}{*}{ I_SIZE } & & 0.054 & $0.071^{*}$ & 0.027 \\
\hline & & $(1.35)$ & $(1.84)$ & $(0.32)$ \\
\hline \multirow[t]{2}{*}{$I \_R O A$} & & $-0.204 * *$ & $-0.209 * *$ & 0.190 \\
\hline & & $(-2.30)$ & $(-2.09)$ & $(0.47)$ \\
\hline \multirow[t]{2}{*}{ I_FUELEXP } & & $-0.295^{*}$ & $-0.334 *$ & -0.349 \\
\hline & & $(1.67)$ & $(-1.89)$ & $(-1.09)$ \\
\hline \multirow[t]{2}{*}{$I_{-} C F O$} & & 1.077 & 0.817 & $3.620 * *$ \\
\hline & & $(1.35)$ & $(0.93)$ & $(2.36)$ \\
\hline \multirow[t]{2}{*}{$I \_L F$} & & 0.288 & 0.272 & 0.492 \\
\hline & & $(0.79)$ & $(0.72)$ & $(0.82)$ \\
\hline \multirow[t]{2}{*}{ I_LOSS } & & -0.127 & -0.162 & -0.141 \\
\hline & & $(-0.70)$ & $(1.01)$ & $(-0.55)$ \\
\hline \multirow[t]{2}{*}{$I \_L E V$} & & $1.142 * * *$ & $1.016 * * *$ & 0.937 \\
\hline & & $(3.42)$ & $(2.73)$ & $(0.96)$ \\
\hline \multirow[t]{2}{*}{$E \_A O C I 3$} & & & 4.923 & -15.554 \\
\hline & & & $(0.96)$ & $(-1.10)$ \\
\hline \multirow[t]{2}{*}{$E \_S I Z E$} & & & 0.041 & 0.184 \\
\hline & & & $(0.58)$ & (1.16) \\
\hline \multirow[t]{2}{*}{$E \_R O A$} & & & $0.455^{* *}$ & $0.894 * *$ \\
\hline & & & $(2.43)$ & $(2.41)$ \\
\hline \multirow[t]{2}{*}{$E \_F U E L E X P$} & & & $-0.610^{*}$ & -0.878 \\
\hline & & & $(-1.78)$ & $(-1.41)$ \\
\hline \multirow[t]{2}{*}{$E \_C F O$} & & & -2.159 & 2.087 \\
\hline & & & $(-1.64)$ & $(0.82)$ \\
\hline \multirow[t]{2}{*}{$E \_L O S S$} & & & $0.255^{*}$ & 0.064 \\
\hline & & & $(1.67)$ & $(0.22)$ \\
\hline \multirow[t]{2}{*}{$E \_L E V$} & & & 0.083 & -0.639 \\
\hline & & & $(0.30)$ & $(-0.94)$ \\
\hline \multirow[t]{2}{*}{ ORIGININCOME } & 0.000 & 0.000 & 0.000 & $0.000^{*}$ \\
\hline & $(0.50)$ & $(0.77)$ & $(0.98)$ & $(1.73)$ \\
\hline \multirow[t]{2}{*}{ DESTINCOME } & 0.000 & 0.000 & 0.000 & -0.000 \\
\hline & $(0.49)$ & (0.69) & $(0.75)$ & $(-0.04)$ \\
\hline$H U B$ & 0.080 & 0.041 & 0.045 & 0.174 \\
\hline
\end{tabular}




\begin{tabular}{lcccc} 
& $(0.62)$ & $(0.33)$ & $(0.36)$ & $(0.81)$ \\
HHI & $2.718^{* * *}$ & $2.703 * * *$ & $3.308^{* * *}$ & $4.155^{* * *}$ \\
DISTANCE & $(7.49)$ & $(7.06)$ & $(7.22)$ & $(6.91)$ \\
DISTANCE2 & 0.055 & $0.057 *$ & 0.054 & 0.098 \\
DENSITY & $(1.62)$ & $(1.83)$ & $(1.63)$ & $(1.58)$ \\
& $-0.002^{*}$ & $-0.002^{* *}$ & $-0.002^{*}$ & -0.003 \\
DENSITY2 & $(-1.72)$ & $(-2.18)$ & $(-1.73)$ & $(-1.52)$ \\
& -0.008 & -0.008 & -0.007 & -0.007 \\
MEANPOP & $(-1.03)$ & $(-0.98)$ & $(-0.85)$ & $(-0.45)$ \\
MKTSIZE & 0.000 & 0.000 & 0.000 & 0.000 \\
Constant & $(0.64)$ & $(0.60)$ & $(0.52)$ & $(0.34)$ \\
YEAR FE & $0.148 * *$ & $0.146 * *$ & $0.156 * * *$ & $0.226 *$ \\
Observations & $(2.35)$ & $(2.49)$ & $(3.05)$ & $(1.85)$ \\
Pseudo $R^{2}$ & 0.027 & 0.021 & 0.012 & -0.080 \\
\hline
\end{tabular}

Columns 1-3 are based on the regression in model (1), and column 4 is based on the regression in model (2). The dependent variable is $E N T R Y$ in all the four columns. ENTRY=1 if the potential entrant enters the route in the year following, and zero otherwise. I_AOCIFH is the incumbents' accumulated other comprehensive income from fuel hedge for the year. If there are more than one incumbent for the route, I_AOCIFH is the weighted average of AOCIFH for each of the incumbent for the route. I_DISC measures the disclosure level for all the incumbents from the route by weighting average each incumbent's disclosure score. $I_{-} D I S C D$ is an indicator variable equal to 1 if the weighted average disclosure score for the route is above the sample median, and zero otherwise. All other incumbent-variables are the weighted average of each individual incumbent's value. Z-statistics with errors clustered by year and route are presented in parentheses. * Significant at 10\%; ** significant at 5\%; *** significant at $1 \%$. All tests are two-tailed tests. Variable definitions are provided in Table 1. 


\begin{tabular}{|c|c|}
\hline & I_DISC \\
\hline \multirow[t]{2}{*}{2002} & -0.0100 \\
\hline & $(-0.29)$ \\
\hline \multirow[t]{2}{*}{2003} & -0.0556 \\
\hline & $(-1.64)$ \\
\hline \multirow[t]{2}{*}{2004} & -0.0240 \\
\hline & $(-0.74)$ \\
\hline \multirow[t]{2}{*}{2005} & $0.0634 *$ \\
\hline & $(1.89)$ \\
\hline \multirow[t]{2}{*}{2006} & -0.0372 \\
\hline & $(-1.11)$ \\
\hline \multirow[t]{2}{*}{2007} & 0.0038 \\
\hline & $(0.11)$ \\
\hline \multirow[t]{2}{*}{2008} & $0.1417 * * *$ \\
\hline & $(4.04)$ \\
\hline \multirow[t]{2}{*}{2009} & $0.1867 * * *$ \\
\hline & $(5.98)$ \\
\hline \multirow[t]{2}{*}{2010} & $0.2972 * * *$ \\
\hline & $(5.75)$ \\
\hline \multirow[t]{2}{*}{ Constant } & $0.1920 * * *$ \\
\hline & (7.16) \\
\hline Observations & 2,829 \\
\hline Adjusted $R^{2}$ & 0.063 \\
\hline
\end{tabular}

The table regresses the disclosure score on year indicator variables. I_DISC is the dependent variable, measuring the incumbents' risk management disclosure level. Value of $\mathrm{t}$ statistics in parentheses. Year 2001 is the reference group.* Significant at 10\%; ** significant at 5\%; *** significant at $1 \%$. All tests are two-tailed tests. 
TABLE 6: The Impact of Incumbents' AOCIFH (I_AOCIFH) on Entry: Pre- and PostSFAS 161 comparisons: Probit Regressions Results

(1)

ENTRY, PRE SFAS161

I_AOCIFH(-)

I_SIZE

I_ROA

I_FUELEXP

I_CFO

I_LF

I_LOSS

I_LEV

E_AOCI

E_SIZE

E_ROA

E_FUELEXP

E_CFO

E_LOSS

E_LEV

ORIGININCOME

DESTINCOME

$H U B$

HHI

DISTANCE
(2)

ENTRY, POST SFAS 161

$-15.302 * * *$

(-2.92)

0.261 *

(1.69)

1.052

(1.14)

$-0.841$

$(-1.38)$

6.086**

(2.51)

1.753

(1.36)

0.699

(0.84)

0.740

(0.56)

3.661

(0.70)

0.197

(1.45)

$2.278 * *$

(2.08)

$-0.919 * * *$

$(-4.17)$

$-1.007$

$(-0.19)$

$-0.134$

(-0.54)

4.753***

(2.72)

$-0.000$

$(-0.90)$

0.000

(1.53)

$-0.764 * *$

(-2.26)

4.299***

(10.37)

0.134 
MKTSIZE

YES

p-value: $\mid \boldsymbol{I} \_$AOCIFH $\mid($pre-161 < post-161)

0.028

Observations

Pseudo $R^{2}$

This table presents the results based on the regression in model (1). The dependent variable is ENTRY in both columns. Column 1 presents results using the pre-SFAS 161 sample and column 2 presents results for the post-SFAS 161 sample. ENTRY=1 if the potential entrant enters the route in the year following, and zero otherwise. The test comparing the magnitude of coefficients on I_AOCIFH for the pre- and postSFAS 161 periods are based on a fully interactive regression. Z-statistics clustered by year and route are presented in parentheses. * Significant at 10\%; ** significant at 5\%; *** significant at $1 \%$. All tests are two-tailed tests. Variable definitions are provided in Table 1. 
TABLE 7: The Effects of Individual Disclosure Items on Entry: Probit Regressions Results

\begin{tabular}{|c|c|c|c|}
\hline & $\begin{array}{c}(1) \\
\text { ENTRY }\end{array}$ & $\begin{array}{c}(2) \\
\text { ENTRY }\end{array}$ & $\begin{array}{c}(3) \\
\text { ENTRY }\end{array}$ \\
\hline \multirow[t]{2}{*}{ I_AOCIFH } & 9.727 & 7.140 & 32.616 \\
\hline & (1.54) & $(0.29)$ & $(1.62)$ \\
\hline \multirow[t]{2}{*}{ I_RECLASSR } & -0.048 & -0.049 & -0.011 \\
\hline & $(-1.20)$ & $(-1.28)$ & $(-0.15)$ \\
\hline \multirow[t]{2}{*}{ INT_RECLASS } & $-3.162 * * *$ & $-3.980 * *$ & $-5.551 * *$ \\
\hline & $(-2.65)$ & $(-2.12)$ & $(-1.98)$ \\
\hline \multirow[t]{2}{*}{ I_OTHER } & & 0.068 & 0.058 \\
\hline & & $(1.20)$ & (1.12) \\
\hline \multirow[t]{2}{*}{ INT_OTHER } & & 0.824 & 0.745 \\
\hline & & $(0.31)$ & $(0.45)$ \\
\hline \multirow[t]{2}{*}{ I_OCI } & & & 0.054 \\
\hline & & & $(1.00)$ \\
\hline \multirow[t]{2}{*}{$I N T \_O C I$} & & & 2.788 \\
\hline & & & (1.32) \\
\hline \multirow[t]{2}{*}{ I_INEFF } & & & -0.013 \\
\hline & & & $(-0.44)$ \\
\hline \multirow[t]{2}{*}{$I N T \_I N E F F$} & & & 0.272 \\
\hline & & & $(0.10)$ \\
\hline \multirow[t]{2}{*}{ I_TYPE } & & & $-0.094 *$ \\
\hline & & & $(-1.91)$ \\
\hline \multirow[t]{2}{*}{ INT_TYPE } & & & $-7.640 * *$ \\
\hline & & & $(-1.97)$ \\
\hline \multirow[t]{2}{*}{ I_FCPRICE } & & & 0.027 \\
\hline & & & $(0.69)$ \\
\hline \multirow[t]{2}{*}{ INT_FCPRICE } & & & -0.801 \\
\hline & & & $(-0.39)$ \\
\hline \multirow[t]{2}{*}{ I_CREDIT } & & & -0.037 \\
\hline & & & $(-1.46)$ \\
\hline \multirow[t]{2}{*}{ INT_CREDIT } & & & 3.525 \\
\hline & & & $(1.25)$ \\
\hline \multirow[t]{2}{*}{ I_REALIZE } & & & -0.010 \\
\hline & & & $(-0.25)$ \\
\hline \multirow[t]{2}{*}{$I N T \_R E A L I Z E$} & & & -1.302 \\
\hline & & & $(-1.07)$ \\
\hline \multirow[t]{2}{*}{ I_CURRENT } & & & 0.053 \\
\hline & & & $(1.54)$ \\
\hline \multirow[t]{2}{*}{ INT_CURRENT } & & & $-3.309 * *$ \\
\hline & & & $(-2.07)$ \\
\hline \multirow[t]{2}{*}{ I_FVDISCLOSURE } & & & 0.002 \\
\hline & & & $(0.05)$ \\
\hline
\end{tabular}




\begin{tabular}{|c|c|c|c|}
\hline & & & $(-0.93)$ \\
\hline \multirow[t]{2}{*}{ I_SIZE } & 0.099 & 0.029 & 0.051 \\
\hline & $(1.52)$ & $(0.38)$ & $(1.15)$ \\
\hline \multirow[t]{2}{*}{ I_ROA } & $-0.632 *$ & $-0.655^{*}$ & -0.352 \\
\hline & $(-1.66)$ & $(-1.75)$ & $(-0.73)$ \\
\hline \multirow[t]{2}{*}{ I_FUELEXP } & $-0.417 * *$ & $-0.317 *$ & -0.325 \\
\hline & $(-2.19)$ & $(-1.72)$ & $(-1.64)$ \\
\hline \multirow[t]{2}{*}{ I_CFO } & 1.066 & 0.943 & 1.153 \\
\hline & $(1.35)$ & (1.17) & $(1.15)$ \\
\hline \multirow[t]{2}{*}{$I \_L F$} & 0.193 & 0.388 & 0.051 \\
\hline & $(0.22)$ & $(0.42)$ & $(0.08)$ \\
\hline \multirow[t]{2}{*}{ I_LOSS } & -0.314 & -0.254 & -0.021 \\
\hline & $(-1.21)$ & $(-1.03)$ & $(-0.10)$ \\
\hline \multirow[t]{2}{*}{$I \_L E V$} & $1.424 * * *$ & $1.369 * * *$ & 1.096 \\
\hline & $(3.08)$ & $(2.80)$ & $(1.26)$ \\
\hline \multirow[t]{2}{*}{$E \_A O C I$} & 5.523 & 3.030 & -1.001 \\
\hline & $(1.32)$ & $(0.81)$ & $(-0.17)$ \\
\hline \multirow[t]{2}{*}{$E \_S I Z E$} & $0.099 *$ & $0.115 *$ & 0.016 \\
\hline & $(1.71)$ & $(1.66)$ & $(0.17)$ \\
\hline \multirow[t]{2}{*}{$E \_R O A$} & $0.174 *$ & 0.205 & $0.471 *$ \\
\hline & $(1.89)$ & $(0.78)$ & (1.68) \\
\hline \multirow[t]{2}{*}{$E \_F U E L E X P$} & -0.386 & -0.344 & $-0.967 * * *$ \\
\hline & $(-1.37)$ & $(-1.58)$ & $(-3.57)$ \\
\hline \multirow[t]{2}{*}{$E \_C F O$} & $-4.137 * * *$ & $-3.432 * * *$ & -1.223 \\
\hline & $(-2.98)$ & $(-2.61)$ & $(-0.63)$ \\
\hline \multirow[t]{2}{*}{$E \_L O S S$} & 0.150 & 0.153 & $0.308 *$ \\
\hline & $(0.80)$ & $(0.68)$ & $(1.72)$ \\
\hline \multirow[t]{2}{*}{$E \_L E V$} & $0.956 * * *$ & $1.249 * * *$ & 0.132 \\
\hline & $(3.37)$ & $(4.57)$ & $(0.28)$ \\
\hline \multirow[t]{2}{*}{ ORIGININCOME } & 0.000 & 0.000 & 0.000 \\
\hline & $(1.28)$ & $(0.87)$ & $(0.67)$ \\
\hline \multirow[t]{2}{*}{ DESTINCOME } & 0.000 & 0.000 & 0.000 \\
\hline & $(1.23)$ & $(0.75)$ & $(0.49)$ \\
\hline \multirow[t]{2}{*}{$H U B$} & -0.037 & -0.126 & -0.082 \\
\hline & $(-0.23)$ & $(-0.83)$ & $(-0.47)$ \\
\hline \multirow[t]{2}{*}{$H H I$} & $4.075 * * *$ & $4.029 * * *$ & $3.124 * * *$ \\
\hline & $(7.29)$ & (6.29) & $(5.11)$ \\
\hline \multirow[t]{2}{*}{ DISTANCE } & -0.102 & -0.114 & 0.075 \\
\hline & $(-1.46)$ & $(-1.46)$ & $(1.20)$ \\
\hline \multirow[t]{2}{*}{ DISTANCE2 } & 0.001 & 0.001 & -0.003 \\
\hline & $(0.59)$ & $(0.54)$ & $(-1.48)$ \\
\hline DENSITY & $-0.032 *$ & $-0.034 * *$ & -0.004 \\
\hline
\end{tabular}




\section{DENSITY2}

MEANPOP

MKTSIZE

Constant

YEAR FE

Observations

Pseudo $R^{2}$
(-1.94)

0.000

(1.24)

0.168

(1.59)

$0.739 * * *$

(2.87)

$-15.902 * * *$

$(-3.54)$

YES

2,817

$17.11 \%$
$(-2.32)$

0.000

(1.34)

0.135

(1.26)

$0.838 * * *$

(3.84)

$-17.632 * * *$

(-4.97)

YES

2,817

$17.31 \%$
(-0.33)

0.000

(0.10)

$0.132 * *$

0.028

(0.20)

$-6.909$

(-1.56)

YES

1,857

$20.00 \%$

This table shows results on how different individual disclosure items enhance the informativeness of accounting signals differently. The dependent variable is ENTRY in all the three columns. In column 1, the disclosure variable is $I_{-} R E C L A S S$, indicating whether the incumbents disclose their estimated reclassification of AOCI into net income in the next year. In column 2, I_OTHER, the variable for all other disclosure items aggregated, is added to the regression. Column 3 presents results when more individual disclosure items are added. $E N T R Y=1$ if the potential entrant enters the route in the year following, and zero otherwise. The prefix "INT_" indicates the interaction term between I_AOCIFH and disclosure scores. Z-statistics clustered by year and route are presented in parentheses. ${ }^{*}$ Significant at $10 \%$; ** significant at 5\%; *** significant at $1 \%$. All tests are two-tailed tests. Variable definitions are provided in Table 1. 
TABLE 8: 2SLS for Disclosure, Using $I \_F R$ as the Instrument Variable

\begin{tabular}{|c|c|c|}
\hline & $\begin{array}{l}\text { FIRST STAGE } \\
\text { ISCORED }\end{array}$ & $\begin{array}{c}\text { SECOND STAGE } \\
\text { ENTRY }\end{array}$ \\
\hline$I \_F R(+)$ & $\begin{array}{c}1.834 * * * \\
(6.06)\end{array}$ & \\
\hline I_AOCI (-) & & $\begin{array}{c}-6.455^{* *} \\
(-1.99)\end{array}$ \\
\hline I_AOCI $\times I \_D I S C D P R E(-)$ & & $\begin{array}{c}-10.767 * * * \\
(-3.31)\end{array}$ \\
\hline I_SCOREDPRE & & $\begin{array}{l}-0.150 \\
(-0.43)\end{array}$ \\
\hline I_SIZE & $\begin{array}{c}0.435 * * * \\
(12.17)\end{array}$ & $\begin{array}{l}0.057 \\
(0.60)\end{array}$ \\
\hline$I \_R O A$ & $\begin{array}{c}-0.236 * * * \\
(-5.45)\end{array}$ & $\begin{array}{l}0.047 \\
(0.09)\end{array}$ \\
\hline I_FUELEXP & $\begin{array}{c}0.281 * * \\
(2.01)\end{array}$ & $\begin{array}{l}-0.364 \\
(-0.97)\end{array}$ \\
\hline I_CFO & $\begin{array}{c}3.147 * * * \\
(6.95)\end{array}$ & $\begin{array}{l}3.610 * \\
(1.84)\end{array}$ \\
\hline$I \_L F$ & $\begin{array}{l}0.432 \\
(1.52)\end{array}$ & $\begin{array}{l}0.783 \\
(1.35)\end{array}$ \\
\hline I_LOSS & $\begin{array}{c}0.917 * * * \\
(11.38)\end{array}$ & $\begin{array}{l}-0.284 \\
(0.83)\end{array}$ \\
\hline I_LEV & $\begin{array}{c}-1.183 * * * \\
(-5.78)\end{array}$ & $\begin{array}{l}1.156 \\
(1.12)\end{array}$ \\
\hline$E \_A O C I$ & $\begin{array}{l}-0.804 \\
(-0.27)\end{array}$ & $\begin{array}{l}-16.648 \\
(-1.20)\end{array}$ \\
\hline E_SIZE & $\begin{array}{c}0.064 * * \\
(1.99)\end{array}$ & $\begin{array}{l}0.255 \\
(1.30)\end{array}$ \\
\hline$E \_R O A$ & $\begin{array}{l}-0.101 \\
(1.62)\end{array}$ & $\begin{array}{c}1.134 * \\
(1.83)\end{array}$ \\
\hline E_FUELEXP & $\begin{array}{l}0.058 \\
(0.44)\end{array}$ & $\begin{array}{c}-1.232 * * * \\
(-3.31)\end{array}$ \\
\hline$E_{-} C F O$ & $\begin{array}{l}-0.662 \\
(1.06)\end{array}$ & $\begin{array}{l}3.503 \\
(1.25)\end{array}$ \\
\hline$E \_L O S S$ & $\begin{array}{c}-0.319 * * * \\
(-4.19)\end{array}$ & $\begin{array}{l}0.018 \\
(0.04)\end{array}$ \\
\hline$E \_L E V$ & $\begin{array}{c}0.689 * * * \\
(2.92)\end{array}$ & $\begin{array}{l}-0.796 * \\
(-1.68)\end{array}$ \\
\hline ORIGININCOME & $\begin{array}{c}0.000 * * * \\
(6.65)\end{array}$ & $\begin{array}{c}0.000 * * \\
(2.13)\end{array}$ \\
\hline DESTINCOME & $\begin{array}{c}0.000 * * * \\
(5.43)\end{array}$ & $\begin{array}{l}-0.000 \\
(-0.27)\end{array}$ \\
\hline
\end{tabular}


HHI

0.399

$4.459 * * *$

DISTANCE

(1.63)

(7.15)

$-0.034$

0.060

$(-1.40)$

(0.84)

DISTANCE2

0.001

$-0.002$

(1.06)

$(-0.72)$

DENSITY

$-0.013 * * *$

$-0.014$

$(-2.97)$

$(-0.76)$

DENSITY2

$0.000 * * *$

0.000

MEANPOP

(2.72)

(0.54)

$-0.044$

0.247

$(-0.96)$

(1.59)

MKTSIZE

$-0.024$

$-0.052$

$(-0.48)$

(-0.38)

CONSTANT

$-6.877 * * *$

$-10.289$

(-7.89)

(-1.12)

YEAR FE

YES

YES

Observations

2,817

2,817

Pseudo $R^{2}$

$26.67 \%$

$17.88 \%$

Z-statistics clustered by year and route are presented in parentheses. ${ }^{*}$ Significant at $10 \%$; ** significant at 5\%; *** significant at 1\%. All tests are two-tailed tests. Variable definitions are provided in Table 1. 
TABLE 9: Change in Ticket Fares before and after Entry, for Entry and Matched no Entry Routes

\begin{tabular}{|c|c|}
\hline & MEAN TICKET FARE \\
\hline ENTRY (Before-After) & 1.661 \\
\hline NOENTRY (Before-After) & 0.015 \\
\hline DIFF (Entry-Noentry) & $1.646 * * *$ \\
\hline \multirow[t]{2}{*}{$p$-value } & 0.005 \\
\hline & MEDIAN TICKET FARE \\
\hline ENTRY (Before-After) & -0.769 \\
\hline NOENTRY (Before-After) & -1.987 \\
\hline DIFF (Entry-Noentry) & $1.218 * *$ \\
\hline \multirow[t]{2}{*}{ p-value } & 0.046 \\
\hline & $\begin{array}{l}\text { STANDARD DEVIATION OF TICKET } \\
\text { FARE }\end{array}$ \\
\hline ENTRY (Before-After) & 5.536 \\
\hline NOENTRY (Before-After) & 3.589 \\
\hline DIFF (Entry-Noentry) & $1.947 * * *$ \\
\hline p-value & $<0.001$ \\
\hline
\end{tabular}


TABLE 10: Entrant-Incumbent-Year Level Analyses: Dependent Variable $=\%$ of Entered Market Share

\begin{tabular}{|c|c|c|c|c|c|c|}
\hline & \multicolumn{2}{|c|}{$\%$ of Routes Entered } & \multicolumn{2}{|c|}{$\%$ of RSM Entered } & \multicolumn{2}{|c|}{$\%$ of RSM run by the incumbent Entered } \\
\hline & Coef. & t-stat & Coef. & t-stat & Coef. & t-stat \\
\hline I_AOCIFH & $-0.161 * *$ & -2.12 & $-0.078 * *$ & 2.13 & $-0.026^{*}$ & -1.94 \\
\hline I_SIZE & -0.008 & -1.08 & -0.007 & -0.76 & -0.011 & -1.17 \\
\hline$I \_R O A$ & -0.003 & -0.07 & -0.006 & -0.11 & 0.074 & 1.25 \\
\hline I_LEV & 0.030 & 0.51 & 0.090 & 1.29 & 0.024 & 0.32 \\
\hline I_CFO & 0.114 & 0.91 & 0.043 & 0.29 & -0.051 & -0.32 \\
\hline I_LOSS & 0.011 & 0.47 & -0.008 & -0.26 & 0.019 & 0.64 \\
\hline E_AOCIFH & 1.115 & 1.62 & $1.343^{*}$ & 1.66 & $1.643 *$ & 1.92 \\
\hline E_SIZE & $0.015 * *$ & 2.06 & $0.018 * *$ & 2.04 & $0.022 * * *$ & 2.44 \\
\hline$E \_R O A$ & $0.251 * *$ & 2.00 & $0.285^{*}$ & 1.92 & $0.313 * *$ & 1.99 \\
\hline$E \_L E V$ & -0.064 & -0.92 & -0.054 & -0.66 & -0.109 & -1.25 \\
\hline$E \_C F O$ & 0.000 & -1.12 & 0.000 & -0.8 & -0.001 & -1.41 \\
\hline$E \_L O S S$ & $-0.051 * *$ & -2.09 & $-0.067 * *$ & -2.33 & $-0.066^{* *}$ & -2.2 \\
\hline$Y E A R F E$ & YES & & YES & & YES & \\
\hline$N$ & 665 & & 665 & & 665 & \\
\hline Adjusted $R^{2}$ & $3.17 \%$ & & $1.02 \%$ & & $4.27 \%$ & \\
\hline
\end{tabular}


TABLE 11: Using Alternative Variable of Interest Measure: $I \_A O C I F H \_A S I F$

\begin{tabular}{|c|c|c|}
\hline & (1) & $(2)$ \\
\hline & ENTRY & ENTRY \\
\hline \multirow[t]{2}{*}{ I_AOCIFH_ASIF (-) } & $-13.456^{* *}$ & 0.844 \\
\hline & $(-2.04)$ & $(0.10)$ \\
\hline \multirow[t]{2}{*}{$I \_A O C I F H \_A S I F \times I \_D I S C D(-)$} & & $-16.946^{*}$ \\
\hline & & $(-1.79)$ \\
\hline \multirow[t]{2}{*}{$I \_D I S C D$} & & 0.172 \\
\hline & & $(0.61)$ \\
\hline \multirow[t]{2}{*}{ I_SIZE } & 0.041 & 0.042 \\
\hline & $(0.44)$ & $(0.41)$ \\
\hline \multirow[t]{2}{*}{$I \_R O A$} & 0.098 & 0.135 \\
\hline & $(0.26)$ & $(0.36)$ \\
\hline \multirow[t]{2}{*}{$I \_F U E L E X P$} & -0.319 & -0.371 \\
\hline & $(-0.88)$ & $(-1.01)$ \\
\hline \multirow[t]{2}{*}{ I_CFO } & 2.677 & 2.845 \\
\hline & $(1.26)$ & $(1.35)$ \\
\hline \multirow[t]{2}{*}{$I \_L F$} & 0.613 & 0.502 \\
\hline & (1.13) & $(0.85)$ \\
\hline \multirow[t]{2}{*}{ I_LOSS } & -0.196 & -0.238 \\
\hline & $(-0.76)$ & $(-0.91)$ \\
\hline \multirow[t]{2}{*}{$I \_L E V$} & 0.836 & 0.999 \\
\hline & $(0.82)$ & $(0.96)$ \\
\hline \multirow[t]{2}{*}{$E \_A O C I 3$} & -15.049 & -14.514 \\
\hline & $(-1.09)$ & $(-1.08)$ \\
\hline \multirow[t]{2}{*}{$E \_S I Z E$} & 0.176 & 0.179 \\
\hline & $(1.17)$ & (1.13) \\
\hline \multirow[t]{2}{*}{$E \_R O A$} & $0.909 * *$ & $0.879 * *$ \\
\hline & $(2.30)$ & $(2.19)$ \\
\hline \multirow[t]{2}{*}{$E \_F U E L E X P$} & -0.83 & -0.855 \\
\hline & $(-1.24)$ & $(-1.34)$ \\
\hline \multirow[t]{2}{*}{$E_{-} C F O$} & 2.354 & 2.170 \\
\hline & $(0.97)$ & $(0.87)$ \\
\hline \multirow[t]{2}{*}{$E \_L O S S$} & 0.095 & 0.077 \\
\hline & $(0.33)$ & $(0.26)$ \\
\hline \multirow[t]{2}{*}{$E \_L E V$} & -0.624 & -0.665 \\
\hline & $(-1.00)$ & $(-1.02)$ \\
\hline \multirow[t]{2}{*}{ ORIGININCOME } & $0.000 *$ & $0.000 *$ \\
\hline & $(1.87)$ & (1.87) \\
\hline \multirow[t]{2}{*}{ DESTINCOME } & 0.000 & 0.000 \\
\hline & $(0.04)$ & $(0.07)$ \\
\hline \multirow[t]{2}{*}{$H U B$} & 0.144 & 0.161 \\
\hline & $(0.68)$ & $(0.73)$ \\
\hline
\end{tabular}


DENSITY2

Columns lis based on the regression in model (1), and column 2 is based on the regression in model (2). The dependent variable is ENTRY in all the four columns. ENTRY=1 if the potential entrant enters the route in the year following, and zero otherwise. I_AOCIFH_ASIF is the incumbents' accumulated other comprehensive income from fuel hedge for the year plus total value of net income from non-designated fuel hedges. If there are more than one incumbent for the route, I_AOCIFH_ASIF is the weighted average of AOCIFH for each of the incumbent for the route. I_DISC measures the disclosure level for all the incumbents from the route by weighting average each incumbent's disclosure score. I_DISCD is an indicator variable equal to 1 if the weighted average disclosure score for the route is above the sample median, and zero otherwise. All other incumbent-variables are the weighted average of each individual incumbent's value. Z-statistics with errors clustered by year and route are presented in parentheses. * Significant at $10 \%$; ** significant at 5\%; *** significant at $1 \%$. All tests are two-tailed tests. Variable definitions are provided in Table 1. 
TABLE 12: The Impact of Incumbents' AOCIFH (I_AOCIFH) on Entry: Partition by the Sign of $I \_A O C I F H$ and by the Direction of Fuel Price Change

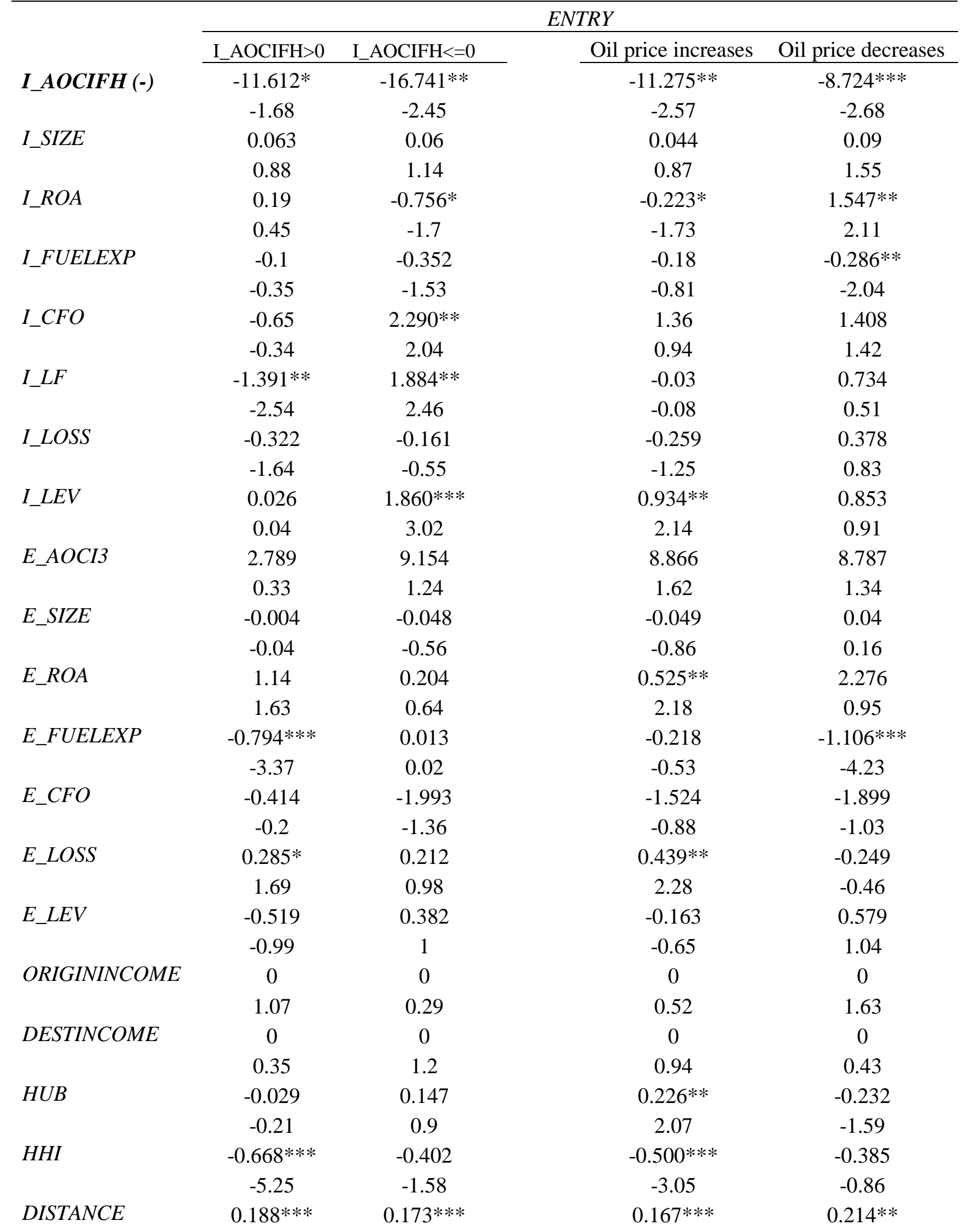




\begin{tabular}{lcccc} 
& 2.89 & 3.41 & 4.56 & 2.2 \\
DISTANCE2 & $-0.006^{* * *}$ & $-0.005^{* * *}$ & $-0.005^{* * *}$ & $-0.007 * *$ \\
DENSITY & -2.7 & -3.59 & -4.57 & -2.26 \\
& 0.000 & 0.000 & 0.000 & 0.000 \\
DENSITY2 & 0.61 & 0.48 & 0.43 & 0.81 \\
& 0.000 & 0.000 & 0.000 & 0.000 \\
MEANPOP & 0.52 & 0.91 & 0.08 & 0.61 \\
& $0.176^{* *}$ & 0.084 & $0.131^{*}$ & 0.01 \\
MKTSIZE & 2.02 & 0.85 & 1.85 & 0.08 \\
& 0.059 & 0.075 & 0.13 & -0.047 \\
Constant & 0.54 & 0.61 & 1.01 & -0.25 \\
& -6.674 & $-6.019 * *$ & $-5.339 * * *$ & -1.766 \\
YEAR FE & -1.12 & -2.24 & -3.47 & -0.68 \\
Observations & YES & YES & YES & YES \\
Pseudo $R^{2}$ & 1,204 & 1,613 & & 820 \\
\hline Thistable & $13.54 \%$ & $18.24 \%$ & 1,997 & $13.75 \%$
\end{tabular}

This table presents the results based on the regression in model (1). The dependent variable is ENTRY for all four columns. Column 1 presents results using the positive $I \_A O C I F H$ sample and column 2 presents results for the non-positive $I \_A O C I F H$ sample. Column 3 focuses on years when oil price increases and Column 4 on years when oil price decreases. $E N T R Y=1$ if the potential entrant enters the route in the year following, and zero otherwise. Z-statistics clustered by year and route are presented in parentheses. * Significant at 10\%; ** significant at 5\%; *** significant at $1 \%$. All tests are two-tailed tests. Variable definitions are provided in Table 1. 
TABLE 13: The Impact of Incumbents' AOCIFH $\left(I_{-} A O C I F H\right)$ and its Interaction with Disclosure on Entry: Probit Regressions Using One-airport Present Carriers as Entrants

\begin{tabular}{|c|c|c|c|c|}
\hline & (1) & $(2)$ & (3) & (4) \\
\hline & ENTRY & ENTRY & ENTRY & ENTRY \\
\hline \multirow[t]{2}{*}{ I_AOCIFH (-) } & $-8.925 * * *$ & $-11.563 * * *$ & $-11.168 * * *$ & -1.679 \\
\hline & $(-3.21)$ & $(-3.63)$ & $(-3.25)$ & $(-0.19)$ \\
\hline I_AOCIFH $\times I \_D I S C D(-)$ & & & & $\begin{array}{c}-17.863 * * * * \\
(-2.96)\end{array}$ \\
\hline I_DISCD & & & & $\begin{array}{c}0.49 \\
(1.18)\end{array}$ \\
\hline I_SIZE & & $\begin{array}{l}-0.008 \\
(-0.14)\end{array}$ & $\begin{array}{l}0.004 \\
(0.06)\end{array}$ & $\begin{array}{c}-0.08 \\
(-0.76)\end{array}$ \\
\hline$I \_R O A$ & & $\begin{array}{l}-0.262 \\
(-0.7)\end{array}$ & $\begin{array}{l}-0.314 \\
(-0.73)\end{array}$ & $\begin{array}{l}-0.063 \\
(-0.10)\end{array}$ \\
\hline I_FUELEXP & & $\begin{array}{c}-0.06 \\
(-0.36)\end{array}$ & $\begin{array}{l}-0.067 \\
(-0.43)\end{array}$ & $\begin{array}{l}0.229 \\
(0.84)\end{array}$ \\
\hline$I_{-} C F O$ & & $\begin{array}{c}1.652 * * \\
(2.22)\end{array}$ & $\begin{array}{c}1.520^{* *} \\
(2.14)\end{array}$ & $\begin{array}{l}2.017 \\
(0.96)\end{array}$ \\
\hline$I \_L F$ & & $\begin{array}{l}0.281 \\
(1.14)\end{array}$ & $\begin{array}{l}0.274 \\
(1.09)\end{array}$ & $\begin{array}{c}0.62 \\
(0.80)\end{array}$ \\
\hline I_LOSS & & $\begin{array}{l}0.139 \\
(1.12)\end{array}$ & $\begin{array}{l}0.087 \\
(0.60)\end{array}$ & $\begin{array}{l}-0.311 \\
(-1.01)\end{array}$ \\
\hline$I \_L E V$ & & $\begin{array}{l}0.238 \\
(0.68)\end{array}$ & $\begin{array}{l}0.093 \\
(0.23)\end{array}$ & $\begin{array}{l}-1.306 \\
(-1.26)\end{array}$ \\
\hline$E \_A O C I 3$ & & & $\begin{array}{l}4.072 \\
(0.73)\end{array}$ & $\begin{array}{l}-2.591 \\
(-0.32)\end{array}$ \\
\hline E_SIZE & & & $\begin{array}{l}0.055 \\
(0.95)\end{array}$ & $\begin{array}{l}-0.164 \\
(-0.78)\end{array}$ \\
\hline$E \_R O A$ & & & $\begin{array}{l}0.195 \\
(0.33)\end{array}$ & $\begin{array}{l}0.386 \\
(0.41)\end{array}$ \\
\hline E_FUELEXP & & & $\begin{array}{l}0.128 \\
(0.44)\end{array}$ & $\begin{array}{l}-0.404 \\
(-0.49)\end{array}$ \\
\hline$E_{-} C F O$ & & & $\begin{array}{c}-3.000 * * * \\
(-3.35)\end{array}$ & $\begin{array}{c}-3.495 * * * \\
-2.74\end{array}$ \\
\hline E_LOSS & & & $\begin{array}{l}-0.117 \\
(-0.72)\end{array}$ & $\begin{array}{c}-0.148 \\
-0.55\end{array}$ \\
\hline$E \_L E V$ & & & $\begin{array}{c}-0.906 * * * \\
(-3.22)\end{array}$ & $\begin{array}{c}-1.819^{* * *} \\
-4.19\end{array}$ \\
\hline ORIGININCOME & $\begin{array}{c}0.000 \\
0.71\end{array}$ & $\begin{array}{c}0.000 \\
0.71\end{array}$ & $\begin{array}{l}0.000 \\
(0.67)\end{array}$ & $\begin{array}{c}0.000 \\
0.28\end{array}$ \\
\hline
\end{tabular}




\begin{tabular}{lcccc} 
DESTINCOME & 0.000 & 0.000 & 0.000 & $0.000^{* *}$ \\
HUB & 1.07 & 1.34 & 1.32 & 2.25 \\
& 0.054 & 0.04 & 0.044 & 0.261 \\
HHI & 0.58 & 0.43 & 0.51 & 0.99 \\
DISTANCE & $2.828^{* * *}$ & $2.848^{* * *}$ & $3.149^{* * *}$ & $4.159^{* * *}$ \\
& 7.09 & 6.66 & 7.19 & 4.35 \\
DISTANCE2 & $0.001^{* *}$ & $0.001^{* * *}$ & $0.001^{* *}$ & $0.002^{*}$ \\
& 2.29 & 2.6 & 2.51 & 1.81 \\
DENSITY & $-0.000^{* * *}$ & $-0.000^{* * *}$ & $-0.000^{* * *}$ & $-0.000^{* * *}$ \\
& -3.13 & -3.28 & -3.24 & -2.2 \\
DENSITY2 & 0.000 & 0.000 & 0.000 & 0.000 \\
& 1.48 & 1.46 & 1.48 & 0.54 \\
MEANPOP & 0.000 & 0.000 & 0.000 & 0.000 \\
& 0.00 & 0.00 & 0.00 & 0.00 \\
MKTSIZE & -0.041 & -0.03 & -0.022 & 0.125 \\
& -0.77 & -0.55 & -0.39 & -0.67 \\
YEAR FE & -0.073 & -0.079 & -0.08 & -0.138 \\
& -1.14 & -1.15 & -1.26 & -1.26 \\
Observations & YES & YES & YES & YES \\
Pseudo $R^{2}$ & & & & \\
\hline
\end{tabular}

In this table I define potential entrants as airlines that are present in at least one of the airports and this results an expanded sample with 4,021 route-entrant-year level observations. Columns 1-3 are based on the regression in model (1), and column 4 is based on the regression in model (2). The dependent variable is $E N T R Y$ in all the four columns. ENTRY=1 if the potential entrant enters the route in the year following, and zero otherwise. I_AOCIFH is the incumbents' accumulated other comprehensive income from fuel hedge for the year. If there are more than one incumbent for the route, I_AOCIFH is the weighted average of AOCIFH for each of the incumbent for the route. I_DISC measures the disclosure level for all the incumbents from the route by weighting average each incumbent's disclosure score. $I \_D I S C D$ is an indicator variable equal to 1 if the weighted average disclosure score for the route is above the sample median, and zero otherwise. All other incumbent-variables are the weighted average of each individual incumbent's value. Z-statistics with errors clustered by year and route are presented in parentheses. * Significant at $10 \%$; ** significant at 5\%; *** significant at $1 \%$. All tests are two-tailed tests. Variable definitions are provided in Table 1. 
TABLE 14: Variables Definition-Chapter 2

\begin{tabular}{|c|c|}
\hline \multicolumn{2}{|c|}{ Firm Characteristics } \\
\hline DISC & $\begin{array}{l}\text { Risk management disclosure score based on the } 13 \text { items in } \\
\text { Appendix B. For each of the } 13 \text { items, if disclosed, an indicator } \\
\text { variable takes the value of } 1 \text {, and zero otherwise. DISC takes the } \\
\text { average value of the } 13 \text { indicator variables, averaged for } 2005- \\
2008 \text {. }\end{array}$ \\
\hline SCOPE & $\begin{array}{l}\text { Percentage of expected fuel consumption in the } 12 \text { month that is } \\
\text { being hedged averaged for } 2005-2008 \text {. }\end{array}$ \\
\hline$A O C I \_R A W$ & $\begin{array}{l}\text { Accumulated other comprehensive income from fuel hedge (in } \\
\text { millions) averaged for } 2005-2008 \text {. }\end{array}$ \\
\hline$R O A$ & Net income scaled by total assets averaged for $2005-2008$ \\
\hline$A O C I F H$ & $\begin{array}{l}\text { Accumulated other comprehensive income from fuel hedge } \\
\text { divided by total assets, averaged for 2005-2008. }\end{array}$ \\
\hline LOWCOST & $\begin{array}{l}\text { Indicator variable, taking the value of } 1 \text { if the airline is a low-cost } \\
\text { carrier, and zero otherwise. }\end{array}$ \\
\hline \multicolumn{2}{|c|}{ Event Indicators } \\
\hline D1 & $\begin{array}{l}\text { Indicator variable, }=1 \text { for the three-day window around Event } 1 \text {, } \\
\text { and } 0 \text { otherwise. }\end{array}$ \\
\hline$D 2$ & $\begin{array}{l}\text { Indicator variable, }=1 \text { for the three-day window around Events } 2-5 \text {, } \\
\text { and } 0 \text { otherwise. }\end{array}$ \\
\hline D3 & $\begin{array}{l}\text { Indicator variable, }=1 \text { for the three-day window around Event } 6 \text {, } \\
\text { and } 0 \text { otherwise. }\end{array}$ \\
\hline D4 & $\begin{array}{l}\text { Indicator variable, }=1 \text { for the three-day window around Events } 7 \text { - } \\
10, \text { and } 0 \text { otherwise. }\end{array}$ \\
\hline D5 & $\begin{array}{l}\text { Indicator variable, }=1 \text { for the three-day window around Event } 11 \text {, } \\
\text { and } 0 \text { otherwise. }\end{array}$ \\
\hline D6 & $\begin{array}{l}\text { Indicator variable, }=1 \text { for the three-day window around Event } 12 \text {, } \\
\text { and } 0 \text { otherwise. }\end{array}$ \\
\hline$D 7$ & $\begin{array}{l}\text { Indicator variable, }=1 \text { for the three-day window around Event } 13 \text {, } \\
\text { and } 0 \text { otherwise. }\end{array}$ \\
\hline
\end{tabular}


TABLE 15: Descriptive Statistics and Correlations (2005-2008 average)

\begin{tabular}{|c|c|c|c|c|c|c|c|}
\hline \multirow[b]{2}{*}{ Variable } & \multicolumn{5}{|c|}{ Panel A: Descriptive Statistics } & \multirow[b]{2}{*}{ P75 } & \multirow[b]{2}{*}{ P95 } \\
\hline & Mean & Median & Std Dev & P5 & $\mathbf{P} 25$ & & \\
\hline DISC & 0.756 & 0.780 & 0.089 & 0.533 & 0.716 & 0.833 & 0.838 \\
\hline AOCI_RAW (Million) & -37.117 & -0.500 & 233.699 & -631.000 & -57.375 & 0.000 & 437.500 \\
\hline АOCIFH & $-0.057 \%$ & $-0.024 \%$ & $1.003 \%$ & $-1.395 \%$ & $-0.510 \%$ & $0.000 \%$ & $2.819 \%$ \\
\hline SCOPE (\%) & 25.117 & 21.750 & 16.771 & 4.067 & 13.875 & 35.125 & 61.250 \\
\hline LOWCOST & 0.417 & 0.000 & 0.515 & 0.000 & 0.000 & 1.000 & 1.000 \\
\hline ROA & -0.004 & -0.005 & 0.047 & -0.074 & -0.025 & 0.018 & 0.085 \\
\hline
\end{tabular}

Panel B: Correlations

$\begin{array}{llll}D I S C L O S E & \text { SCOPE } & \text { LOCIFH }\end{array}$

$\begin{array}{cccc}\text { SCOPE } & 0.521 & & \\ \text { AOCIFH } & 0.032 & 0.489 & \\ \text { LOWCOST } & -0.403 & -0.114 & 0.491\end{array}$

$R O A$

0.157

$-0.152$

0.391

0.229

Please see Table 14 for variables definition. My sample consists of 41 U.S. airline-year observations with available return and accounting information for the period 2005-2008. For each variable, I take the average value for 2005-2008 and provide descriptive statistics, following Beatty et al. (1996) and Dou et al. (2013). 
TABLE 16: Average Stock Returns around Event Dates during the Deliberation of SFAS 161: U.S. Airline Industry

\begin{tabular}{|c|c|}
\hline Event Indicator & Mean return \\
\hline$D 1$ & $\begin{array}{l}-0.008 \\
(-0.62)\end{array}$ \\
\hline$D 2$ & $\begin{array}{l}0.006 \\
(0.46)\end{array}$ \\
\hline D3 & $\begin{array}{l}0.008 \\
(0.63)\end{array}$ \\
\hline$D 4$ & $\begin{array}{l}-0.018 * \\
(-1.72)\end{array}$ \\
\hline D5 & $\begin{array}{l}0.012 \\
(0.94)\end{array}$ \\
\hline D6 & $\begin{array}{c}0.039 * * * \\
(3.04)\end{array}$ \\
\hline D7 & $\begin{array}{c}0.028 * * \\
(2.21)\end{array}$ \\
\hline Mean & $\begin{array}{c}0.013 * * \\
(2.19)\end{array}$ \\
\hline
\end{tabular}

The table reports mean stock price reaction (t-statistics) of a portfolio of the sample firms around key event dates during the deliberation of SFAS 161 (with t-statistics in the parentheses). The stock price reactions are estimated using an augmented market model over the period from January 1, 2005 to December 31, 2008. Daily portfolio returns are computed by value weighting the daily returns of the sample firms. Events 1-13 are listed in Appendix A and D1-D7 are defined in Table 14. ***, **, and * denote statistical significance at the $1 \%, 5 \%$, and $10 \%$ levels, respectively. 
TABLE 17: Sefcik and Thompson (1986) Cross-sectional Analyses of Stock Price Reactions

\begin{tabular}{lcccc}
\multicolumn{5}{c}{ around Key Events: 1 Indicator } \\
\cline { 2 - 5 } DISC & $(1)$ & $(2)$ & $(3)$ & $(4)$ \\
& $0.097^{* *}$ & 0.029 & $0.153^{* *}$ & $0.085^{*}$ \\
SCOPE & $(1.97)$ & $(0.34)$ & $(2.00)$ & $(1.95)$ \\
& $-0.001^{* *}$ & $-0.001^{* *}$ & $-0.001^{* * *}$ & $-0.001^{*}$ \\
LOWCOST & $(-2.25)$ & $(-1.97)$ & $(-2.87)$ & $(-1.72)$ \\
& & $-0.025^{* *}$ & & \\
ROA & $(-2.04)$ & & \\
& & & $-0.322^{* * *}$ & \\
AOCIFH & \multicolumn{3}{c}{$(-2.89)$} & -0.345 \\
& & & $(-1.54)$ \\
\hline
\end{tabular}

This table reports the Sefcik and Thompson (1986) portfolio time-series regression results for my sample firms (with t-statistics in the parentheses). Key events are listed in Appendix A. In this table, one event indicator is assigned to all the 13 events. $* * *, * *$, and $*$ denote statistical significance at the $1 \%, 5 \%$, and $10 \%$ levels, respectively. 
TABLE 18: Sefcik and Thompson (1986) Cross-sectional Analyses of Stock Price Reactions around Key Events: 7 Indicators

\begin{tabular}{|c|c|c|c|c|c|c|c|}
\hline & $D 1$ & D2 & D3 & D4 & D5 & D6 & D7 \\
\hline \multicolumn{8}{|l|}{ Panel A } \\
\hline DISC & $\begin{array}{l}-0.038 \\
(-0.42)\end{array}$ & $\begin{array}{l}-0.016 \\
(-0.18)\end{array}$ & $\begin{array}{l}0.138 \\
(1.52)\end{array}$ & $\begin{array}{l}0.007 \\
(0.08)\end{array}$ & $\begin{array}{l}-0.075 \\
(-0.82)\end{array}$ & $\begin{array}{c}0.185 * * \\
(2.03)\end{array}$ & $\begin{array}{c}0.098 * \\
(1.78)\end{array}$ \\
\hline$S C O P E$ & $\begin{array}{l}0.000 \\
(0.16)\end{array}$ & $\begin{array}{c}0.000 \\
(-1.03)\end{array}$ & $\begin{array}{l}0.000 * \\
(-1.68)\end{array}$ & $\begin{array}{l}0.000 \\
(0.15)\end{array}$ & $\begin{array}{c}0.000 \\
(-0.04)\end{array}$ & $\begin{array}{c}-0.001 * * * \\
(-3.51)\end{array}$ & $\begin{array}{c}-0.001 * * \\
(-2.28)\end{array}$ \\
\hline \multicolumn{8}{|l|}{ Panel B } \\
\hline DISC & $\begin{array}{l}-0.063 \\
(-0.73)\end{array}$ & $\begin{array}{l}-0.04 \\
(-0.47)\end{array}$ & $\begin{array}{c}0.148^{*} \\
(1.71)\end{array}$ & $\begin{array}{l}0.066 \\
(0.76)\end{array}$ & $\begin{array}{l}-0.066 \\
(-0.76)\end{array}$ & $\begin{array}{l}0.153^{*} \\
(1.772)\end{array}$ & $\begin{array}{c}0.03 \\
(0.35)\end{array}$ \\
\hline SCOPE & $\begin{array}{l}0.000 \\
(0.29)\end{array}$ & $\begin{array}{c}0.000 \\
(-0.94)\end{array}$ & $\begin{array}{c}0.000 \\
(-1.58)\end{array}$ & $\begin{array}{c}0.000 \\
(-0.16)\end{array}$ & $\begin{array}{c}0.000 \\
(-0.09)\end{array}$ & $\begin{array}{c}-0.001 * * * \\
(-3.451)\end{array}$ & $\begin{array}{c}-0.001 * * \\
(-1.99)\end{array}$ \\
\hline LOWCOST & $\begin{array}{l}-0.009 \\
(-0.73)\end{array}$ & $\begin{array}{l}-0.009 \\
(-0.73)\end{array}$ & $\begin{array}{l}0.004 \\
(0.30)\end{array}$ & $\begin{array}{c}0.022 * \\
(1.77)\end{array}$ & $\begin{array}{l}0.003 \\
(0.26)\end{array}$ & $\begin{array}{c}-0.011 \\
(-0.942)\end{array}$ & $\begin{array}{c}-0.025 * * \\
(-2.05)\end{array}$ \\
\hline \multicolumn{8}{|l|}{ Panel C } \\
\hline DISC & $\begin{array}{l}-0.034 \\
(-0.36)\end{array}$ & $\begin{array}{l}0.006 \\
(0.06)\end{array}$ & $\begin{array}{c}0.139^{*} \\
(1.86)\end{array}$ & $\begin{array}{l}-0.041 \\
(-0.43)\end{array}$ & $\begin{array}{l}-0.081 \\
(-0.85)\end{array}$ & $\begin{array}{l}0.164 * \\
(1.711)\end{array}$ & $\begin{array}{c}0.154^{*} \\
(1.91)\end{array}$ \\
\hline SCOPE & $\begin{array}{l}0.000 \\
(0.07)\end{array}$ & $\begin{array}{c}0.000 \\
(-1.26)\end{array}$ & $\begin{array}{c}0.000 \\
(-1.32)\end{array}$ & $\begin{array}{l}0.000 \\
(0.89)\end{array}$ & $\begin{array}{l}0.000 \\
(0.07)\end{array}$ & $\begin{array}{c}-0.001 * * * \\
(-2.763)\end{array}$ & $\begin{array}{c}-0.001 * * * \\
(-2.89)\end{array}$ \\
\hline$R O A$ & $\begin{array}{l}-0.023 \\
(-0.21)\end{array}$ & $\begin{array}{l}-0.126 \\
(-1.13)\end{array}$ & $\begin{array}{l}-0.005 \\
(-0.04)\end{array}$ & $\begin{array}{c}0.276^{* * * *} \\
(2.48)\end{array}$ & $\begin{array}{l}0.038 \\
(0.34)\end{array}$ & $\begin{array}{c}0.123 \\
(1.103)\end{array}$ & $\begin{array}{c}-0.321 * * * \\
(-2.89)\end{array}$ \\
\hline \multicolumn{8}{|l|}{ Panel D } \\
\hline DISC & $\begin{array}{c}-0.046 \\
(-0.515)\end{array}$ & $\begin{array}{c}-0.03 \\
(-0.337)\end{array}$ & $\begin{array}{l}0.151^{*} \\
(1.680)\end{array}$ & $\begin{array}{c}0.039 \\
(0.433)\end{array}$ & $\begin{array}{c}-0.071 \\
(-0.785)\end{array}$ & $\begin{array}{c}0.186 * * \\
(2.071)\end{array}$ & $\begin{array}{c}0.086 \\
(0.958)\end{array}$ \\
\hline SCOPE & $\begin{array}{c}0.000 \\
(0.414)\end{array}$ & $\begin{array}{c}0.000 \\
(-0.433)\end{array}$ & $\begin{array}{c}-0.001 * \\
(-1.779)\end{array}$ & $\begin{array}{c}0.000 \\
(-0.972)\end{array}$ & $\begin{array}{c}0.000 \\
(-0.171)\end{array}$ & $\begin{array}{c}-0.001 * * * \\
(-3.219)\end{array}$ & $\begin{array}{l}-0.001^{*} \\
(-1.664)\end{array}$ \\
\hline AOCIFH & $\begin{array}{c}-0.229 \\
(-0.489)\end{array}$ & $\begin{array}{c}-0.414 \\
(-0.887)\end{array}$ & $\begin{array}{c}0.372 \\
(0.797)\end{array}$ & $\begin{array}{c}0.921 * * \\
(1.971)\end{array}$ & $\begin{array}{l}0.112 \\
(0.24)\end{array}$ & $\begin{array}{c}0.045 \\
(0.097)\end{array}$ & $\begin{array}{c}-0.344 \\
(-0.736)\end{array}$ \\
\hline
\end{tabular}

This table reports the Sefcik and Thompson (1986) portfolio time-series regression results for my sample firms (with t-statistics in the parentheses). Key events are listed in Appendix A and indicators are defined in Table 14. In this table, seven event indicators are assigned to all the 13 events. ***,**, and * denote statistical significance at the $1 \%, 5 \%$, and $10 \%$ levels, respectively. 
TABLE 19: Average Stock Returns around Event Dates during the Deliberation of SFAS 161: CRSP Sample

\begin{tabular}{|c|c|}
\hline Event Indicator & Mean return \\
\hline$D 1$ & $\begin{array}{l}-0.000 \\
(-0.10)\end{array}$ \\
\hline D2 & $\begin{array}{l}0.001 \\
(1.46)\end{array}$ \\
\hline D3 & $\begin{array}{l}0.000 \\
(0.23)\end{array}$ \\
\hline$D 4$ & $\begin{array}{c}-0.002 * * \\
(-1.96)\end{array}$ \\
\hline D5 & $\begin{array}{l}0.000 \\
(0.20)\end{array}$ \\
\hline D6 & $\begin{array}{c}0.002 * \\
(1.69)\end{array}$ \\
\hline D7 & $\begin{array}{l}-0.000 \\
(-0.28)\end{array}$ \\
\hline Mean & $\begin{array}{l}-0.000 \\
(-0.28)\end{array}$ \\
\hline
\end{tabular}

The table reports mean stock price reaction (t-statistics) of a portfolio of the whole CRSP firms around key event dates during the deliberation of SFAS 161 (with t-statistics in the parentheses). The stock price reactions are estimated using an augmented market model over the period from January 1, 2005 to December 31, 2008. Daily portfolio returns are computed by value weighting the daily returns of the sample firms. Events 1-13 are listed in Appendix A and D1-D7 are defined in Table 14. ***, **, and * denote statistical significance at the $1 \%, 5 \%$, and $10 \%$ levels, respectively. 